\title{
We Are What We Watch: Movie Plots Predict the Personalities of
}

\section{Their Fans}

\section{Gideon Nave}

Marketing Department, The Wharton School, University of Pennsylvania

3730 Walnut St., Philadelphia PA 19104, USA

Tel: +1 (215) 8988248

Email: gnave@wharton.upenn.edu

\section{Jason Rentfrow}

Social \& Developmental Psychology, University of Cambridge

Free School Lane, Cambridge, Cambridgeshire, CB2 3RQ, UK

Tel: +44(0)1223 (7) 67805

E-mail: pjr39@cam.ac.uk

\section{Sudeep Bhatia}

Psychology Department, University of Pennsylvania

3720 Walnut Street, Philadelphia PA 19104, USA

Tel: +1 (215) 8985096

Email: bhatiasu@psych.upenn.edu

\section{Acknowledgments}

We thank Dylan Manfredi for research assistance. We thank Eric Bradlow, Joshua Eliashberg, Nadja C. Furtner, and Olivier Toubia for their comments on earlier versions of the manuscript. Gideon Nave thanks Carlos and Rosa de la Cruz and the Wharton School of Business Dean's Research Fund for ongoing support. Sudeep Bhatia received funding from the National Science Foundation grant SES-1847794 


\begin{abstract}
How do features of movie content relate to the psychological makeup of the audiences they attract? We study this question by employing advanced analytical tools to a new rich dataset that combines detailed characterizations of movies and their plots with personality measures of social-media users who "liked" them. We identify novel associations between movie features such as quality, revenue and genre, and the personality dimensions of their fans. We then use machine-learning to show that movie plots — captured via text—predict the personalities of fans beyond all other variables studied. We further use text analytical methods to quantify how different psychological themes (e.g., leisure) and unique concepts that organically emerge from the data (e.g., adultery) relate to fans' personalities, and show that movie plots align with the characteristic ways in which their fans think, feel, and behave. For example, films with anxiety have neurotic fans, where social films attract extraverted fans. Our findings provide fine-grained mappings between dimensions of personality and movie preferences, facilitate scalable automated assessment of audience psychographics, and showcase a text-analytic framework for studying how features of multidimensional cultural products relate to psychological characteristics of their consumers.
\end{abstract}

Keywords: personality, movie preferences, psychographics, text analysis, machine learning. 


\section{INTRODUCTION}

Understanding how psychological traits are expressed in consumer preferences is central to marketing theory and practice (Beane and Ennis 1987; Kassarjian 1971; Steenkamp and MaydeuOlivares 2015; Weinstein 1994; Wells 1975). Such insight is particularly useful in the entertainment industry, where firms can reach consumers based on the content that they choose to watch, and customize marketing actions_-such as product placements in movies and advertising in the cinema and online - to their psychological and behavioral tendencies (Eliashberg, Elberse and Leenders 2006; Hennig-Thurau, Houston and Others 2019; Hixson 2006; Marich 2013; Sandy, Gosling and Durant 2013; Wiles and Danielova 2009).

With the proliferation of online streaming services_-such as Netflix, Hulu, and Amazon Prime - the selection of content available for personalized consumption has substantially increased, and the task of assessing the psychographic profiles that distinct content attracts has become increasingly important (Palomba 2020). Traditionally, researchers have approached this task by surveying consumers about their psychological profiles and their content preferences, and explored the links between the two. But this approach, which has been proven useful for studying the links between consumers' traits and their preferences for a small number of genre categories (e.g., Rentfrow, Goldberg and Zilca 2011; Weaver 1991), is not scalable when studying the psychographics that a large number of distinct movies attract — as it would require surveying consumers about all options under consideration (Toubia et al. 2019).

With the traditional means outmoded, the current work employs new types of data and advanced analytical tools to explore how features and plots of movies can be used to explain and predict the psychological profiles of the consumers they attract. To this end, we extract and analyze a rich new dataset that combines detailed characterizations of movies and their plots from the Internet 
Movies Database (IMDb) with information on the aggregate psychological profile of their fans, obtained from the myPersonality project (Kosinski, Stillwell and Graepel 2013).

We quantify consumers' psychological tendencies via the Big Five personality dimensions: Openness to experience, Conscientiousness, Extraversion, Agreeableness, and Neuroticism. This framework has two main advantages that make it well-suited for our study's objectives. First, a growing literature relates the Big Five to behavioral tendencies of individuals in their roles as consumers, from their dispositions to buy from specific brands and categories to their decisionmaking styles (for reviews, see Matz and Hirsh 2020; Steenkamp and Maydeu-Olivares 2015). Furthermore, the Big Five can be accurately predicted, at the individual level, from digital footprints, such as Facebook Likes, Tweets, and even profile pictures (e.g., Kosinski et al. 2013; Nave et al. 2018; Quercia et al. 2011), and such predictions allow advertisers to reach populations that differ on these traits using existing digital platforms (Matz et al. 2017). Thus, these traits are theoretically important and managerially relevant, as they allow customization of marketing mixes to particular personality types that are more likely to respond to them. Second, previous research has pointed to associations between aspects of movie preferences and the Big Five (e.g., Rentfrow, Goldberg and Zilca 2011; Weaver 1991). Although these early works have relied on small-scale studies that only measured preferences for a few broad genres categories, they suggest that our task may be feasible.

Our research makes three broad contributions. First, we extend the literature on the links between general features of content, like genre, and the personality traits of the audiences they attract — which to date has relied on small-scale studies with limited external validity. Our investigation employs a large diverse sample, measures preferences via active expressions of attitudes towards content in the field, and accounts for previously unaccounted factors such as movies' quality and commercial success. Our analysis comprehensively maps between dimensions of personality and movie preferences, and by doing so, reaffirms previous findings in the literature and 
reveals novel associations. For example, high Openness is associated with liking movies that have higher quality ratings and lower revenue at the box office, and fans of Horror movies score high on measures of Neuroticism and low on measures of Agreeableness.

Second, we go beyond the boundaries imposed by classification of content into broad genre categories, and use text analysis to investigate how more nuanced information about movie plots is informative of the personalities of the consumers they attract. To this end, we carry out a preregistered analysis that trains machine-learning models on movie plots (quantified via text keywords) to predict the aggregate personality profiles of their fans, and use these models as predictive tools (Yarkoni and Westfall 2017). We find that movie plots are informative about their fans' personalities, above and beyond their genre classifications, the demographic profiles of the fans, and all other movie attributes that we study. We further show, in a pre-registered online study, that predictions of our text-based models generalize to a new set of movies, different measures of preferences, and a sample recruited from a different population. These findings suggest that our models allow assessment of the psychological profiles associated with liking distinct content at scale, using readily available data.

Third, we use advanced text analytic tools to quantify how different psychological themes (e.g., anxiety, friends, leisure) and unique concepts that organically emerge from the data (e.g., adultery, baseball, science) appear in movie plots, and link them to the psychological profiles of fans. This analysis shows that consumers are drawn to movies whose plots align with the characteristic ways in which they think, feel, and behave. For example, movies with plots emphasizing social themes have fans that are more extraverted, movies with anger have fans with lower Agreeableness, and fans of movies with anxiety have, on average, higher levels of Neuroticism. 
Taken together, our findings provide fine-grained mappings between dimensions of personality and preferences for content, demonstrate how these links enable automated psychographic assessment of audiences at scale, and showcase a novel analytical framework for studying how multidimensional cultural products relate to characteristics of their consumers.

\section{RELATED LITERATURE}

The Big Five in Consumer Research

Personality traits reflect individual-difference dimensions that represent stable patterns of thoughts, feelings, and behaviors in response to given situations. The study of personality in the context of consumer research has a long history, though scholars have used various constellations to model it (Fry 1971; Holbrook and Olney 1995; Horton 1979; Kassarjian 1971; Koponen 1960; Lastovicka and Joachimsthaler 1988). Since the early 1990s, the dominant paradigm for studying personality has been the Five Factor Model (FFM), or the Big Five (John, Srivastava and Others 1999). The Big Five traits - Openness to experience, Conscientiousness, Extraversion, Agreeableness, and Neuroticism - reliably predict a wide range of behavioral dispositions and reallife outcomes (Ozer and Benet-Martínez 2006; Soto 2019), and have become a consensus model in the research community (McCrae 2009).

The relevance of the Big Five for marketing research is grounded in a large literature demonstrating that these traits predict consumer preferences and behavior (e.g., Brown and Taylor 2014; Ebert et al. 2020; Goldsmith 2016; Hirsh, Kang and Bodenhausen 2012; Lin 2010; MacInnis and Folkes 2017; Matz and Hirsh 2020; Mulyanegara, Tsarenko and Anderson 2009; Teeny et al. 2020; Wheeler, Petty and Bizer 2005). In general, findings support the notion that consumers prefer products, brands, and marketing communications that "fit" their Big Five profiles. Openness, which 
is associated with greater needs for cognition, creativity, and uniqueness (Dollinger 2003) predicts spending on art, culture, and travel (Matz, Gladstone and Stillwell 2016), exploratory information search, and early adoption of innovations (Steenkamp and Maydeu-Olivares 2015). Conscientious customers are more sensitive to price and quality, are more likely to respond to deal offers (Steenkamp and Maydeu-Olivares 2015), spend more on insurance products (Matz et al. 2016), and prefer "trusted" brands (Mulyanegara et al. 2009). Extraversion is characterized by interest in social interactions and predicts social-media use frequency (Bowden-Green, Hinds and Joinson 2020), higher engagement in word-of-mouth activity (Mooradian and Swan 2006), market mavenism (Awais et al. 2020), affinity towards "social" brands (Mulyanegara et al. 2009), and more spending on dining and entertainment (Matz et al. 2016). Agreeable individuals, who are more prosocial and trusting, donate more to charity (Yarkoni, Ashar and Wager 2015), are less skeptical of information in advertisements, and buy brands that conform to social norms (Steenkamp and Maydeu-Olivares 2015). Neuroticism is characterized by frequent experience of negative emotions and associated with impulsive and compulsive shopping behavior (Shahjehan 2012), and predicts post-purchase dissatisfaction, complaining, and negative word-of-mouth (Mooradian and Olver 1994).

Predicting the Big Five from Digital Footprints

The advent of big data has led to a deluge of studies demonstrating that the Big Five are predictable from digital traces of consumers' behavior online. The seminal publication along this research stream (Kosinski et al. 2013) has shown that the Big Five can be inferred from Facebook "likes," with accuracy that approaches the test-retest reliability of their survey-based measures. Subsequent work has shown that an algorithm can assess a person's Big Five as accurately as the judgment of their human work colleague using as few as 10 "likes," where with as many as 300 
"likes" the algorithm becomes more accurate than the judgment of one's spouse (Youyou, Kosinski and Stillwell 2015). Other research has shown that the Big Five can be inferred from many other types of digital footprints, including spending records (Gladstone, Matz and Lemaire 2019), social media language (Park et al. 2015; Quercia et al. 2011), flickr images (Segalin et al. 2017), and musical playlists (Ferwerda, Tkalcic and Schedl 2017). These findings imply that marketing strategies that rely on the Big Five traits for segmentation, targeting, and positioning have become increasingly actionable - as it is now possible to reach consumers that differ along these dimensions and customize product offerings, promotions, and advertisements to their personality profiles (Matz et al. 2017; Teeny et al. 2020).

The Big Five and Movie Preferences

Interactionist psychological theories posit that individuals seek out occupations, hobbies, and relationships that reinforce and verify their needs and dispositions (Buss 1987; Swann 1987). Selfcongruence theory extends this hypothesis to the domain of consumer research and proposes that consumers are drawn to brands and products that match their own self-concepts (Aaker 1999; Fournier 1998). As personality typifies one's psychological dispositions, a natural prediction of the theory is that individuals are drawn to content that converges with their psychological profiles.

Some previous research has empirically investigated this prediction by exploring the personality correlates of preferences for different content types (e.g., Golbeck and Norris 2013; Hall 2005; Möller and Karppinen 1983; Rentfrow et al. 2011; Weaver 1991, 2003; Weaver, Brosius and Mundorf 1993). For example, Rentfrow and colleagues (2011) investigated associations between personality and preferences for film, music, television, and books. They revealed distinct preference dimensions defined in terms of similar genres (e.g., horror, thriller, heavy metal) as opposed to 
medium (film, television, music). Furthermore, individual differences in media preference correlated with the Big Five. For instance, liking "cerebral" media genres were associated with Openness, where preferences for "light-hearted" media content were linked to Extraversion and Agreeableness.

Despite these advances, several important questions remain. First, the generalizability and external validity of past findings is not well-established, as previous work has relied on small-scale studies with limited statistical power, and measured preferences via self-reports. Such measures might be susceptible to demand effects (Orne 1962), and could systematically differ from behavior in naturally occurring environments (Levitt and List 2007). For example, participants of laboratory studies might feel compelled by social norms to downplay their liking of violent or sexual content (Friedrich-Cofer and Huston 1986).

Second, previous work has not investigated the links between personality and preferences for general attributes of movie content, such as quality and popularity-and consequently did not account for their potentially confounding influence. For example, it may be the case that extroverts prefer popular content, and in turn, popularity may differ by genre (e.g., historical documentaries tend to be less popular than action films). Thus, failing to consider popularity might confound observed relationships between personality and preferences for content types.

A third important limitation of current knowledge is that all previous studies operationalized movie preferences by measuring liking of a few broad genre categories (e.g., Hirschman 1985; Kraaykamp and Eijck 2005; Möller and Karppinen 1983; Rentfrow et al. 2011). ${ }^{1}$ Although genres have yielded consistent findings across studies, reliance on genre as the unit of analysis has important drawbacks. First, movie content is complex and multidimensional, and reducing it to a few broadly

\footnotetext{
${ }^{1}$ Reliance on a small number of broad genre categories was also common in early models of media consumption behavior (Ansari, Essegaier and Kohli 2000; Eliashberg and Sawhney 1994; Rust and Alpert 1984; Shachar and Emerson 2000; Ying, Feinberg and Wedel 2006).
} 
defined genre classifications eliminates important and potentially relevant information. For example, the films Good Morning Vietnam (1987) and The Big Short (2015) belong to the same three genre categories (Biography, Comedy, and Drama) according to IMDb. However, the former tells the story of an irreverent DJ broadcasting on the US Armed Forces Radio during the Vietnam War, where the latter is about a group of investors betting against the housing market before the 2008 crisis. Relying solely on genre categories fails to account for substantial differences between these films' content.

Furthermore, the correspondence between genres and actual media content is often ambiguous. For example, the Academy-Award winning film The Shape of Water (2017) is classified by IMDb as belonging to no less than five different genres: Adventure, Drama, Fantasy, Romance, and Thriller. Thus, because of their broad nature, genres can be difficult to interpret and yield imprecise preference assessments - especially when the task at hand is predicting the psychological profiles that specific contents attract. Of note, the incompleteness of genre-based classification is recognized by current entertainment industry practices. For example, Netflix was reported to use 76,897 manually-tagged "micro-genre" categories, including esoteric labels such as "Visuallystriking foreign nostalgic dramas" (Madrigal 2014). Likewise, content recommendation systems, as well as choice-models of media consumption in the quantitative marketing literature, have begun to represent content via richer sets of attributes that are typically derived via automated text analysis (Ansari, Li and Zhang 2018; Eliashberg, Hui and Zhang 2014; Jung and Lee 2004; Melville, Mooney and Nagarajan 2002; Szomszor et al. 2007; Toubia et al. 2019).

The current work addresses the above limitations by studying a large diverse sample, measuring preferences via active expressions of attitudes in the field, controlling for previously unaccounted potential confounds, and using a content representation that is not bounded by broad genre categorization. 


\section{RESEARCH OVERVIEW}

We report three empirical studies. The first two rely on data collected via myPersonality, a Facebook app through which roughly 3.5 million users completed personality questionnaires and consented to share their Facebook data with researchers. We use this data to capture a fivedimensional Aggregate Fan Personality Profile (AFPP) of movies, by averaging the Big Five scores of all myPersonality users who 'like' them on Facebook. We also obtain rich representations of movies from IMDb, an online database containing over 5 million titles of movies and TV episodes. Each IMDb entry represents a title, and includes general information that we refer to as "metadata" (e.g., quality ratings, revenue at the box office), genre classifications, and plot keywords.

In Study 1, we systematically investigate how high-level movie characteristics-including metadata, the fans' demographics, and their genre - relate to their fans' personalities. We identify associations between several such attributes and AFPPs, and interpret them based on previous research findings. Study 2 goes beyond the boundaries of genre categorization, to investigate if movie plots capture more nuanced information about fan personalities. We train machine-learning test-based models to predict the AFPPs from plot keywords, and find that plots are predictive of aggregate fan personalities above genre and all other movie attributes considered. To further illuminate the underlying mechanism, we rely on the keywords to quantify the presence of various psychological themes and other concepts that organically emerge from the data in the movies. We identify manifold links between these themes and personality dimensions-which confirm that consumers are drawn to movies whose plots reflect their own psychological tendencies. Finally, Study 3 is a pre-registered online experiment, evaluating how predictions of the text-based models trained in Study 2 generalize across movies, participant samples, and preferences elicitation methods.

\section{STUDY 1}


Study 1 conceptualizes movies via their genre classifications, general characteristics such as quality ratings and revenue, and their fans' demographics. We map these features to the aggregate personalities of the movies' fans, and interpret the results based on previous research findings.

\section{Data Sources and Measures}

Figure 1 summarizes the method of constructing the variables used in Study 1 and Study 2. myPersonality Database. myPersonality is a Facebook app that ran from 2007 to 2012 (Kosinski et al. 2013). It presented users the opportunity to take scientific research questionnaires and get feedback on their results. Overall, about 7 million users took at least one questionnaire, and roughly half of them shared their personal Facebook data with the app for research purposes. myPersonality data includes "likes"- digital records that denote positive attitude expressions of users towards various contents (e.g., friends' status updates, photos, and Facebook pages of various entities, including movies). When liking a movie's page, users opt to receive communications that relate to the movie (e.g., short clips, pictures, and marketing messages) directly to their Facebook newsfeed (John et al. 2017). The myPersonality sample is geographically diverse, with $42 \%$ of the participants residing outside the US and 44 countries that are represented by more than 1,000 respondents. The average participant age was 23.5 years at the time of data collection, and $63 \%$ were female (Stillwell and Kosinski 2012).

Movie Personality Dataset. Our main study dataset (or Movie Personality Dataset) includes information on 846 movies. It combines (1) aggregate psychographic and demographic profiles of the movies' social media fans from myPersonality, with (2) movie characteristics such as quality ratings, genre, and plot keywords from IMDb. To select the set of movies included in the study, we excluded all of the Facebook Likes in the myPersonality database that were either not categorized by 
Facebook as movie-related or liked by fewer than 250 users. We then searched for each of the remaining Likes on IMDb (based on the movie's name, using an automated process) and included only movies that appeared on the website's database. Finally, we manually inspected the movies that were not found in the automatic search and (a) included movies whose corresponding IMDb entries were not found due to differences in spelling and typos (e.g., "singing in the rain" was matched with the IMDb entry of "singin' in the rain"; (b) included movie series, in which case we associated the value with the IMDb entry of first movie in the series (e.g., "the twilight saga" was matched with the title "twilight"); (c) In case we found more than one IMDb ID corresponding to the same Facebook Like, we linked the Facebook Like to the entry that had the greatest number of reviews (e.g., "Phantom of the opera" was linked to the IMDb ID of the 1998 production). (d) We excluded movie quotes (e.g., "supercalifragilistic") and characters (e.g., "Eeyore"). The final dataset includes $M=$ 846 feature films whose Facebook pages were liked a total of 994,175 times by myPersonality users. The average movie was liked by $U=1,172$ unique users ( $\mathrm{SD}=1,829$; Max: 18,597; Min: 252). Aggregate Fan Personality Profile (AFPP). The myPersonality app measured the Big Five traits of its users via the International Personality Item Pool (IPIP) questionnaire, which quantifies a FiveFactor Model (FFM) of personality (20 to 100 items; Goldberg et al. 2006/2). We z-score these measures across the entire myPersonality database and calculate a five-dimensional AFPP for each movie in the dataset, by averaging the z-scored Big Five measures of all users who liked its page. Figure 2 displays the distributions of the five AFPP dimensions across all movies, and Compared to the average myPersonality user, the average film has fans that are comparatively high on Openness, and low on Conscientiousness and Extraversion. This pattern was expected because Openness is related to liking arts, and because watching movies is a leisure activity that does not require social interaction (which therefore may appeal to people low in Conscientiousness and Extraversion). The correlations between the five AFPP dimensions in the Movie Personality Dataset are summarized in 
Supplementary Figure 1. While the pairwise correlations between the Big Five traits are typically small when measured across people (Gerlach et al. 2018), the AFPP dimensions are correlated across movies. Openness and Neuroticism positively correlate with one another and negatively correlate with Conscientiousness, Extraversion, and Agreeableness, where the latter three dimensions positively correlated with one another. The correlations are of medium size, indicating that each of the AFPP dimensions captures a unique variance of interest.

Aggregate Fan Demographic Profile (AFDP). We generate the AFDP for each movie by calculating the average age, proportion of females, and proportion of users who reported being in a relationship among the myPersonality users who liked its page. Supplementary Figure 2 shows the distributions of the different AFDP dimensions across movies.

The Internet Movie Database (IMDb). IMDb (www.IMDb.com) is an online database that contains information about movies, TV shows, home videos, video games, and internet streams. As of 2021, IMDb is the most popular movie website worldwide, with over 250 million unique visitors monthly. It includes information about cast, production crew, plot summaries, trivia, trailers, photo galleries, and box office revenue of over 5 million titles.

Metadata. We extract the following about each movie in the Movie Personality Dataset from IMDb: (1) Average quality rating; (2) number of ratings; (3) release year; (4) budget (log transformed); (5) gross box office income (log transformed); (6) return on investment (ROI), calculated as the net profit divided by the budget and multiplied by 100; and (7) runtime duration (minutes). We refer to this group of variables as "Metadata." Supplementary Table 2 summarizes the summary statistics of these variables, and their distributions are in Supplementary Figure 2. Missing values are inferred using the means of the remaining values. ${ }^{2}$

\footnotetext{
${ }^{2}$ Metadata variables with missing values include budget (85 missing), income (236), ROI (258), and runtime (31).
} 
FIGURE 1

OVERVIEW OF DATA STRUCTURES AND MAIN STUDY VARIABLES

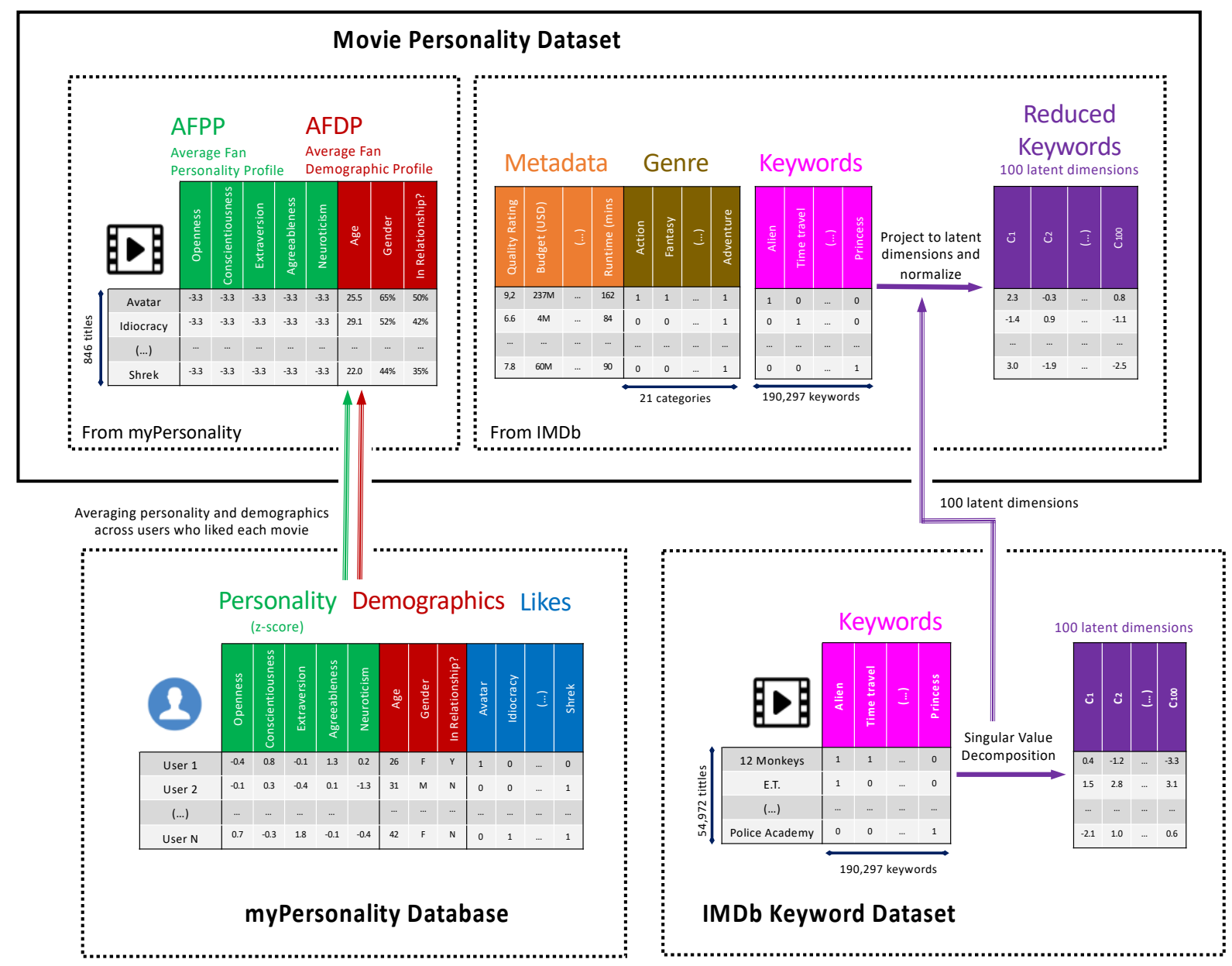

NOTE.- Our study dataset ("Movie Personality Dataset") combines information about 846 movies, coming from two sources: myPersonality—a Facebook app through which about 3.5 million users completed psychological questionnaires and shared their profile data for research purpose, and $\mathrm{IMDb}$ - the most popular movie website worldwide. The dataset includes the following variables: (1) Average Fan Personality Profile (AFPP) is a five-dimensional vector denoting the average z-scored Big Five traits of all myPersonality users who Liked each movie. (2) Average Fan Demographic Profiles (AFDP) is a three-dimensional vector denoting the average age, proportion of females and proportion of people who reported being in relationship of all myPersonality users who Liked each movie. (3) Metadata variables are general movie characteristics such as quality ratings and revenue. (4) Genre is a 21-dimensional binary vector representing each movie's genre classifications. (5) Keywords are binary vectors representing each movie's plot keywords. (6) Reduced Keywords are 100-dimensional vectors, calculated by projecting each movie's Keywords vectors onto 100 latent dimensions, and normalizing these projections' magnitudes. The latent dimensions were computed by performing single value decomposition (SVD) on an IMDb Keyword Matrix, which represents 54,972 IMDb titles and their associated keywords. 


\section{FIGURE 2}

\section{HISTOGRAMS OF THE AVERAGE FAN PERSONALITY PROFILE (AFPP) DIMENSIONS ACROSS MOVIES}
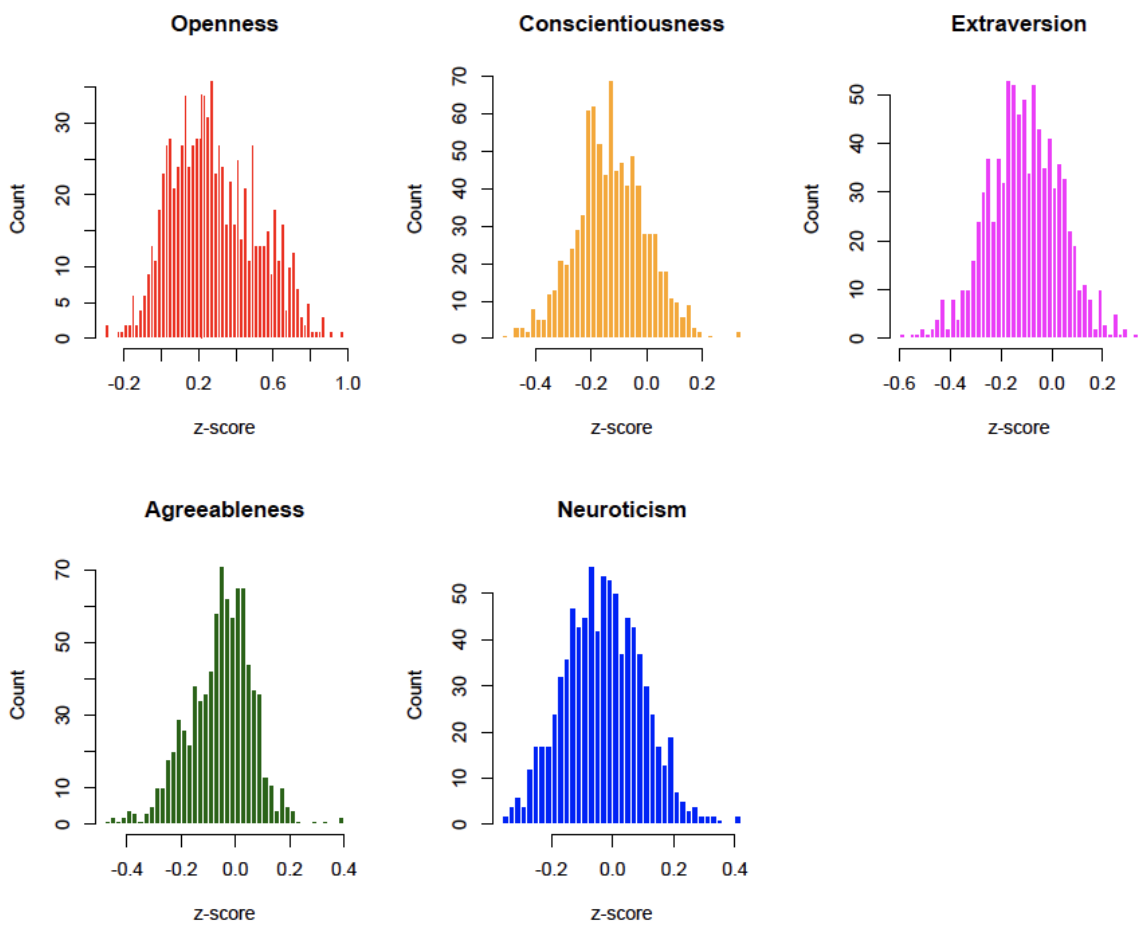

Genre. IMDb includes $G=21$ unique movie genre categories (e.g., Adventures, Drama), where the average film in the Movie Personality Dataset is associated with three genre categories (SD: 1.26). We assign each genre an integer between 1 and $G$ and represent each movie's genre information using a $G$-dimensional binary vector (or "Genre"). The value of the Genre vector's $\mathrm{g}^{\text {th }}$ dimension equals one if the corresponding genre $g$ is associated with the movie on IMDb, and zero otherwise. Supplementary Table 3 summarizes all genre categories and the number of titles associated with each in the Movie Personality Dataset.

Statistical Analyses 
We estimate, for each of the five AFPP dimensions (e.g., Extraversion) in the Movie Personality Dataset, an ordinary least squares (OLS) regression model with the corresponding dimension as the outcome. All models include the movies' AFDP dimensions (age, gender, relationship status), non-categorical Metadata variables, ${ }^{3}$ and Genre as explanatory variables. We account for multiple hypothesis testing using Bonferroni correction, by setting the alpha level of statistical significance to $a=0.05 / 31$, where 31 is the number of explanatory variables in each model. Because most movies are associated with multiple genres, we can include all of the Genre vector dimensions in the model without introducing collinearity. The regression coefficient for each dimension can be interpreted as the change in the corresponding AFPP dimension related to each genre category, relative to a movie with no genre information.

Data Availability. Data are available in the study's OSF page: https://bit.ly/2IgijkS.

Results

We estimate five OLS regressions with the movies' AFPP dimensions as outcomes and their respective Metadata, AFDPs, and Genre as explanatory variables. Figure 3 displays the standardized beta coefficients of all variables that have at least one statistically significant effect after Bonferroni correction (for the full model, see Supplementary Tables 4 and 5). The results show unique patterns of association between movie attributes and their fans' personalities.

We identify several novel associations between general movie characteristics, quantified as Metadata variables, and personality dimensions. The factors showing the strongest relationships with AFPP dimensions are quality ratings, box office revenue, and budget. Openness is associated with

\footnotetext{
${ }^{3}$ We do not include categorical metadata variables (e.g., country) because these variables are represented via a large number of dummy-coded variables, which generates overfitting.
} 
liking movies that receive greater quality ratings [standardized $\beta=0.32,95 \%$ confidence interval $(\mathrm{CI})=(0.24,0.39), \mathrm{t}(814)=8.33, \mathrm{p}<.001]$, but yield less revenue [standardized $\beta=-0.17,95 \% \mathrm{CI}=$ $(-0.22,-0.11), \mathrm{t}(815)=-5.68, \mathrm{p}<.001]$. These findings may reflect the trait's relationships with aesthetic sensitivity (Myszkowski et al. 2014) and the needs for cognition and uniqueness (Dollinger 2003). On the other hand, fans of popular movies are more conscientious [standardized $\beta=0.14$, $95 \% \mathrm{CI}=(0.08,0.20), \mathrm{t}(815)=4.75, \mathrm{p}<.001]$ and agreeable $[$ standardized $\beta=0.12,95 \% \mathrm{CI}=(0.06$, $0.18), t(815)=3.81, \mathrm{p}<.001]$ —in line with these traits' well-established links with conformity (DeYoung, Peterson and Higgins 2002; Roccas et al. 2002). Extraversion, which is predictive of consumers' word-of-mouth activity (Mooradian and Swan 2006) is also positively associated with liking movies that succeed at the box office [standardized $\beta=0.11,95 \% \mathrm{CI}=(0.04,0.17), \mathrm{t}(815)=$ $3.29, \mathrm{p}<.001]$.

We also identify several links between personality dimensions and demographic factors across films. The proportion of females among a movie's fan base correlates with all five AFPP dimensions: negatively with Openness and positively with the remaining traits. The positive associations with Agreeableness, Extraversion, and Neuroticism are consistent with previous findings that females tend to score higher on these traits (Costa, Terracciano and McCrae 2001; Weisberg, Deyoung and Hirsh 2011; Wilson and Dishman 2015). The pattern of associations between AFPPs and age mirrors a typical evolution of the Big Five within individuals during adulthood (Soto et al. 2011). Most notably, movies liked by older people also have more conscientious fans [standardized $\beta=0.66,95 \% \mathrm{CI}=(0.59,0.73), \mathrm{t}(815)=18.40, \mathrm{p}<.001]$. Age also shows weaker positive relationships with Agreeableness and Openness, and a negative relationship with Neuroticism. According to Social Investment Theory, such changes reflect people's psychological adaptations to their normative roles at particular life phases (Roberts, Wood and Smith 2005). For example, as 
people mature, they become parents, pursue careers, and attain financial independence. As a result of these roles and responsibilities, individuals adapt by becoming more conscientious.

Eight genre categories have significant relationships with personality dimensions. Each genre has a unique pattern of relationships with the Big Five, where most effects are small to medium in size (Figure 3). ${ }^{4}$ The genre with the strongest links to personality traits is Sports, whose liking has not assessed in any previous studies of the links between movie preferences and personality. Fans of Sports movies are lower on Openness and Neuroticism, and are higher on Conscientiousness, Extraversion, and Agreeableness. These associations mirror the relationships of the Big Five and actual physical activity among people, for all traits except Agreeableness (Wilson and Dishman 2015). However, Agreeableness tends to be higher among supporters of sports teams (Donavan, Carlson and Zimmerman 2005).

Crime movies have fans that are more extroverted and less agreeable, akin to people who gravitate towards crime in real life (Kern et al. 2013; O'Riordan and O'Connell 2014; Rogers, Seigfried and Tidke 2006). Devotees of Sci-fi and Fantasy movies have greater Openness, lower Extraversion, and lower Conscientiousness - indicating that movies of these genres attract imaginative, reflective, and spontaneous people (Feist and Barron 2003). Family movies have fans that are higher on Agreeableness, a trait which is high among people who value close relationships and family ties (Laakasuo et al. 2017; Tov, Nai and Lee 2016).

Finally, fans of Horror movies are more Neurotic, perhaps because Horror provides anxious individuals a means to experience their anxiety in a nonthreatening and controllable setting (Scrivner and Christensen 2021). Fans of Horror films are also less Agreeable and less Extraverted. Of note, Horror has been shown to generate stronger fear responses among individuals higher in either

\footnotetext{
${ }^{4}$ Due to the small number of Documentaries $(N=6)$ and Westerns $(N=9)$, our analysis has low statistical power to detect associations between personality and liking of these genres (Supplementary Table 3).
} 
Neuroticism or Agreeableness (Clasen, Kjeldgaard-Christiansen and Johnson 2020). However, these two traits show the opposite relationship with liking Horror, suggesting that the psychological mechanism underlying these links might differ between the two traits.

\section{FIGURE 3}

\section{RELATIONSHIPS BETWEEN MOVIE CHARACTERISTICS AND FAN PERSONALITIES}

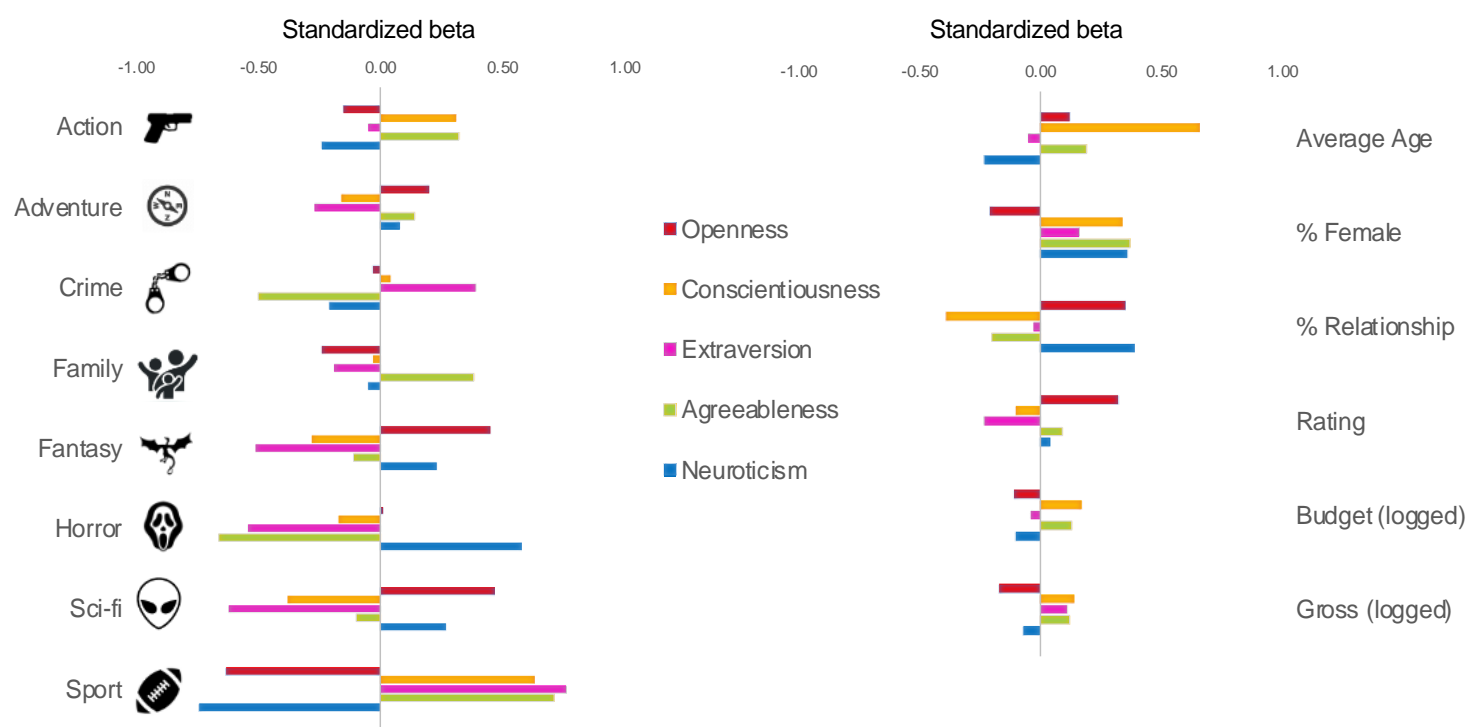

NOTE. - The relationships are estimated as standardized coefficients of five regression models, with AFPP dimensions as outcomes. Explanatory variables included genre, ADFPs and meta-data.

\section{Discussion}

Study 1 combines data from IMDb and myPersonality, to map movie characteristics to the personalities of their fans. We find novel associations between movies' budget, revenue, and quality ratings, as well as the demographics of their fans, and different Big Five dimensions. These findings illustrate the importance of controlling for such attributes when studying the links between consumer traits and their preferences for content. We also identify associations between liking several genres and personality traits. Some of these links reaffirm previous findings in small-scale studies of college 
students that measured genre preferences via self-reports. For example, Rentfrow and colleagues (2011) found that preferences for "dark" media genres, which included Horror, were associated with lower Agreeableness. Our research, which relies on a large diverse sample and measures preferences via active naturally occurring attitude expressions in the field, establishes the external validity of this finding. Other associations that we observe, however, have not been previously reported. For example, we find that Horror movies have more neurotic audiences, where Rentfrow et al. (2011) did not observe a link between Neuroticism and liking of "dark" genres. Most notably, liking of Sports movies, which has not been assessed in any previous studies, strongly relates to all of the Big Five traits.

The findings of Study 1 hint that consumers are drawn to movies that reflect their own psychological dispositions. The correlations between the Big Five and liking Sports films mirror their associations with engagement in real-life physical activity; fans of Crime movies are more extroverted and less agreeable, just as people who engage in crime outside the big screen; and fearloaded Horror movies have neurotic fans, who tend to experience more anxiety in their own lives. However, this analysis is bounded by its reliance on genres as the unit of analysis, which limits the capacity to understand the underlying psychological mechanisms. For example, fans of Horror movies are more neurotic and less agreeable, but the association between liking Horror and these traits may arise from different causes (e.g., neurotic people are drawn to Horror because it is fearful, where low Agreeableness people like Horror for its violence). In the next study, we obtain a more nuanced representation of the movies' plots, and investigate whether characterizing movies via their content facilitates additional psychological insight. 


\section{STUDY 2}

In Study 2 we characterize movies via their plots, quantified using text keywords, and investigate whether this representation facilitates more accurate predictions of aggregate fan personalities. We further use text analysis to quantify how different psychological themes appear in the movies, and link these themes, as well as other concepts that organically emerge from the data, with personality dimensions - in order to generate additional insight into the underlying mechanisms.

\section{Data Sources and Measures}

Similar to Study 1, we rely on data from myPersonality and IMDb and include all movie titles in the Movie Personality Dataset. In addition to the variables described in Study 1 (AFPPs, AFDP, Metadata, and Genre), Study 2 relies on additional data structures, described in detail below and illustrated in Figure 1.

Plot Keywords. A keyword is a single lower-case word (e.g., 'police') or a phrase of several words (e.g., 'time travel') attached to a movie title. IMDb users generate these keywords to facilitate easy search and discovery of titles by other users. As such, keywords describe "any notable object, concept, style or action that takes place during a title." 5 The average movie in the Movie Personality Dataset has 168 keywords (SD = 100.1; Max: 865 Min: 7).

IMDb Keywords Matrix. Our analysis employs the dataset of Bhatia and Stewart (2018), which scrapped the IMDb website in 2014 to obtain 160,322 unique keywords associated with 44,972 titles. We updated this dataset in 2018, by adding the keywords of the 9,067 additional movies (the most voted feature film titles on IMDb at that time, with the exception of movies that

\footnotetext{
${ }^{5}$ See https://imdb.to/32Ct6Lc
} 
were already in the myPersonality database and movies that did not have plot keywords on IMDb). The number of unique keywords in the updated dataset, which we call "IMDb Keywords Dataset," is $K=190,297$. We assign each of these keywords an integer between 1 and $K$, and represent the keywords associated with each title using a $K$-dimensional binary vector (or "Keywords"), where the value of the $k^{\text {th }}$ dimension equals one if keyword $k$ appears as a descriptor of the movie on IMDb, and zero otherwise. We rely on the Keyword vectors of the titles in the IMDb Keywords Dataset to construct an IMDb Keyword Matrix. Each row of the matrix represents an IMDb title, and consists of its Keywords vector. This resulted in a 54,972 (titles) x 190,297 (keywords) dimensional matrix. Reduced Keywords. We reduce the dimensionality of the IMDb Keyword Matrix by performing single value decomposition (SVD; Deerwester, Dumais and Furnas 1990; Landauer and Dumais 1997) and keeping the first 100 SVD components, similar to previous work (Bhatia and Stewart 2018; Kosinski et al. 2013). We then project the Keywords vectors of all titles in the Movie Personality Dataset onto these 100 latent dimensions, and normalize the projections' magnitudes (L2). We refer to the normalized projection vector of each movie's Keywords vector as its Reduced Keywords vector.

Metadata. In addition to all Metadata variables used in Study 1, we include the following measures: (1) Number of keywords; (2) Language (86 languages, dummy coded); and (3) Country (40 countries, dummy coded). The language and country variables were not included in Study 1 as they are represented via a large number of variables, which generates overfitting.

Statistical Analyses

Predicting Aggregate Fan Personalities from Plot Keywords. For each of the five AFPP dimensions, we conduct a "leave one out" cross-validated prediction exercise (Stone 1978; Zhang 
1993). We carry out predictions for each title in the Movie Personality Dataset by fitting regularized linear regressions with the Least Absolute Shrinkage and Selection Operator (LASSO; Tibshirani 1996) to the data of all other movies in this dataset, and recording the models' predictions (Camerer, Nave and Smith 2018; Nave et al. 2018). We train our models using different combinations of the movies' (1) Reduced Keywords vectors; (2) AFDPs; (3) Metadata; and (4) Genre. We define predictive accuracy as the Pearson correlation between the actual and predicted values across movies (Kosinski et al. 2013; Nave et al. 2018). The main results that we report are obtained using a LASSO with a regularization parameter value of $\chi=0.001$. We also report results of analyses using LASSO regressions with other parameter values and Ridge regressions with various parameter values, as robustness tests.

Estimating the associations between aggregate fan personalities and unique plot keywords. We project the 1,000 most common keywords on IMDb onto the 100-dimensional reduced keyword space and denote the $k^{\text {th }}$ keyword loading on the $d^{\text {th }}$ SVD dimension by $L_{k, d}$. Next, we fit LASSO regressions (as described above) to predict the AFPPs of all titles in the Movie Personality Dataset from these Reduced Keywords vectors, controlling for all AFDP and Metadata variables. We denote the beta coefficients for the $d^{\text {th }}$ dimension and trait $t$ by $b_{d, t}$, and quantify the relationship between each personality traits $t$ and a keyword $k$ by

$$
\text { (1) } \quad b_{0, t}+\sum_{d=1}^{100} b_{d, t} \cdot L_{k, d} \text {. }
$$

We interpret this relationship as the predictive score of trait $t$ for a movie with only one keyword, and this keyword is $k$.

\section{Estimating the associations between aggregate fan personalities and the movies'}

psychological themes. We estimate how the plot keywords of each movie are related to 33 word 
categories from the Linguistic Inquiry and Word Count (LIWC). ${ }^{6}$ LIWC is a language analysis program commonly used to study relationships between language and psychological variables, including personality (Berger and Milkman 2012; Netzer, Lemaire and Herzenstein 2019; Pennebaker, Francis and Booth 2001; Pennebaker and King 1999; Yarkoni 2010). We estimate these associations by calculating the semantic similarity between each movie's plot keywords and the LIWC dictionary words. To this end, we obtain a 300-dimensional word2vec embedding representation (Mikolov et al. 2013) for each plot keyword in a movie and average across keywords to get a single 300-dimensional vector representation for each movie. We then calculate the cosine similarity between each movie and each LIWC category by summing the movie's similarities with all the words in that category. Finally, we estimate the links between LIWC categories and the AFPPs via partial linear correlations between the two across movies, adjusting for the AFDP dimensions and non-categorical metadata variables. We account for multiple hypothesis testing using Bonferroni correction that sets the alpha level of each coefficient's statistical significance tests to $a=0.05 / 33$, where 33 is the number of partial correlations computed for each trait.

Pre-registration. Before analyzing the data, we registered our analysis on the Open Science Framework (OSF): https://bit.ly/2IgijkS. Our pre-registration included ten hypotheses, predicting that Reduced Keywords vectors would be predictive of all five AFPP dimensions above chance, and that Reduced Keywords vectors would be predictive of all five AFPP dimensions above AFDPs and Metadata variables. The tests of all pre-registered hypotheses yielded statistically significant effects. The main findings reported in the paper include several deviations from the pre-registered analyses, summarized in detail in the study's OSF page.

Data Availability. Data are available in the study's OSF page.

\footnotetext{
${ }^{6}$ LIWC has more than 33 categories, but we exclude grammatical categories (e.g., pronouns) and only keep those with thematic/semantic content.
} 
Results

Predicting Fan Personalities from Plot Keywords. As a first step, we train five machinelearning models that predict the movies' AFPPs from their Reduced Keyword Vectors. Figure 4 plots the actual values against the out-of-sample predicted AFPPs across movies. The most accurate predictions are for Extraversion $(\mathrm{r}(846)=.67,95 \% \mathrm{CI}=(.63, .71), \mathrm{p}<0.001)$, followed by Neuroticism $(\mathrm{r}(846)=.67,95 \% \mathrm{CI}=(.62, .70), \mathrm{p}<0.001)$, Agreeableness $(\mathrm{r}(846)=.64,95 \% \mathrm{CI}=(.60, .68)$ $\mathrm{p}<0.001)$, Openness $(\mathrm{r}(846)=.64,95 \% \mathrm{CI}=(.60, .68), \mathrm{p}<0.001)$, and Conscientiousness $(\mathrm{r}(846)=.55$, $95 \% \mathrm{CI}=(.50, .59), \mathrm{p}<0.001)$. Thus, the models leverage information contained in the movie plots to predict all of the Big Five dimensions, explaining out-of-sample variance between $R^{2}=30 \%$ to $R^{2}=45 \%$.

Figure 5 displays the out-of-sample variance explained $\left(R^{2}\right)$ of models using Genre, Metadata, AFDPs, Reduced Keyword Vectors, and different combinations of these variables. Models that rely on Reduced Keyword Vectors alone are significantly more accurate than models that use either Metadata or Genre for all traits (all p's $<0.001$ ) and are significantly more accurate than models that rely on AFDPs for three traits (Openness p<0.017; Extraversion and Agreeableness $\mathrm{p}<0.001$ ). The gain in predictive accuracy relative to genre is particularly notable for Openness, where models trained using plot keywords increase the out-of-sample variance explained by $200 \%\left(\Delta R^{2}=27 \%\right)$. The gain is notable for the other traits as well, with increases in out-of-sample variance explained ranging from $35 \%$ to $55 \%\left(\Delta R^{2}\right.$ between $10 \%$ and $\left.15 \%\right)$. Furthermore, adding plot keywords to the models that include all other variables significantly improves predictive accuracy of all dimensions (all p's $<0.01$, Williams z-test), with additional out-of-sample variance explained ranging from $\Delta R^{2}=4 \%$ to $\Delta R^{2}=12 \%$. 
We conducted several analyses to investigate our conclusions' sensitivity to specific analytical choices (Steegen et al. 2016). First, we repeat the analyses using LASSO regressions with $\chi=\{0.0001,0.001 .0 .01\}$, Ridge regressions with $a=\{0.01,0.1,1,10,100\}$, and OLS regressions. The results confirm that keywords are predictive of all five AFPP dimensions and are informative above all other variable groups under these specifications (Supplementary Table 6). ${ }^{7}$ Second, we investigate if our conclusions hold when there is no overlap between the data used to compute the SVD dimensions and the data used to train and test the predictive models. To this end, we repeat our analysis using a different set of Reduced Keyword Vectors, composed by projecting the Keyword Vectors of the movies in the Movie Personality Dataset onto a different set of 100 latent dimensions. We calculated these dimensions by performing SVD on the keyword matrix of the 10,000 most voted feature film titles on IMDb up to 2018, excluding the titles in the Movie Personality dataset ${ }^{8}$. Our conclusions hold under this alternative specification (Supplementary Table 7 and Supplementary Figure 4).

Investigating the Links between Movies' Themes and Concepts and Fan Personalities. Plot keywords predict the AFPP dimensions above all the other variables included in our analyses. Our reliance on text keywords as explanatory variables allows us to conduct more nuanced analyses to understand the relationships between movies' psychological themes and the personality traits of fans. To do this, we quantify the degree that each movie contains 33 different psychological themes, and calculate the partial correlations between these themes and the AFPPs across movies (adjusting for AFDPs and Metadata). We substantiate this analysis by isolating plot keywords that emerge as the

\footnotetext{
${ }^{7}$ OLS regression models (expectedly) yielded poor performance in analyses that had a large number of variables, due to overfitting (Hawkins 2004). Overfitting was driven by the large number of Metadata variables, which included dummy variables indicating the movies' country and language.

${ }^{8}$ We excluded the entire Bhatia and Stewart (2018) dataset from the SVD calculation in this analysis, because we could not identify every title in this dataset, since IMDb's title-naming scheme had changed since its assembly in 2014. As a result, we could not ensure that all titles in the Movie Like dataset were excluded from this dataset.
} 
strongest predictors of the Big Five dimensions in the dataset (for a similar approach, see Netzer et al. 2019).

Figure 6 displays the correlations across movies between the AFPP dimensions and a subset of the psychological themes studied (for all themes, see Supplementary Table 8). Table 1 lists the top 20 keywords that most positively and negatively predict each of the Big Five dimensions. In total, we quantify 165 correlations between the Big Five and 33 psychological themes. After Bonferroni correction, $74(44.8 \%)$ remain statistically significant at the $a=.05$ level and $67(40.6 \%)$ are significant at the $\mathrm{a}=.01$ level. Although not all of observed correlations have a straightforward interpretation, the general pattern of associations indicates that movie plots are congruent with the psychological tendencies of the audiences they attract.

The themes that most strongly correlate with AFPP dimensions are from the Affective Processes and Personal Concerns categories (Figure 6, top). For Affective Processes, the largest positive correlations are between Neuroticism and Negative Emotions, Anxiety, and Anger. Further underscoring these findings, keywords such as 'unrequited love,' 'nightmare,' and 'screaming' are among the strongest predictors of Neuroticism. Neuroticism also correlates with the themes of Body, Health, and Death. The keywords 'fainting,' 'mental illness,' and 'serial killer,' which are also highly predictive of Neuroticism, suggest that these links arise as neurotic audiences are drawn to movies that involve psychological hardship. Conversely, the keywords that most strongly predict low Neuroticism denote appearances of weapons ('uzi,' 'ak 47') and combat personnel ('sniper,' 'FBIagent'), which typically occur in action-loaded films with easygoing protagonists (e.g., Mission Impossible, James Bond). Taken together, these findings suggest that neurotic people prefer movies that mirror their negative emotions as a way to validate or maintain them, rather than seek out movies that distract these emotions away. 
Openness shows associations with themes in the Affective Processes and Personal Concerns categories, which are qualitatively similar to the patterns observed for Neuroticism, but with smaller effects. These findings were expected, as these AFPP dimensions correlate across movies (Supplementary Figure 1). The only two themes for which Openness has stronger correlations than Neuroticism are Religion and Power - which tend to appear in dark comedies, political satires, and movies about taboo topics (e.g., Monty Python and the Holy Grail, Dogma, I Care a Lot). This interpretation is supported by the list of keywords that predict high Openness, which includes 'cult director,' 'dark comedy,' 'adultery,' and 'satire.' Openness also correlates with Cognitive Processes (most strongly with the Insight theme), where other keyword predictors ('surrealism,' 'hallucination,' 'record player') reflect the trait's association with aesthetic sensitivity and creativity. The keywords that most strongly predict low Openness are ones that often appear in lighthearted mainstream films (e.g., 'college student,' 'gym,' 'baseball')—-suggesting that high-Openness individuals, who have greater needs for cognition and uniqueness (Dollinger 2003; Florida and Mellander 2014), avoid such movies.

Agreeableness, which is characterized by affiliative behavior and conflict avoidance (Graziano and Eisenberg 1997; Vliert, van de Vliert and Euwema 1994) positively correlates with Positive Emotions and themes that are lighter and optimistic, including Family, Friends, Achievement, Leisure, Money, and Work. The keywords that most strongly predict Agreeableness are indicative of functioning relationships ('marriage proposal,' 'wedding,' 'grandmother-grandson relationship'), leisure ('fishing,' 'baseball,' 'waterfall') and 'feel good' action ('hero,' 'hand-to-hand combat'). On the other hand, Agreeableness shows strong negative correlations with Anger and the themes of Sexuality, Body, and Health. The keywords that most strongly predict low Agreeableness are terms that indicate violence ('attempted rape,' 'gore,' 'sadism,' 'self-mutilation') and sexual 
imagery ('bare breasts,' 'female nudity') — revealing that violent and sexual content draws low Agreeableness audiences.

Among all traits, Extraversion-which is characterized by energetic social interactions — has the strongest associations with the Friends theme, where the trait's most predictive keywords include social interactions of all types (e.g., 'best friend,' 'flirting,' 'dating,' 'break-up,' 'roommate,' 'barfight,' 'raised middle finger'). Extraversion also has a positive correlation with the Sexual theme and negative correlations with Negative Emotions and Anxiety-in line with previous reports of high sexual drive and low anxiety among extraverts (Barnes, Malamuth and Check 1984; Jylhä and Isometsä 2006; Schenk and Pfrang 1986). Other themes that correlate with Extraversion are Ingestion and Leisure, where the predictive keywords list—which includes terms such as 'beer,' 'bar,' 'singing in a car,' 'motel,' and 'strip club' - hints that these relationships stem from the social aspects of dining and vacations.

Introverted AFPPs, on the other hand, are most strongly associated with Cognitive Processes and serious themes, like Death and Religion. The strongest keyword predictors of introversion point to three unique topics: (1) fantasy ('monster,' 'creature,' 'surrealism,' 'fictional war') —in line with findings that introverts score higher on measures of imagination and fantasy (Feist and Barron 2003); (2) science ('laboratory,' 'scientist,' 'doctor') — consistent with introverts' interest in scientific professions (Feist 2012); and (3) World War II ('tunnel,' 'gas-mask,' 'German')—which is among the more serious topics appearing in award-winning movies over the past decades (e.g., Saving Private Ryan, Life is Beautiful, Schindler's List; Basinger and Arnold 2003).

Finally, Conscientiousness is the only trait that negatively correlates with all the types of Emotional Processes, as well as the themes of Sexuality, Body, and Health. Contrary to our expectations, we do not observe correlations between Conscientiousness and the Work and Achievement themes, though several of the trait's predictive keywords may reflect career aspirations 
('businessman,' 'Manhattan New York City,' 'Chicago Illinois'), or characteristics of an organized and predictable lifestyle ('marriage,' 'church,' 'prayer,' 'fishing,' 'baseball'). Conscientiousness reflects the degree to which individuals conform to social norms (DeYoung et al. 2002; Roccas et al. 2002), so it is conceivable that plot themes that appeal to the status quo might be more enjoyable among people who have traits that encourage such compliance. The keywords that are most predictive of low Conscientiousness mirror these findings, with terms related to instability ('disfigurement,' 'transformation'), moral conflict ('good versus evil'), and fantasy ('reversefootage,' 'spoof,' 'monster,' 'creature').

\section{Discussion}

Study 2 goes beyond genre categories, to represent movies via plot keywords. This approach facilitates more accurate predictions of the fan personalities, above and beyond genre and all other metadata and demographic variables considered. Reliance on plot keywords also allows us to quantify various concepts and psychological themes that appear in the movies, and relate them to the Big Five of their fans. This analysis reveals that consumers are drawn to movies that align with their own psychological dispositions. For example, movies with Anxiety have neurotic fans, social movies have extroverted fans, and violent movies have fans low on Agreeableness.

While our analyses focused on themes from the widely used LIWC dictionary, a similar approach can be used to quantify the presence of any other theme in the movies. To this end, researchers can rely on semantic categories from other existing lexicons (e.g., Mohammad and Turney 2013; Nielsen 2011; Rocklage and Fazio 2015), or manually construct new dictionaries for any given theme (e.g., Science, Environmentalism, The Cold War) by asking participants to list phrases associated with them (Berger et al. 2020; Humphreys and Wang 2017; Toubia et al. 2019). 
Once such dictionaries are constructed, researchers can follow our method to compute the degree that these themes appear in the movies using word embeddings, and investigate their relationship with fan characteristics.

\section{FIGURE 4}

\section{OBSERVED VERSUS PREDICTED AGGREGATE FAN PERSONALITIES}
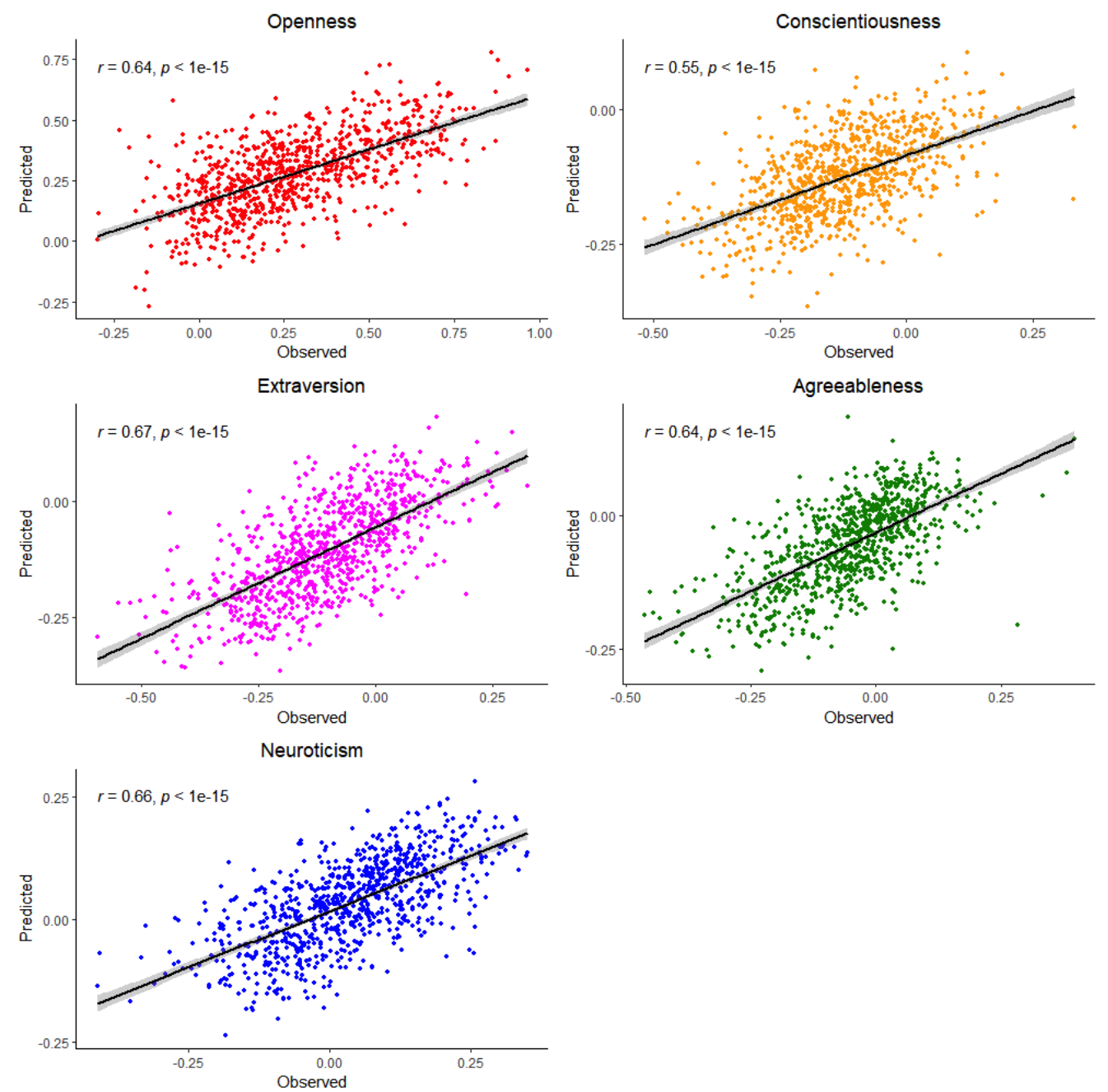

NOTE.-Each data point represents a movie. Lines represent fitted regressions and their associated 95\% confidence intervals. 


\section{FIGURE 5}

\section{OUT OF SAMPLE AGGREGATE FAN PERSONALITY VARIANCE EXPLAINED}

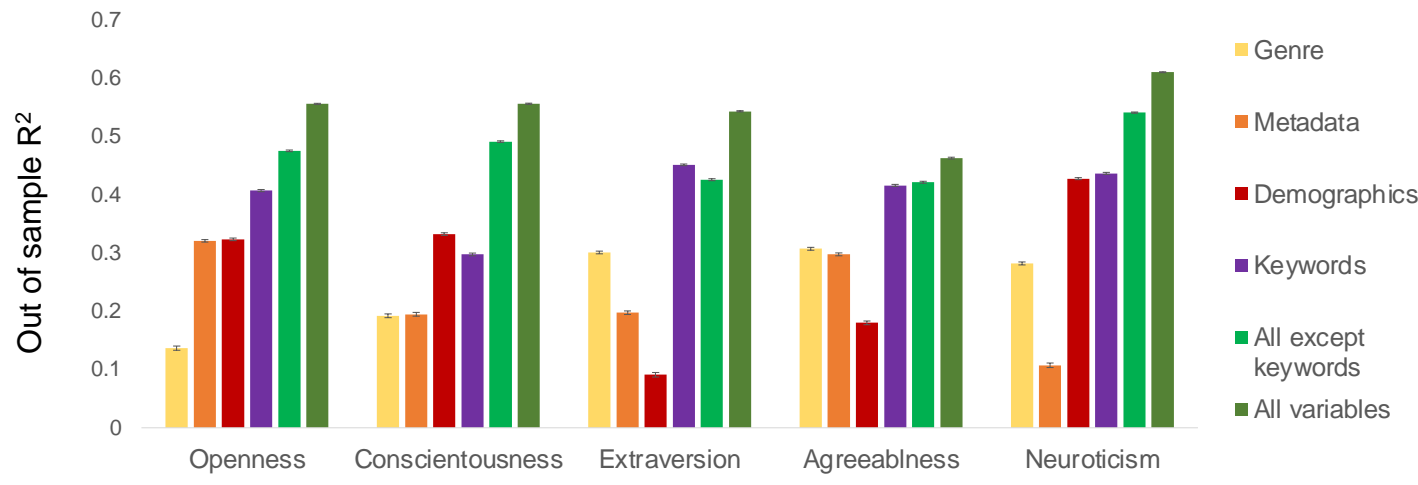

NOTE. - Values represent the $\mathrm{R}^{2}$ between actual and predicted values across movies. Each color denotes a model trained using a different subset of the study's variables.

\section{TABLE 1}

\section{TOP 20 POSITIVE AND NEGATIVE PREDICTIVE KEYWORDS OF THE BIG FIVE}

\begin{tabular}{|c|c|c|c|c|c|c|c|c|c|c|}
\hline \multirow{21}{*}{\begin{tabular}{|l|} 
Trait \\
High \\
\end{tabular}} & Opennesss & \begin{tabular}{|l|} 
Percentile \\
\end{tabular} & Conscientiousness & \begin{tabular}{|l|l} 
Percentile \\
\end{tabular} & Extraversion & Percentile & Agreeableness & \begin{tabular}{|l|} 
Percentile \\
\end{tabular} & Neuroticism & Percentile \\
\hline & cult director & $11 \%$ & marriage proposal & $19 \%$ & dating & $13 \%$ & baseball & $16 \%$ & insanity & $22 \%$ \\
\hline & surrealism & $15 \%$ & wedding & $21 \%$ & gay slur & $17 \%$ & wedding & $16 \%$ & obsession & $22 \%$ \\
\hline & recording & $17 \%$ & new york city & $21 \%$ & break up & $18 \%$ & training & $17 \%$ & self mutilation & $22 \%$ \\
\hline & cult film & $18 \%$ & fistfight & $21 \%$ & ex boyfriend ex girffriend relation & $18 \%$ & hand to hand combat & $17 \%$ & based on novel & $22 \%$ \\
\hline & tea & $22 \%$ & new york & $21 \%$ & roommate & $19 \%$ & fishing & $17 \%$ & doll & $24 \%$ \\
\hline & cynicism & $22 \%$ & manhattan new york city & $21 \%$ & bar fight & $19 \%$ & fireworks & $17 \%$ & fainting & $24 \%$ \\
\hline & mirror & $23 \%$ & church & $22 \%$ & beer & $19 \%$ & marriage proposal & $17 \%$ & key & $25 \%$ \\
\hline & record player & $23 \%$ & chicago illinois & $23 \%$ & basketball & $19 \%$ & competition & $17 \%$ & necklace & $25 \%$ \\
\hline & satire & $24 \%$ & semiautomatic pistol & $23 \%$ & best friend & $20 \%$ & action hero & $17 \%$ & mental illness & $26 \%$ \\
\hline & key & $26 \%$ & fishing & $24 \%$ & machismo & $20 \%$ & construction site & $17 \%$ & ghost & $26 \%$ \\
\hline & cigarette smoking & $26 \%$ & prayer & $25 \%$ & motel & $20 \%$ & waterfall & $18 \%$ & screaming & $26 \%$ \\
\hline & dark comedy & $26 \%$ & rural setting & $25 \%$ & gym & $20 \%$ & ak 47 & $19 \%$ & dream sequence & $27 \%$ \\
\hline & older man younger woman relation & $26 \%$ & divorce & $25 \%$ & obscene finger gesture & $20 \%$ & hero & $19 \%$ & poison & $27 \%$ \\
\hline & insanity & $26 \%$ & love & $25 \%$ & & $21 \%$ & mixed martial arts & $19 \%$ & drawing & $27 \%$ \\
\hline & memory & $27 \%$ & marriage & $25 \%$ & stripper & $21 \%$ & product placement & $19 \%$ & serial killer & $28 \%$ \\
\hline & shaving & $27 \%$ & businessman & $25 \%$ & flirting & $22 \%$ & blockbuster & $20 \%$ & unrequited love & $28 \%$ \\
\hline & destiny & $29 \%$ & grief & $25 \%$ & strip club & $22 \%$ & grandmother grandson relation & $20 \%$ & nightmare & $28 \%$ \\
\hline & adultery & $29 \%$ & baseball & $25 \%$ & raised middle finger & $22 \%$ & speech & $20 \%$ & disfigurement & $28 \%$ \\
\hline & hallucination & $29 \%$ & river & $26 \%$ & singing in a car & $23 \%$ & village & $20 \%$ & flower & $28 \%$ \\
\hline & radio & $29 \%$ & hairy chest & $26 \%$ & hit in the crotch & $23 \%$ & terrorist & $20 \%$ & incest & $28 \%$ \\
\hline \begin{tabular}{|l|l} 
Trait \\
\end{tabular} & Opennesss & \begin{tabular}{|l|} 
Percentile \\
\end{tabular} & Conscientiousness & \begin{tabular}{|l|} 
Percentile \\
\end{tabular} & Extraversion & Percentile & Agreeableness & \begin{tabular}{|l|} 
Percentile \\
\end{tabular} & Neuroticism & Percentile \\
\hline Low & laptop & $98 \%$ & cult director & $79 \%$ & laboratory & $83 \%$ & female frontal nudity & $75 \%$ & machine gun & $86 \%$ \\
\hline & wedding & $95 \%$ & surrealism & $79 \%$ & skeleton & $81 \%$ & female rear nudity & $73 \%$ & ak 47 & $82 \%$ \\
\hline & & $95 \%$ & cult film & $76 \%$ & scientist & $81 \%$ & female nudity & $70 \%$ & shootout & $82 \%$ \\
\hline & product placement & $94 \%$ & disfigurement & $76 \%$ & self sacrifice & $81 \%$ & gore & $70 \%$ & american flag & $82 \%$ \\
\hline & basketball & $94 \%$ & good versus evil & $72 \%$ & creature & $80 \%$ & covered in blood & $70 \%$ & sniper & $80 \%$ \\
\hline & baseball & $93 \%$ & monster & $72 \%$ & nurse & $80 \%$ & murder & $70 \%$ & uzi & $80 \%$ \\
\hline & gym & $93 \%$ & creature & $72 \%$ & evacuation & $80 \%$ & blood splatter & $70 \%$ & rocket launcher & $80 \%$ \\
\hline & helicopter & $93 \%$ & fictional war & $72 \%$ & radio & $80 \%$ & nudity & $69 \%$ & sniper rifle & $80 \%$ \\
\hline & college student & $93 \%$ & insanity & $72 \%$ & german & $80 \%$ & self mutilation & $69 \%$ & exploding car & $80 \%$ \\
\hline & $2000 \mathrm{~s}$ & $92 \%$ & nurse & $68 \%$ & monster & $78 \%$ & bare breasts & $69 \%$ & bulletproof vest & $78 \%$ \\
\hline & fishing & $92 \%$ & transformation & $68 \%$ & surrealism & $78 \%$ & female full frontal nudity & $68 \%$ & hand grenade & $78 \%$ \\
\hline & accident & $91 \%$ & reverse footage & $68 \%$ & key & $78 \%$ & attempted rape & $68 \%$ & target practice & $78 \%$ \\
\hline & scene during end credits & $91 \%$ & skeleton & $68 \%$ & statue & $78 \%$ & nipples & $67 \%$ & & $78 \%$ \\
\hline & church & $91 \%$ & destiny & $68 \%$ & map & $78 \%$ & cult director & $66 \%$ & gunfight & $78 \%$ \\
\hline & cell phone & $90 \%$ & robot & $68 \%$ & attack & $78 \%$ & insanity & $66 \%$ & press conference & $78 \%$ \\
\hline & internet & $90 \%$ & self mutilation & $68 \%$ & destruction & $78 \%$ & breasts & $66 \%$ & silencer & $78 \%$ \\
\hline & $2010 \mathrm{~s}$ & $89 \%$ & hallucination & $68 \%$ & fictional war & $78 \%$ & sadism & $65 \%$ & machismo & $74 \%$ \\
\hline & ak 47 & $89 \%$ & laboratory & $68 \%$ & surgery & $78 \%$ & pubic hair & $65 \%$ & exploding building & $74 \%$ \\
\hline & singing in a car & $89 \%$ & spoof & $68 \%$ & doctor & $78 \%$ & lust & $64 \%$ & fbi agent & $74 \%$ \\
\hline & lake & $89 \%$ & virgin & $68 \%$ & gas mask & $78 \%$ & topless female nudity & $64 \%$ & shotgun & $74 \%$ \\
\hline
\end{tabular}

NOTE.-Percentile denotes the predicted percentile of a movie that only has the keyword in the corresponding trait, relative to the movies in the Movie Personality Dataset (e.g., a movie that only has the keyword 'cult director' would be in the top $11 \%$ of Openness in our dataset). 


\section{FIGURE 6}

\section{RELATIONSHIPS BETWEEN MOVIE THEMES AND FAN PERSONALITIES}

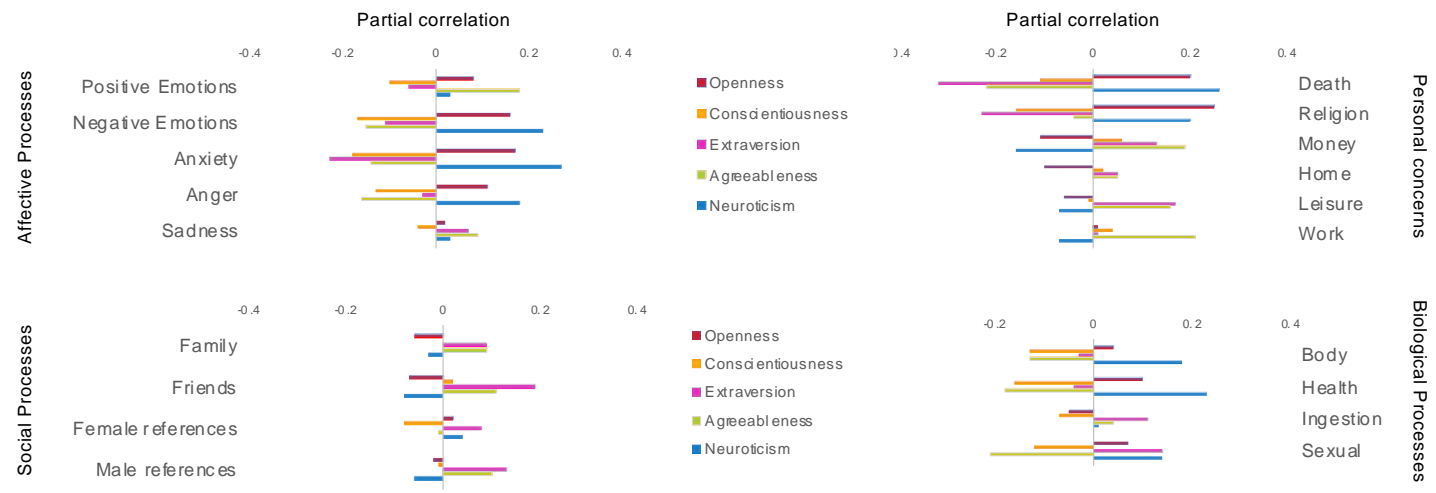

NOTE. - Relationships are estimated via partial correlations, controlling for AFDP and metadata. The figure displays a subset of the correlations. For all correlations and their significance, see Supplementary Table 8.

The prospect of using plots to predict the psychographics associated with liking distinct movies has many potential applications, from cinema advertising to product placements in movies (see General Discussion). Nonetheless, such applications depend on the capacity to generalize the insight of our models across movies and populations. We address this question in the next study.

\section{STUDY 3}

Study 2 estimated models that predicted the aggregate personalities of movie fans from their plot keywords. Study 3 evaluates how insights obtained from these models generalize (Yarkoni 2020) in three manners. First, Study 2 used relatively popular movies released before 2012, the year when myPersonality concluded data collection. Study 3 tests our models' predictions using less popular movies released more recently, as some applications (e.g., assessing the psychographics associated with liking a new 'niche' movie) would require. Second, the AFPPs of all movies in 
Study 2 were estimated on data from myPersonality. Study 3 evaluates the generalizability of our predictions to a different sample. Third, Study 2 operationalized preferences via Facebook Likes, which were likely generated by users who had already watched the full movies before Liking them. Likes are active evaluative expressions, and assessing the characteristics of users who Like distinct contents may be, by itself, of interest to marketers (John et al. 2017; Matz et al. 2017). However, some business applications (e.g., promotion of new releases) require assessing the psychographics of prospective audiences who have not yet watched the movies. In Study 3, we elicit preferences from participants who have not watched the movies before, based on posters and trailers-which are commonly available to consumers when deciding what to watch.

In sum, Study 3 evaluates our model's generalizability across movies, participants, and preferences elicitation methods. To this end, we use our text-based models to generate personality predictions for a new set of 9,067 movies, and select four pairs of relatively unknown movies that were 1) released after 2012,2 ) similar in quality and genre classifications, and 3) are expected to draw audiences that differ in their levels of Openness, based on their plots. We test our models' predictions in a pre-registered online experiment $(N=1,018)$. Each participant watched the trailers of both movies in a pair, rated their quality, and indicated which of them (if any) they would like to watch. To evaluate the generalizability of our models' insight, we test if participants' Openness is indeed related to their ratings and choices.

Materials and Methods

Predicting Personality in a New Set of Movies. Using our models, we generate predictions for the AFPPs of 9,067 additional movies that were not included in the original Movie Personality Dataset. These movies include the 10,000 most rated films on IMDb as of 2018, except for titles that already 
appear in the Movie Personality Dataset and titles that do not have keywords. We make these predictions publicly available (https://bit.ly/2IgijkS), and they can be used in future studies that further test the generalizability of our models' insight to different settings.

Movies Selection. From the 9,067 movies above, we pre-selected four pairs of movies that were released after 2012 and were rated by less than 50,000 IMDb users (for comparison, movies in the Movie Personality Dataset were rated by an average of over 250,000 users). The two movies in each pair had the same IMDb genre classifications (e.g., both were classified as Comedy and Drama, and not as any other genre) and had similar quality ratings (the difference in ratings was less than 1 on a 10-point scale). However, using our keywords-based model, the movies in each pair were selected so that one movie ("High-O") would have a stronger appeal to people high in Openness, and the other ("Low-O") would attract people with average Openness. Our decision to use Openness as the target trait was based on Study 2, which showed that this dimension was the least predictable from a movie's genre (see Figure 5). Table 2 summarizes the characteristics of the movie pairs used in the study.

Behavioral Task. We randomly assigned each participant to one of the four movie pairs. Each participant saw the posters, short verbal descriptions from IMDb, and the trailers (each about 2:30 minutes long; see YouTube link in Table 2) of the two movies in the pair in randomized order. We asked participants to report how much they liked each trailer (on a 5-star scale), whether they had seen either of the movies before, and which of the two movies (if any) they would prefer to watch. After reporting their ratings and choices, participants completed the BFI-2 Big Five questionnaire (Soto and John 2017), and reported their gender and age. The task lasted approximately 10 minutes, and participants received $\$ 1.25$ for participation.

Sample and Exclusion Criteria. We recruited $N=1,200$ US-based participants between the ages of 25 and 40 on the Prolific Academic platform. The sample size was maximized subject to 
budget constraints, and would allow detecting effects as small as $f^{2}=0.1$ with $90 \%$ power at the $\alpha .=05$ level (two tailed). Each participant had to click a box stating that they were not a robot and correctly answer an attention-check question to start the survey. We excluded from our analyses participants who did not complete the survey, and participants who reported having seen either of the movies before. The Institutional Review Board of the University of Pennsylvania approved the study, and all participants provided informed consent.

Statistical Analyses. Prior to analysis, we standardized participants’ Big Five scores, akin to Studies 1 and 2. To mitigate the influence of outlying personality values, we winsorized values of the Big Five that were 2.5 SD above or below the mean (as pre-registered), and report effects without winsorization as an additional robustness check.

Our primary dependent variable of interest is 'Choice' — a binary indicator that equals one if a participant chose the High-O movie and zero otherwise (i.e., chose the Low-O movie or was indifferent). To test the relationship between participants' Openness and their movie choice, we estimated a logistic regression with Choice as the dependent variable and participants' Openness as an independent variable, controlling for gender, age, and movie pair fixed effects. We report models that control for the other Big Five traits and models that exclude participants who were indifferent between the two movies as additional robustness tests.

To quantify the relationship between Openness and participants' ratings of the trailers, we estimate linear regressions with the ratings (separately for the High-O and Low-O movies) as the dependent variable and the same explanatory variables as in the analysis of Choice. For illustration purposes, we also conduct a quintile split of the sample on participants' Openness and plot how the behavioral outcomes differ based on this categorical split. 
Pre-registration. Before data collection, we registered our experiment and analysis plan on OSF: https://bit.ly/3rIHFvZ. We did not deviate from the pre-registered protocol but provide robustness tests using different specifications.

Data Availability. Data are available in the study's OSF page.

Results

Supplemental Figure 5 displays the distributions of the Big Five traits of the study participants. After applying our pre-registered exclusion criteria, $N=1,018$ participants remained in our primary analysis (Age: $31.4 \pm 4.6$; 584 females; 15 non-binary gender). Supplemental Figure 6 displays the distributions of movie choices and trailer ratings.

We first estimate a logistic regression that predicts participants' movie choice from their Openness score, controlling for age and gender (Table 3). As predicted, we observe a significant effect of Openness $(\beta=0.17,95 \% \mathrm{CI}=[0.04,0.30], \mathrm{t}(1,010)=2.61, \mathrm{p}<0.01)$, indicating that one standard deviation increase in Openness translates into a $19 \%$ increase in the odds of choosing the High-O movie. The effect holds when controlling for the other Big Five traits, and under all other model specifications tested (Supplemental Table 9). Figure 7A illustrates the effect using a quintile split, showing that participants whose Openness level is at the top quintiles are more likely to choose the High-O movies, and participants at the lower Openness quintiles are less likely to choose them.

Next, we estimate OLS regressions that quantify how participants' Openness is related to their trailer ratings (Table 3). As predicted, Openness is positively related to the ratings of the high-O trailer $(\beta=0.14,95 \% \mathrm{CI}=[0.07,0.21], \mathrm{t}(1,010)=3.74, \mathrm{p}<0.0002)$. The relationship between Openness and the ratings of the low-O trailers is negative and insignificant $(\beta=-0.04,95 \% \mathrm{CI}=[-$ $0.12,0.04], t(1,010)=-1.01, p>0.31)$, and becomes significant once we control for the other Big Five 
traits $(\beta=-0.09,95 \% \mathrm{CI}=[-0.17-0.01], \mathrm{t}(1,010)=-2.22, \mathrm{p}<0.03)$. Figure 7 illustrates this effect visually, showing that participants at the top Openness quintiles rate the High-O trailers higher than those at the bottom quintiles.

\section{Discussion}

Study 2 constructed models that relied on plot keywords to predict the Big Five profiles associated with liking distinct movies. We trained these models using data from myPersonality, which included information on the aggregate personalities of Facebook users who Liked relatively popular movies released before 2012. Study 3 shows that our models' insight generalizes to a new set of relatively unknown movies released after 2012, when preferences are assessed using different methods in a new sample. Specifically, our models predicted how participants' Openness would relate to their choice between movies from the same genre after watching their trailers, as well as their ratings of these trailers. Our findings suggest that our models allow assessing the psychographics of audiences that new movies are expected to attract among new populations, as applications such as cinema advertising and promotion of new movies would require. To allow exploration of our findings' generalizability, we provide AFPP predictions derived from our models for 9,067 additional movies (see Materials and Methods). We invite researchers to test their insights amid additional circumstances. 
TABLE 2

STUDY 3: MOVIE PAIRS

\begin{tabular}{|c|c|c|c|c|c|c|c|}
\hline & Title & Year & IMDb ID & $\begin{array}{c}\text { Predicted } \\
\text { Openness }\end{array}$ & $\begin{array}{l}\text { Quality } \\
\text { Rating }\end{array}$ & Genre & Trailer link \\
\hline High-O & The Little Hours & 2017 & tt5666304 & 0.30 & 5.8 & Comedy, Romance & https://www.youtube.com/watch?v=o-q5iROzPNY \\
\hline Low-O & Overboard & 2018 & $\mathrm{tt} 1563742$ & 0.04 & 6 & Comedy, Romance & https://www.youtube.com/watch?v=OLAJ0ooorDU \\
\hline High-O & Lucky & 2017 & tt5859238 & 0.42 & 7.4 & Comedy, Drama & https://www.youtube.com/watch?v=2KLLkj84GAo \\
\hline Low-O & The Best Man Holiday & 2013 & $\mathrm{tt} 2083355$ & 0.16 & 6.7 & Comedy, Drama & https://www.youtube.com/watch?v=k6iNiJivOoQ \\
\hline High-O & Clouds of Sils Maria & 2014 & $\mathrm{tt} 2452254$ & 0.48 & 6.7 & Drama & https://www.youtube.com/watch?v=Zup27u6tMzY \\
\hline Low-O & Do You Believe? & 2015 & $\mathrm{tt} 4056738$ & 0.06 & 6.1 & Drama & https://www.youtube.com/watch?v=og|X2Q7tEdc \\
\hline High-O & Disobedience & 2017 & tt6108178 & 0.55 & 6.6 & Drama, Romance & https://www.youtube.com/watch?v=NpKiUPrNI3Y \\
\hline Low-O & Love Is Strange & 2014 & $\mathrm{tt} 2639344$ & 0.08 & 6.7 & Drama, Romance & https://www.youtube.com/watch?v=NpKiUPrNI3Y \\
\hline
\end{tabular}

TABLE 3

STUDY 3: REGRESSION RESULTS

\begin{tabular}{|c|c|c|c|c|c|c|}
\hline & \multicolumn{6}{|c|}{ Dependent variable: } \\
\hline & \multirow{2}{*}{\multicolumn{2}{|c|}{$\begin{array}{c}\text { Choice } \\
\text { Logistic regression }\end{array}$}} & \multirow{2}{*}{\multicolumn{2}{|c|}{$\begin{array}{l}\text { High-O rating } \\
\text { OLS regression }\end{array}$}} & \multirow{2}{*}{\multicolumn{2}{|c|}{$\begin{array}{l}\text { Low-O rating } \\
\text { OLS regression }\end{array}$}} \\
\hline & & & & & & \\
\hline & (A) & (B) & (C) & (D) & (E) & (F) \\
\hline \multirow[t]{2}{*}{ Openness } & $0.170^{* * *}$ & $0.139^{* *}$ & $0.140^{* * *}$ & $0.107^{* * *}$ & -0.041 & $-0.092^{* *}$ \\
\hline & $(0.065)$ & $(0.068)$ & $(0.037)$ & $(0.039)$ & $(0.040)$ & $(0.041)$ \\
\hline Big Five controls & No & Yes & No & Yes & No & Yes \\
\hline Observations & 1,018 & 1,018 & 1,018 & 1,018 & 1,018 & 1,018 \\
\hline Log Likelihood & -695.538 & -687.627 & $-1,600.047$ & $-1,593.944$ & $-1,670.454$ & $-1,653.062$ \\
\hline Akaike Inf. Crit. & $1,407.076$ & $1,399.253$ & $3,216.094$ & $3,211.887$ & $3,356.907$ & $3,330.124$ \\
\hline
\end{tabular}

NOTE.-Regressions with measures of movie preferences as outcomes, and Openness level (z-scored) and controls as exploratory variable. All models control for gender, age and pair fixed effects. Standard Errors in Parenthesis. 


\section{FIGURE 7}

\section{STUDY 3: RESULTS}

A

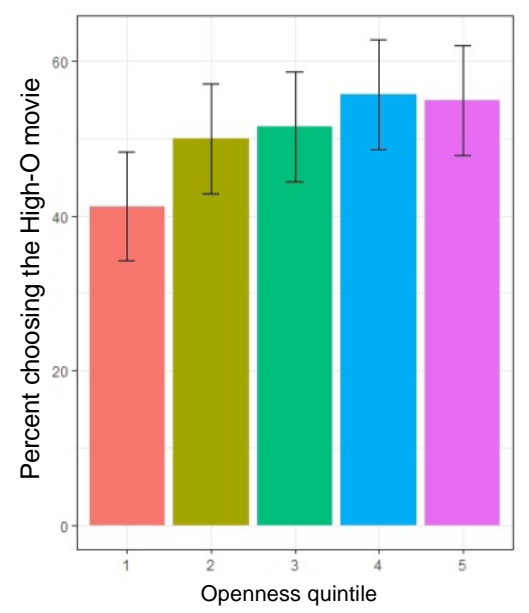

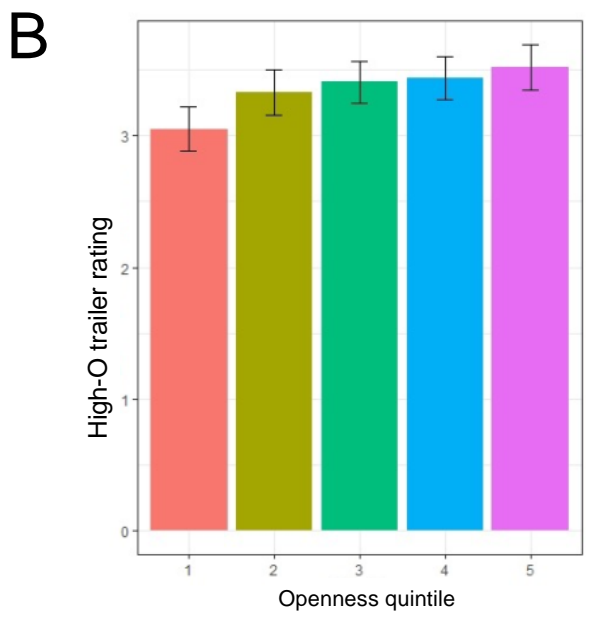

NOTE.- (A) Proportion of participants choosing the high Openness movie for each Openness quintile in the sample ( 1 is the lowest and 5 is the highest quintile). (B) Average trailer ratings (five-star scale) of the high Openness movies for each Openness quintile in the sample.

\section{GENERAL DISCUSSION}

Personalized streaming services have altered the media landscape. These services provide consumers the ability to choose between thousands of movies and allow marketers to reach distinct audiences based on the content that they choose to watch. In this new world, understanding how content features relate to the psychological tendencies of their audience is increasingly important. To date, all knowledge on the topic has relied on findings from small-scale laboratory studies that correlated personality traits with self-reported preference measures for a few broad genre categories. We push the boundaries of knowledge by obtaining fine-grained representations of movie features 
and plots, and use advanced analytical techniques to link these features to the psychological profiles of social media users who expressed their movie preferences behaviorally, in a large diverse sample.

We identify novel associations between general features of movies, such as quality ratings and box office revenue, and the aggregate Big Five profiles of their fans. For example, movies whose fans have higher Openness levels tend to have better quality ratings and generate less revenue. These findings highlight the importance of appropriately controlling for such factors when studying how features of the content itself relate to its audience characteristics. We also identify links between the Big Five and liking specific genres, which tentatively suggest that people like content that aligns with their own behavioral dispositions. For example, liking Crime movies is associated positively with Extraversion and negatively with Agreeableness, mirroring the traits' links to actual criminal behavior, whereas liking Sports movies is associated with all of the Big Five traits, in a manner that resembles their relationship with engagement in Sports in real life.

Representing movies via their plots allows us to obtain more nuanced information, resulting in notable gains when predicting the personalities of their fans relative to genre and all other variables studied. By investigating the themes and concepts that organically emerge as the most predictive of the different Big Five dimensions, we shed light on the underlying psychological mechanisms and provide further evidence that movie plots are compatible with the characteristic ways in which their fans think, feel, and behave in real life-in line with Self-congruence theory (Aaker 1999; Fournier 1998) For example, movies with plots associated with Anxiety appeal to audiences high in Neuroticism, movies with themes about Anger draw fans that are low in Agreeableness, and movies with Social themes have fans that are more extraverted.

Our findings contribute to a growing literature using automated text-based analytical methods to advance marketing theory and practice (Chung et al. 2021.; Humphreys and Wang 2017;

Luangrath, Peck and Barger 2017; Netzer et al. 2012, 2019; Packard and Berger 2017, 2020; 
Tirunillai and Tellis 2014). Specifically, we showcase how text analysis can improve predictive accuracy while also generating psychological insight into the underlying mechanisms (Berger et al. 2020). Previous text-mining studies of multidimensional cultural products have focused either on predicting overall market-level outcomes (Berger and Milkman 2012; Eliashberg et al. 2014), or on making personalized content recommendations to users, based on historical panel data (Ansari, Essegaier and Kohli 2000; Ansari et al. 2018; Szomszor et al. 2007; Toubia et al. 2019). Our work substantiates this line of research by presenting a novel analytical approach that uses text analysis to characterize the psychological types that different contents attract. In future studies, this framework could be easily extended to study how other multidimensional cultural products that can be described via text, such as songs, books, and news articles-relate to the characteristics of consumer that they draw.

Managerial Applications

The Big Five capture information about consumers' attitudes, motivations, interests, and behavior, and can be inferred from digital footprints at the individual level. For these reasons, predicting the personalities of potential audiences of particular movies may be useful for various elements of marketing strategy. IMDb contains plot keywords for millions of movie titles, and one can readily generate new ones for any given content by listing events, places, and concepts that appear. Plot keywords may also be generated before a movie is produced, based on information from its script. Our work demonstrates that the psychological profiles associated with liking distinct movies are predictable from such keywords (Study 2), and that these predictions generalize across movies, participants, and preferences elicitation methods (Study 3). Our automated and scalable 
method of psychographic assessment can reduce the burden of conducting large-scale surveys, which can be expensive and time-consuming, and can be deployed at various stages of a movie's life cycle.

Before production, content creators may be able to rely on a movie's script to predict the personality profile of its future fans. Such knowledge can guide the identification of brands and products that may benefit from their placement in the movies (Karniouchina, Uslay and Erenburg 2011; Wiles and Danielova 2009). For example, producers of a movie whose protagonist drives a car may choose a car brand that appeals to the personality of its projected audience (e.g., high Openness is related to liking cutting-edge brands such as Tesla, whereas Conscientiousness is associated with liking established and reliable brands such as Volvo). Alternatively, insight regarding the themes that most strongly link to fan personality dimensions (Figure 6 and Table 1) can guide the creation of new content that appeals to the profiles of unique target audiences.

Post-production and pre-release, knowing the psychological makeup of the audience that a movie is expected to attract can guide segmentation, targeting, and positioning strategies for its release. For example, advertisers can rely on social media for reaching extraverted users, and use this communication channel to promote movies that are expected to attract extraverted consumers in a manner that appeals to them (Matz et al. 2017). As personality correlates with geo-location (Rentfrow 2010), such knowledge may also inform decisions on screening locations. For example, emotional stability is comparatively high in Atlanta, Dallas, Los Angeles, and Chicago, but low in New York, Boston, Philadelphia, and New Orleans (Ebert et al. 2021), so films that emphasize themes associated with Anxiety may be screened first in cities where the average level for emotional stability is low. Of note, most other variables that strongly predict fan personalities in our studies, such as quality ratings, revenue, and fan demographics (Figure 3), become available to marketers only after a movie has been released. 
The links between movies' themes and fan personalities (Figure 6 and Table 1) can also guide the creation of new marketing instruments, such as posters and trailers (Hixson 2006; Liu et al. 2018), that appeal to audiences with distinct profiles. For example, fans of Horror films tend to be neurotic and low in Agreeableness. Based on the themes that draw audiences with these traits, a promoter of the movie may generate two different trailers: one that highlights fearful situations in the movie, and another that showcases violent action. Once created, marketers can use social media advertising to tailor the fearful trailer to neurotic audiences, and the violent trailer to low Agreeableness audiences (akin to Matz et al. 2017).

Once a movie is released, cinemas and media streaming services may be able to use personality predictions for tailoring ads (including previews of other unreleased movies) to the psychological characteristics of its audience (Danker 2005). For example, a recent trend in the streaming market has been the rise of Ad-supported Video-on-Demand (AVOD) platforms, which make an enormous selection of movies freely available for streaming without subscription, and monetize via advertising. ${ }^{9}$ AVOD platforms provide users who are either unwilling to pay a premium or are reluctant to share personal information online access to diverse content, allowing marketers to reach large audiences based on the movies that they choose to watch. In such settings, where there is limited information about each individual viewer, personalization crucially depends on the capacity to draw links between the content itself and the characteristics of the viewership that it draws, as our models allow. ${ }^{10}$

\footnotetext{
9 AVOD has been growing faster than its subscription-based counterpart, attracting industry leaders' attention (Adgate 2020). For example, Fox entertainment recently acquired Tubi (https://tubitv.com), an AVOD service that reported 33 million monthly active users in August 2020, a 65\% year-over-year increase (Tubi corporation 2020).

${ }^{10}$ Subscription-based streaming services possess granular demographic and behavioral data, and can tailor content recommendations and advertisements to individual users regardless of what they currently watch. However, as users can stream without setting up an account, and amid growing privacy concerns and regulations (Brough and Martin 2020; Kim, Barasz and John 2019; Martin, Borah and Palmatier 2017; Martin and Murphy 2017; Teeny et al. 2020), there might be limited information about their profiles and past behavior.
} 
Limitation and Future Directions

Our study leaves several open questions for future research. First, while we link movie preferences to stable personality traits, preferences are certainly also influenced by situational context (Belk 1975). For example, the film industry is seasonal (Einav 2007) and people seem to prefer romantic movies when it is colder (Hong and Sun 2012). Continuous investigation of how situational context influences movie preferences may benefit from studying interactions between personality and situational variables. For example, cold weather may have stronger effects on Neurotic individuals, who have greater needs for psychological warmth in the winter.

Second, although Facebook Likes are active, naturalistic expressions of attitudes, they do not necessarily reflect what people de facto watch and could be affected by impression-management concerns. Other biases may arise because specific types of people may have a greater disposition to like movies on Facebook or become research participants online. In general, such selection bias would be expected to attenuate the associations we quantified, as it restricts the range of personality that we observe and constrains the variance that could potentially be explained by our models (Sackett and Yang 2000; Yarkoni 2010). We hope that the growing availability of video-streaming services will facilitate the generation of new datasets that measure the associations between personality and movie preferences with actual watching behavior and with less selection bias.

Third, our findings are silent about causal relations. Personality is partially heritable (Daviet, Nave and Wind 2020), and it is reasonable that one's personality influences their taste for movies. However, research within the "media effects"' paradigm (Adorno and Horkheimer 1997) suggests that media exposure can also generate lasting effects on one's internal world. For example, violent media consumption has been shown to increase aggressive thoughts (Anderson et al. 2003; Wood, 
Wong and Chachere 1991). Moreover, although our analyses include covariates that were not accounted for in earlier studies, we cannot control for all possible factors that might affect both personality and movie preferences, and generate non-causal correlations between them (e.g., geolocation, socioeconomic status, and culture).

Fourth, associations between personality and psychological themes of movie plots are expected to evolve over time, due to cultural change. High-Openness individuals, for example, appear to be interested in topics that are considered taboo. Yet, topics that were taboo in the past may become a part of mainstream culture. For example, consider the topic of sexual harassment before and after the emergence of the \#metoo movement. Likewise, the city of San Francisco was mostly associated with Hippy culture in the 1960s, but became synonymous with Tech in the early 2000s. As a result, movies that take place in San Francisco in the 1960s are expected to have fans that are less Conscientious, relative to movies that take place in the city in the 2000 s.

Fifth, although we have no reason to believe that our results depend on the characteristics of the participants, materials, or context, continuous exploration of their generalizability is worthwhile. In particular, while the set of movies used in the current study represents a wide array of genres, the lion's share of the movies was produced in Western countries. Relatedly, although our analysis is focused on movie content, our findings are potentially relevant for other content types, such as TV shows and radio podcasts. We hope that further work will study the generalizability of our findings to non-Western movies and other types of entertainment media.

Finally, when considering avenues for future research, we recognize that the complexity of movies is far greater than what is captured by plot keywords. We therefore see our results as a lower bound for the predictive accuracy that can be achieved when predicting fan personalities from movie content. Predictive accuracy is expected to rise with the incorporation of additional movie characteristics, such as information about the cast (Wallace, Seigerman and Holbrook 1993), text 
features derived from scripts (Eliashberg et al. 2014), auditory features retrieved from movie scores (Lindenbaum et al. 2010), and visual features obtained from video frames (Chen et al. 2011). We look forward to future work that combines data driven machine learning techniques with rich datasets of movie content to better understand and predict the personalities of target viewers.

\section{REFERENCES}

Aaker, J. L. (1999). The malleable self: The role of self-expression in persuasion. Journal of marketing research, 36(1), 45-57.

Adgate, Brad (2020), “TV Networks Look Toward Ad Supported Streaming To Grow Revenue," Forbes, September 17.

Adorno, Theodor W. and Max Horkheimer (1997), Dialectic of Enlightenment: Verso.

Anderson, Craig A., Leonard Berkowitz, Edward Donnerstein, L. Rowell Huesmann, James D. Johnson, Daniel Linz, Neil M. Malamuth, and Ellen Wartella (2003), "The Influence of Media Violence on Youth," Psychological Science in the Public Interest, 4 (3), 81-110.

Ansari, Asim, Skander Essegaier, and Rajeev Kohli (2000), “Internet Recommendation Systems,” Journal of Marketing Research, 37 (3), 363-75.

Ansari, Asim, Yang Li, and Jonathan Z. Zhang (2018), "Probabilistic Topic Model for Hybrid Recommender Systems: A Stochastic Variational Bayesian Approach” Marketing Science, 37 (6), 987-1008.

Awais, Muhammad, Tanzila Samin, Muhammad Awais Gulzar, Jinsoo Hwang, and Muhammad Zubair (2020), "Unfolding the Association between the Big Five, Frugality, E-Mavenism, and Sustainable Consumption Behavior," Sustainability, 12 (2), 490.

Barnes, Gordon E., Neil M. Malamuth, and V. P. James Check (1984), "Personality and Sexuality," Personality and Individual Differences, 5 (2), 159-72.

Basinger, Jeanine and Jeremy Arnold (2003), The World War II Combat Film: Anatomy of a Genre: Wesleyan University Press.

Beane, T. P. and D. M. Ennis (1987), "Market Segmentation: A Review," European Journal of Marketing, $21(5), 20-42$.

Belk, Russell W. (1975), "Situational Variables and Consumer Behavior," Journal of Consumer Research, 2 (3), 157-64. 
Berger, Jonah, Ashlee Humphreys, Stephan Ludwig, Wendy W. Moe, Oded Netzer, and David A. Schweidel (2020), "Uniting the Tribes: Using Text for Marketing Insight," Journal of Marketing, 84 (1), 1-25.

Berger, Jonah and Katherine L. Milkman (2012), "What Makes Online Content Viral?," Journal of Marketing Research, 49 (2), 192-205.

Bhatia, Sudeep and Neil Stewart (2018), "Naturalistic Multiattribute Choice," Cognition, 179 (October), 71-88.

Bornman, Elirea (2009), "Measuring Media Audiences," in Media Studies Volume 3: Media Content and Media Audiences, ed. P. J. Fourie, Lansdowne, Cape Town, South Africa: Juta, 515-540.

Bowden-Green, Thomas, Joanne Hinds, and Adam Joinson (2020), "How Is Extraversion Related to Social Media Use? A Literature Review," Personality and Individual Differences, 164 (October), 110040.

Brough, Aaron R. and Kelly D. Martin (2020), "Critical Roles of Knowledge and Motivation in Privacy Research," Current Opinion in Psychology, 31 (February), 11-15.

Brown, Sarah and Karl Taylor (2014), "Household Finances and the 'Big Five' Personality Traits," Journal of Economic Psychology, 45 (December), 197-212.

Buss, D. M. (1987), "Selection, Evocation, and Manipulation,” Journal of Personality and Social Psychology, 53 (6), 1214-21.

Camerer, Colin F., Gideon Nave, and Alec Smith (2019), "Dynamic Unstructured Bargaining with Private Information: Theory, Experiment, and Outcome Prediction via Machine Learning," Management Science, 65 (4), 1867-1890.

Chen, Liang-Hua, Hsi-Wen Hsu, Li-Yun Wang, and Chih-Wen Su (2011), "Violence Detection in Movies," in 2011 Eighth International Conference Computer Graphics, Imaging, and Visualization, Singapore: IEEE, 119-24.

Chung, Jaeyeon (Jae), Gita Venkataramani Johar, Yanyan Li, Oded Netzer and Matthew Pearson (2021), "Mining Consumer Minds: Downstream Consequences of Host Motivations for Home- Sharing Platforms," Journal of Consumer Research, ucab034.

Clasen, Mathias, Jens Kjeldgaard-Christiansen, and John A. Johnson (2020), "Horror, Personality, and Threat Simulation: A Survey on the Psychology of Scary Media," Evolutionary Behavioral Sciences, 14 (3), 213-30.

Costa, Paul T., Antonio Terracciano, and Robert R. McCrae (2001), “Gender Differences in Personality Traits Across Cultures: Robust and Surprising Findings," Journal of Personality and Social Psychology, 81 (2), 322-31.

Danker, Daniel (2005), “Targeted Advertising in Conjunction with On-Demand Media Content,” US Patent. 
Daviet, Remi, Gideon Nave, and Jerry Wind (2021), "Genetic Data: Potential Uses and Misuses in Marketing," Journal of Marketing, February.

Deerwester, Scott, Susan T. Dumais, George W. Furnas, Thomas K. Landauer, and Richard Harshman (1990), "Indexing by Latent Semantic Analysis," Journal of the Association for Information Science and Technology, 41 (6), 391-407.

DeYoung, Colin G., Jordan B. Peterson, and Daniel M. Higgins (2002), "Higher-Order Factors of the Big Five Predict Conformity: Are There Neuroses of Health?," Personality and Individual Differences, 33 (4), 533-52.

Dollinger, Stephen J. (2003), "Need for Uniqueness, Need for Cognition, and Creativity," Journal of Creative Behavior, 37 (2), 99-116.

Donavan, D. Todd, Brad D. Carlson, and Mickey Zimmerman (2005), “The Influence of Personality Traits on Sports Fan Identification," Sport Marketing Quarterly, 14 (1), 31-42.

Ebert, Tobias, Jochen E. Gebauer, Thomas Brenner, Wiebke Bleidorn, Samuel D. Gosling, Jeff Potter, and P. Jason Rentfrow (2021), "Are Regional Differences in Psychological Characteristics and Their Correlates Robust? Applying Spatial-Analysis Techniques to Examine Regional Variation in Personality," Perspectives on Psychological Science, October.

Ebert, Tobias, Friedrich M. Götz, Joe J. Gladstone, Sandrine R. Müller, and Sandra C. Matz (2021), "Spending Reflects Not Only Who We Are but Also Who We Are Around: The Joint Effects of Individual and Geographic Personality on Consumption," Journal of Personality and Social Psychology, 121 (2), 378-393.

Einav, Liran (2007), "Seasonality in the U.S. Motion Picture Industry," The Rand Journal of Economics, 38 (1), 127-45.

Eliashberg, Jehoshua, Anita Elberse, and Mark A. A. M. Leenders (2006), “The Motion Picture Industry: Critical Issues in Practice, Current Research, and New Research Directions," Marketing Science, 25 (6), 638-61.

Eliashberg, Jehoshua and Mohanbir S. Sawhney (1994), "Modeling Goes to Hollywood: Predicting Individual Differences in Movie Enjoyment," Management Science, 40 (9), 1151-73.

Eliashberg, Jehoshua, Sam K. Hui, and Z. John Zhang (2014), “Assessing Box Office Performance Using Movie Scripts: A Kernel-Based Approach," IEEE Transactions on Knowledge and Data Engineering, 26 (11), 2639-48.

Feist, Gregory J. (2012), "Predicting Interest in and Attitudes toward Science from Personality and Need for Cognition," Personality and Individual Differences, 52 (7), 771-75.

Feist, Gregory J. and Frank X. Barron (2003), "Predicting Creativity from Early to Late Adulthood: Intellect, Potential, and Personality," Journal of Research in Personality, 37 (2), 62-88. 
Ferwerda, Bruce, Marko Tkalcic, and Markus Schedl (2017), "Personality Traits and Music Genres: What Do People Prefer to Listen To?," in Proceedings of the 25th Conference on User Modeling, Adaptation, and Personalization, New York, NY: Association for Computing Machinery, 285-88.

Finn, Seth (1997), "Origins of Media Exposure: Linking Personality Traits to TV, Radio, Print, and Film Use," Communication Research, 24 (5), 507-29.

Florida, Richard and Charlotta Mellander (2014), "The Psychogeography of Creativity," in Geographical Psychology: Exploring the Interaction of Environment and Behavior, ed. Peter J. Rentfrow, Washington, DC: American Psychological Association, 261-74.

Fournier, S. (1998), "Consumers and their brands: developing relationship theory in consumer research", Journal of Consumer Research, Vol. 24 No. 4, pp. 343-73

Friedrich-Cofer, L., \& Huston, A. C. (1986). Television violence and aggression: the debate continues.

Fry, Joseph N. (1971), "Personality Variables and Cigarette Brand Choice," Journal of Marketing Research, 8 (3), 298-304.

Gerlach, Martin, Beatrice Farb, William Revelle, and Luís A. Nunes Amaral (2018), “A Robust DataDriven Approach Identifies Four Personality Types Across Four Large Data Sets," Nature Human Behaviour, 2 (10), 735-42.

Gladstone, Joe J., Sandra C. Matz, and Alain Lemaire (2019), "Can Psychological Traits Be Inferred From Spending? Evidence From Transaction Data,’ Psychological Science, 30 (7), 1087-96.

Golbeck, Jennifer and Eric Norris (2013), "Personality, Movie Preferences, and Recommendations," in Proceedings of the 2013 IEEE/ACM International Conference on Advances in Social Networks Analysis and Mining, New York, NY: Association for Computing Machinery, 1414-15.

Goldberg, Lewis R., John A. Johnson, Herbert W. Eber, Robert Hogan, Michael C. Ashton, C. Robert Cloninger, and Harrison G. Gough (2006), "The International Personality Item Pool and the Future of Public-Domain Personality Measures,” Journal of Research in Personality, 40 (1), 84-96.

Goldsmith, Ronald (2016), “The Big Five, Happiness, and Shopping,” Journal of Retailing and Consumer Services, 31 (July), 52-61.

Graziano, William G. and Nancy Eisenberg (1997), “Agreeableness: A Dimension of Personality,” in Handbook of Personality Psychology, eds. Robert Hogan, John Johnson, and Stephen Briggs: Academic Press, 795-824.

Hall, Alice (2005), “Audience Personality and the Selection of Media and Media Genres," Media Psychology, 7 (4), 377-98.

Hawkins, Douglas M. (2004), “The Problem of Overfitting," Journal of Chemical Information and Computer Sciences, 44 (1), 1-12. 
Hennig-Thurau, Thorsten and Mark B. Houston (2019), Entertainment Science: Data Analytics and Practical Theory for Movies, Games, Books, and Music: Springer, Cham.

Hirschman, Elizabeth C. (1985), "A Multidimensional Analysis of Content Preferences for Leisure-Time Media,” Journal of Leisure Research, 17 (1), 14-28.

Hirsh, Jacob B., Sonia K. Kang, and Galen V. Bodenhausen (2012), "Personalized Persuasion: Tailoring Persuasive Appeals to Recipients' Personality Traits," Psychological Science, 23 (6), 578-81.

Hixson, Thomas Kim (2006), "Mission Possible: Targeting Trailers to Movie Audiences," Journal of Targeting, Measurement, and Analysis for Marketing, 14 (3), 210-24.

Holbrook, Morris B. and Thomas J. Olney (1995), "Romanticism and Wanderlust: An Effect of Personality on Consumer Preferences," Psychology and Marketing, 12 (3), 207-22.

Hong, Jiewen and Yacheng Sun (2012), "Warm It Up with Love: The Effect of Physical Coldness on Liking of Romance Movies," Journal of Consumer Research, 39 (2), 293-306.

Horton, Raymond L. (1979), "Some Relationships between Personality and Consumer Decision Making," Journal of Marketing Research, 16 (2), 233-46.

Humphreys, Ashlee and Rebecca Jen-Hui Wang (2018), “Automated Text Analysis for Consumer Research,” Journal of Consumer Research, 44 (6), 1274-1306.

John, Leslie K., Oliver Emrich, Sunil Gupta, and Michael I. Norton (2017), "Does 'Liking' Lead to Loving? The Impact of Joining a Brand's Social Network on Marketing Outcomes," Journal of Marketing Research, 54 (1), 144-55.

John, Oliver P. and Sanjay Srivastava (1999), "The Big-Five Trait Taxonomy: History, Measurement, and Theoretical Perspectives" in Handbook of Personality: Theory and Research, eds. L. A. Pervin and O. P. John: Guilford Press, 102-138.

Jung, Kyung-Yong and Jung-Hyun Lee (2004), "User Preference Mining through Hybrid Collaborative Filtering and Content-Based Filtering in Recommendation System," IEICE Transactions on Information and Systems, 87 (12), 2781-90.

Jylhä, Pekka and Erkki Isometsä (2006), "The Relationship of Neuroticism and Extraversion to Symptoms of Anxiety and Depression in the General Population," Depression and Anxiety, 23 (5), 281-89.

Karniouchina, Ekaterina V., Can Uslay, and Grigori Erenburg (2011), "Do Marketing Media Have Life Cycles? The Case of Product Placement in Movies," Journal of Marketing, 75 (3), 27-48.

Kassarjian, Harold H. (1971), "Personality and Consumer Behavior: A Review," Journal of Marketing Research, 8 (4), 409-18.

Kern, Margaret L., Angela L. Duckworth, Sergio Urzúa, Rolf Loeber, Magda Stouthamer-Loeber, and Donald R. Lynam (2013), "Do As You're Told! Facets of Agreeableness and Early Adult Outcomes for Inner-City Boys," Journal of Research in Personality, 47 (6), 795-799. 
Kim, Tami, Kate Barasz, and Leslie K. John (2019), "Why Am I Seeing This Ad? The Effect of Ad Transparency on Ad Effectiveness," Journal of Consumer Research, 45 (5), 906-32.

Koponen, Arthur (1960), "Personality Characteristics of Purchasers," Journal of Advertising Research, 1, 6-12.

Kosinski, Michal, David Stillwell, and Thore Graepel (2013), "Private Traits and Attributes Are Predictable from Digital Records of Human Behavior," Proceedings of the National Academy of Sciences of the United States of America, 110 (15), 5802-5.

Kraaykamp, Gerbert and Koen van Eijck (2005), "Personality, Media Preferences, and Cultural Participation," Personality and Individual Differences, 38 (7), 1675-88.

Laakasuo, Michael, Anna Rotkirch, Venla Berg, and Markus Jokela (2017), “The Company You Keep: Personality and Friendship Characteristics," Social Psychological and Personality Science, 8 (1), 6673.

Landauer, Thomas K. and Susan T. Dumais (1997), “A Solution to Plato's Problem: The Latent Semantic Analysis Theory of Acquisition, Induction, and Representation of Knowledge," Psychological Review, 104 (2), 211-40.

Lastovicka, John L. and Erich A. Joachimsthaler (1988), "Improving the Detection of PersonalityBehavior Relationships in Consumer Research,” Journal of Consumer Research, 14 (4), 583-87.

Levitt, S. D., \& List, J. A. (2007). What do laboratory experiments measuring social preferences reveal about the real world?. Journal of Economic perspectives, 21(2), 153-174.

Lindenbaum, Ofir, Shai Maskit, Ophir Kutiel, and Gideon Nave (2010), "Musical Features Extraction for Audio-Based Search," in 2010 IEEE 26th Convention of Electrical and Electronics Engineers in Israel, Eilat, Israel: IEEE, 000087-000091.

Lin, Long-Yi (2010), "The Relationship of Consumer Personality Trait, Brand Personality, and Brand Loyalty: An Empirical Study of Toys and Video Games Buyers," Journal of Product \& Brand Management, 19 (1), 4-17.

Liu, Xuan, Savannah Wei Shi, Thales Teixeira, and Michel Wedel (2018), "Video Content Marketing: The Making of Clips," Journal of Marketing, 82 (4), 86-101.

Luangrath, Andrea Webb, Joann Peck, and Victor A. Barger (2017), "Textual Paralanguage and Its Implications for Marketing Communications," Journal of Consumer Psychology, 27 (1), 98-107.

MacInnis, Deborah J. and Valerie S. Folkes (2017), "Humanizing Brands: When Brands Seem to Be Like Me, Part of Me, and in a Relationship with Me," Journal of Consumer Psychology, 27 (3), 355-74.

Madrigal, Alexis C. (2014), "How Netflix Reverse Engineered Hollywood," The Atlantic, January 2. 
Marich, Robert (2013), Marketing to Moviegoers: A Handbook of Strategies and Tactics, Third Edition: Southern Illinois University Press.

Martin, Kelly D., Abhishek Borah, and Robert W. Palmatier (2017), "Data Privacy: Effects on Customer and Firm Performance,” Journal of Marketing, 81 (1), 36-58.

Martin, Kelly D. and Patrick E. Murphy (2017), "The Role of Data Privacy in Marketing," Journal of the Academy of Marketing Science, 45 (2), 135-55.

Matz, Sandra C., Joe J. Gladstone, and David Stillwell (2016), "Money Buys Happiness When Spending Fits Our Personality,” Psychological Science, 27 (5), 715-25.

Matz, Sandra and Jacob B. Hirsh (2020), "Marketing and Personality," in The Wiley Encyclopedia of Personality and Individual Differences, eds. Bernardo J. Carducci and Christopher S. Nave: Wiley Blackwell, 587-91.

Matz, S. C., M. Kosinski, G. Nave, and D. J. Stillwell (2017), "Psychological Targeting as an Effective Approach to Digital Mass Persuasion," Proceedings of the National Academy of Sciences of the United States of America, 114 (48), 12714-19.

McCrae, Robert R. (2009), “The Five-Factor Model of Personality Traits: Consensus and Controversy," in The Cambridge Handbook of Personality Psychology, eds. P. J. Corr and G. Matthews: Cambridge University Press, 148-61.

McGuire, William J. (1974), "Psychological Motives and Communication Gratification," The Uses of Mass Communications: Current Perspectives on Gratifications Research, 3, 167-96.

Melville, Prem, Raymond J. Mooney, and Ramadass Nagarajan (2002), "Content-Boosted Collaborative Filtering for Improved Recommendations,” Aaai/Iaai, 23, 187-92.

Mikolov, Tomas, Ilya Sutskever, Kai Chen, Greg Corrado, and Jeffrey Dean (2013), "Distributed Representations of Words and Phrases and their Compositionality," in Advances in Neural Information Processing Systems 26, eds. C. J. C. Burges, L. Bottou, M. Welling, Z. Ghahramani, and K. Q. Weinberger, Red Hook, NY: Curran Associates, Inc., 3111-19.

Mohammad, Saif M. and Peter D. Turney (2013), "Nrc Emotion Lexicon," National Research Council, Canada, 2 (November).

Möller, K. E. Kristian and Pirjo Karppinen (1983), "Role of Motives and Attributes in Consumer Motion Picture Choice," Journal of Economic Psychology, 4 (3), 239-62.

Mooradian, Todd A. and James M. Olver (1994), "Neuroticism, Affect and Postpurchase Processes," in Advances in Consumer Research Volume 21, eds. Chris T. Allen and Deborah Roedder John, Provo, UT: Association for Consumer Research, 595-600.

Mooradian, Todd A. and K. Scott Swan (2006), "Personality-and-Culture: The Case of National Extraversion and Word-of-Mouth," Journal of Business Research, 59 (6), 778-85. 
Mulyanegara, Riza Casidy, Yelena Tsarenko, and Alastair Anderson (2009), “The Big Five and Brand Personality: Investigating the Impact of Consumer Personality on Preferences towards Particular Brand Personality," Journal of Brand Management, 16 (4), 234-47.

Myszkowski, Nils, Martin Storme, Franck Zenasni, and Todd Lubart (2014), "Is Visual Aesthetic Sensitivity Independent from Intelligence, Personality, and Creativity?," Personality and Individual Differences, 59 (March), 16-20.

Nave, Gideon, Juri Minxha, David M. Greenberg, Michal Kosinski, David Stillwell, and Jason Rentfrow (2018), "Musical Preferences Predict Personality: Evidence From Active Listening and Facebook Likes," Psychological Science, 29 (7), 1145-58.

Netzer, Oded, Ronen Feldman, Jacob Goldenberg, and Moshe Fresko (2012), "Mine Your Own Business: Market-Structure Surveillance Through Text Mining," Marketing Science, 31 (3), 521-43.

Netzer, Oded, Alain Lemaire, and Michal Herzenstein (2019), "When Words Sweat: Identifying Signals for Loan Default in the Text of Loan Applications," Journal of Marketing Research, 56 (6), 960-80.

Nielsen, Finn Årup (2011), “A New ANEW: Evaluation of a Word List for Sentiment Analysis in Microblogs," preprint, arXiv.

O’Riordan, Cáit and Michael O’Connell (2014), "Predicting Adult Involvement in Crime: Personality Measures Are Significant, Socio-Economic Measures Are Not," Personality and Individual Differences, 68 (October), 98-101.

Orne, M. T. (1962). On the social psychology of the psychological experiment: With particular reference to demand characteristics and their implications. American psychologist, 17(11), 776.

Ozer, Daniel J. and Verónica Benet-Martínez (2006), "Personality and the Prediction of Consequential Outcomes," Annual Review of Psychology, 57 (January), 401-21.

Packard, Grant and Jonah Berger (2017), "How Language Shapes Word of Mouth's Impact," Journal of Marketing Research, 54 (4), 572-88.

Grant, Packard and Jonah Berger (2021), "How Concrete Language Shapes Customer Satisfaction," Journal of Consumer Research, 47 (5), 787-806.

Palomba, Anthony (2020), "Consumer Personality and Lifestyles at the Box Office and beyond: How Demographics, Lifestyles and Personalities Predict Movie Consumption," Journal of Retailing and Consumer Services, 55 (July), 102083.

Park, Gregory, H. Andrew Schwartz, Johannes C. Eichstaedt, Margaret L. Kern, Michal Kosinski, David J. Stillwell, Lyle H. Ungar, and Martin E. P. Seligman (2015), “Automatic Personality Assessment through Social Media Language," Journal of Personality and Social Psychology, 108 (6), 934-52.

Pennebaker, James W., Martha E. Francis, and Roger J. Booth (2001), "Linguistic Inquiry and Word Count: LIWC 2001,” Mahway: Lawrence Erlbaum Associates, 71 (2001), 2001. 
Pennebaker, James W. and Laura A. King (1999), "Linguistic Styles: Language Use as an Individual Difference," Journal of Personality and Social Psychology, 77 (6), 1296-1312.

Quercia, Daniele, Michal Kosinski, David Stillwell, and Jon Crowcroft (2011), "Our Twitter Profiles, Our Selves: Predicting Personality with Twitter,” in 2011 IEEE Third International Conference on Privacy, Security, Risk and Trust and 2011 IEEE Third International Conference on Social Computing, Boston, MA: IEEE, 180-85.

Rentfrow, Peter J. (2010), "Statewide Differences in Personality: Toward a Psychological Geography of the United States," American Psychologist, 65 (6), 548-58.

Rentfrow, Peter J., Lewis R. Goldberg, and Ran Zilca (2011), "Listening, Watching, and Reading: The Structure and Correlates of Entertainment Preferences," Journal of Personality, 79 (2), 223-58.

Roberts, Brent W., Dustin Wood, and Jennifer L. Smith (2005), "Evaluating Five Factor Theory and Social Investment Perspectives on Personality Trait Development," Journal of Research in Personality, 39 (1), 166-84.

Roccas, Sonia, Lilach Sagiv, Shalom H. Schwartz, and Ariel Knafo (2002), "The Big Five Personality Factors and Personal Values,” Personality and Social Psychology Bulletin, 28 (6), 789-801.

Rocklage, Matthew D. and Russell H. Fazio (2015), "The Evaluative Lexicon: Adjective Use as a Means of Assessing and Distinguishing Attitude Valence, Extremity, and Emotionality," Journal of Experimental Social Psychology, 56 (January), 214-27.

Rogers, Marcus K., Kathryn Seigfried, and Kirti Tidke (2006), "Self-Reported Computer Criminal Behavior: A Psychological Analysis,” Digital Investigation, 3 (September), 116-20.

Rust, Roland T. and Mark I. Alpert (1984), “An Audience Flow Model of Television Viewing Choice,” Marketing Science, 3 (2), 113-24.

Sackett, Paul R. and Hyuckseung Yang (2000), “Correction for Range Restriction: An Expanded Typology," Journal of Applied Psychology, 85 (1), 112-18.

Sandy, Carson J., Samuel D. Gosling, and John Durant (2013), "Predicting Consumer Behavior and Media Preferences: The Comparative Validity of Personality Traits and Demographic Variables," Psychology \& Marketing, 30 (11), 937-49.

Schenk, Josef and Horst Pfrang (1986), "Extraversion, Neuroticism, and Sexual Behavior: Interrelationships in a Sample of Young Men," Archives of Sexual Behavior, 15 (6), 449-55.

Scrivner, Coltan and Kara A. Christensen (2021), "Scaring Away Anxiety: Therapeutic Avenues for Horror Fiction to Enhance Treatment for Anxiety Symptoms," preprint, PsyArXiv.

Segalin, Crisitina, Alessandro Perina, Marco Cristani, and Alessandro Vinciarelli (2017), "The Pictures We Like Are Our Image: Continuous Mapping of Favorite Pictures into Self-Assessed and Attributed Personality Traits," IEEE Transactions on Affective Computing, 8 (2), 268-85. 
Shachar, Ron and John W. Emerson (2000), "Cast Demographics, Unobserved Segments, and Heterogeneous Switching Costs in a Television Viewing Choice Model," Journal of Marketing Research, 37 (2), 173-86.

Shahjehan, Asad, Jaweria Andleeb Qureshi, Faheem Zeb, and Kaleem Saifullah (2012), "The Effect of Personality on Impulsive and Compulsive Buying Behaviors," African Journal of Business Management, 6 (6), 2187-94.

Soto, Christopher J. (2019), "How Replicable Are Links Between Personality Traits and Consequential Life Outcomes? The Life Outcomes of Personality Replication Project," Psychological Science, 30 (5), 711-27.

Soto, Christopher J. and Oliver P. John (2017), “The Next Big Five Inventory (BFI-2): Developing and Assessing a Hierarchical Model with 15 Facets to Enhance Bandwidth, Fidelity, and Predictive Power," Journal of Personality and Social Psychology, 113 (1), 117-43.

Soto, Christopher J., Oliver P. John, Samuel D. Gosling, and Jeff Potter (2011), "Age Differences in Personality Traits from 10 to 65: Big Five Domains and Facets in a Large Cross-Sectional Sample," Journal of Personality and Social Psychology, 100 (2), 330-48.

Steegen, Sara, Francis Tuerlinckx, Andrew Gelman, and Wolf Vanpaemel (2016), "Increasing Transparency Through a Multiverse Analysis," Perspectives on Psychological Science, 11 (5), $702-$ 12.

Steenkamp, Jan-Benedict E. M. and Alberto Maydeu-Olivares (2015), "Stability and Change in Consumer Traits: Evidence from a 12-Year Longitudinal Study, 2002-2013," Journal of Marketing Research, 52 (3), 287-308.

Stillwell, David J. and Michal Kosinski (2004), "myPersonality Project: Example of Successful Utilization of Online Social Networks for Large-Scale Social Research,” American Psychologist, 59 (2), 93-104.

Stone, M. (1978), “Cross-Validation: A Review," Statistics: A Journal of Theoretical and Applied Statistics, 9 (1), 127-39.

Szomszor, Martin, Ciro Cattuto, Harith Alani, Kieron O'Hara, Andrea Baldassarri, Vittorio Loreto, and Vito D. P. Servedio (2007), "Folksonomies, the Semantic Web, and Movie Recommendation," in 4th European Semantic Web Conference, Bridging the Gap between Semantic Web and Web 2.0, Innsbruck, Austria.

Swann, W. B. (1987), "Identity Negotiation: Where Two Roads Meet," Journal of Personality and Social Psychology, 53 (6), 1038-51.

Teeny, Jacob D., Joseph J. Siev, Pablo Briñol, and Richard E. Petty (2021), “A Review and Conceptual Framework for Understanding Personalized Matching Effects in Persuasion," Journal of Consumer Psychology, 31 (2), 382-414.

Tibshirani, Robert (1996), "Regression Shrinkage and Selection Via the Lasso," Journal of the Royal Statistical Society. Series B (Methodological), 58 (1), 267-88. 
Tirunillai, Seshadri and Gerard J. Tellis (2014), "Mining Marketing Meaning from Online Chatter: Strategic Brand Analysis of Big Data Using Latent Dirichlet Allocation," Journal of Marketing Research, 51 (4), 463-79.

Toubia, Olivier, Garud Iyengar, Renée Bunnell, and Alain Lemaire (2019), "Extracting Features of Entertainment Products: A Guided Latent Dirichlet Allocation Approach Informed by the Psychology of Media Consumption," Journal of Marketing Research, 56 (1), 18-36.

Tov, William, Ze Ling Nai, and Huey Woon Lee (2016), "Extraversion and Agreeableness: Divergent Routes to Daily Satisfaction With Social Relationships," Journal of Personality, 84 (1), 121-34.

Tubi corporation (2020), "Tubi Announces Record Monthly Active Users and Total View Time in 2020," September 16.

Van de Vliert, Evert and Martin C. Euwema (1994), “Agreeableness and Activeness as Components of Conflict Behaviors," Journal of Personality and Social Psychology, 66 (4), 674-87.

Wallace, W. Timothy, Alan Seigerman, and Morris B. Holbrook (1993), "The Role of Actors and Actresses in the Success of Films: How Much Is a Movie Star Worth?," Journal of Cultural Economics, 17 (1), 1-27.

Weaver, James B. (1991), "Exploring the Links between Personality and Media Preferences," Personality and Individual Differences, 12 (12), 1293-99.

Weaver, James B. (2003), "Individual Differences in Television Viewing Motives,” Personality and Individual Differences, 35 (6), 1427-37.

Weaver, James B., Hans-Bernd Brosius, and Norbert Mundorf (1993), "Personality and Movie Preferences: A Comparison of American and German Audiences," Personality and Individual Differences, 14 (2), 307-15.

Weinstein, Art T. (1994), Market Segmentation: Using Demographics, Psychographics, and Other Niche Marketing Techniques to Predict Customer Behavior, Chicago, IL: Probus Publishing Company.

Weisberg, Yanna J., Colin G. DeYoung, and Jacob B. Hirsh (2011), "Gender Differences in Personality across the Ten Aspects of the Big Five," Frontiers in Psychology, 2 (August), 178.

Wells, William D. (1975), "Psychographics: A Critical Review," Journal of Marketing Research, 12 (2), 196-213.

Wheeler, S. Christian, Richard E. Petty, and George Y. Bizer (2005), "Self-Schema Matching and Attitude Change: Situational and Dispositional Determinants of Message Elaboration," Journal of Consumer Research, 31 (4), 787-97.

Wiles, Michael A. and Anna Danielova (2009), "The Worth of Product Placement in Successful Films: An Event Study Analysis," Journal of Marketing, 73 (4), 44-63. 
Wilson, Kathryn E. and Rodney K. Dishman (2015), "Personality and Physical Activity: A Systematic Review and Meta-Analysis," Personality and Individual Differences, 72 (January), 230-42.

Wood, Wendy, Frank Y. Wong, and J. Gregory Chachere (1991), "Effects of Media Violence on Viewers' Aggression in Unconstrained Social Interaction," Psychological Bulletin, 109 (3), 371-83.

Yarkoni, Tal (2010), "Personality in 100,000 Words: A Large-Scale Analysis of Personality and Word Use among Bloggers," Journal of Research in Personality, 44 (3), 363-73.

Yarkoni, Tal (2019), “The Generalizability Crisis,” Behavioral and Brain Sciences, 1-37.

Yarkoni, Tal, Yoni K. Ashar, and Tor D. Wager (2015), "Interactions between Donor Agreeableness and Recipient Characteristics in Predicting Charitable Donation and Positive Social Evaluation," PeerJ, 3, e1089.

Yarkoni, Tal and Jacob Westfall (2017), "Choosing Prediction Over Explanation in Psychology: Lessons From Machine Learning,” Perspectives on Psychological Science, 12 (6), 1100-1122.

Ying, Yuanping, Fred Feinberg, and Michel Wedel (2006), "Leveraging Missing Ratings to Improve Online Recommendation Systems," Journal of Marketing Research, 43 (3), 355-65.

Youyou, Wu, Michal Kosinski, and David Stillwell (2015), "Computer-Based Personality Judgments Are More Accurate Than Those Made by Humans," Proceedings of the National Academy of Sciences of the United States of America, 112 (4), 1036-40.

Zhang, Ping (1993), "Model Selection Via Multifold Cross Validation," The Annals of Statistics, 21 (1), 299-313. 


\title{
We Are What We Watch: Movie Plots Predict the Personalities of Their Fans
}

\author{
Web Appendix
}

\author{
SUPPLEMENTAL FIGURE 1
}

CORRELATIONS BETWEEN MAIN STUDY VARIABLES

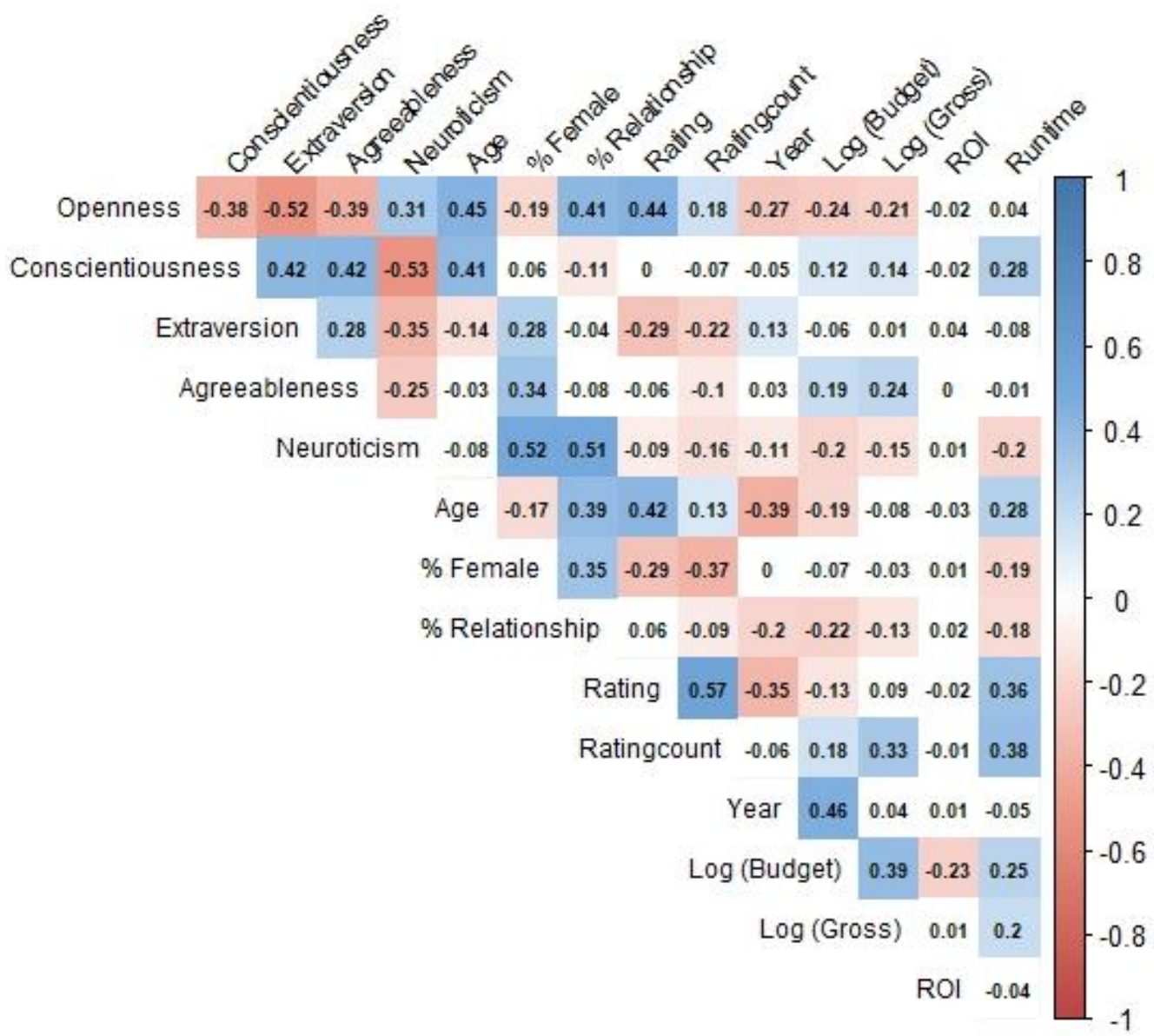




\section{SUPPLEMENTAL FIGURE 2}

DISTRIBUTIONS OF THE AVERAGE FAN PERSONALITY PROFILES
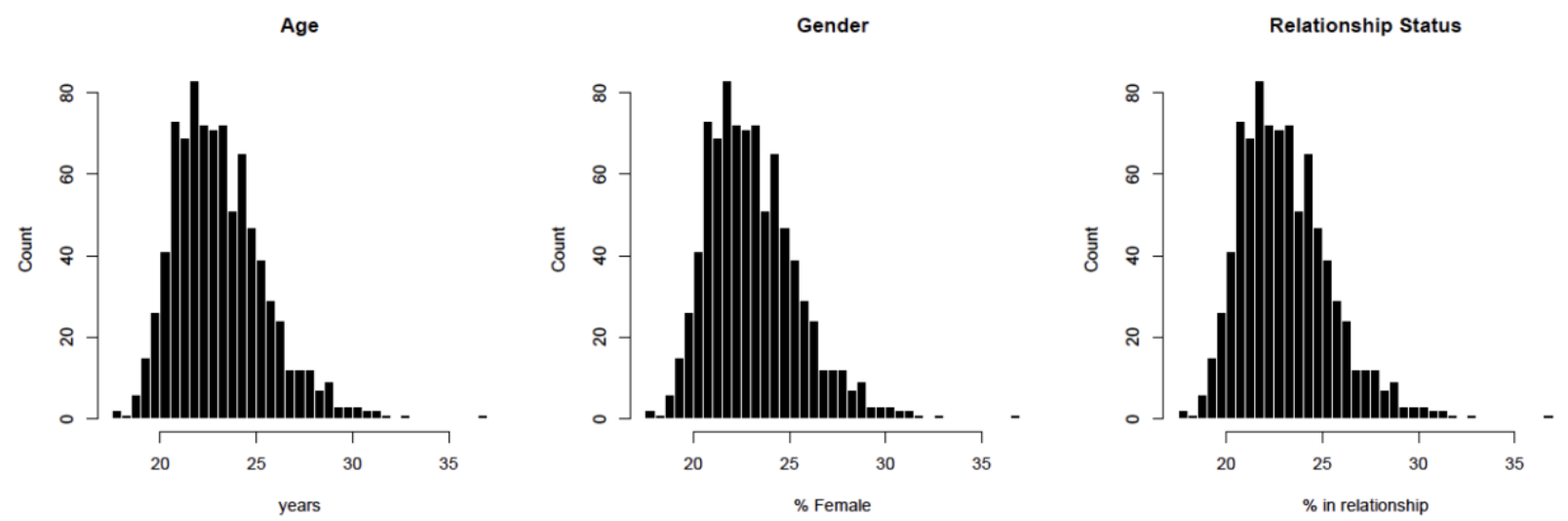


\section{SUPPLEMENTAL FIGURE 3}

\section{DISTRIBUTIONS OF METADATA VARIABLES}
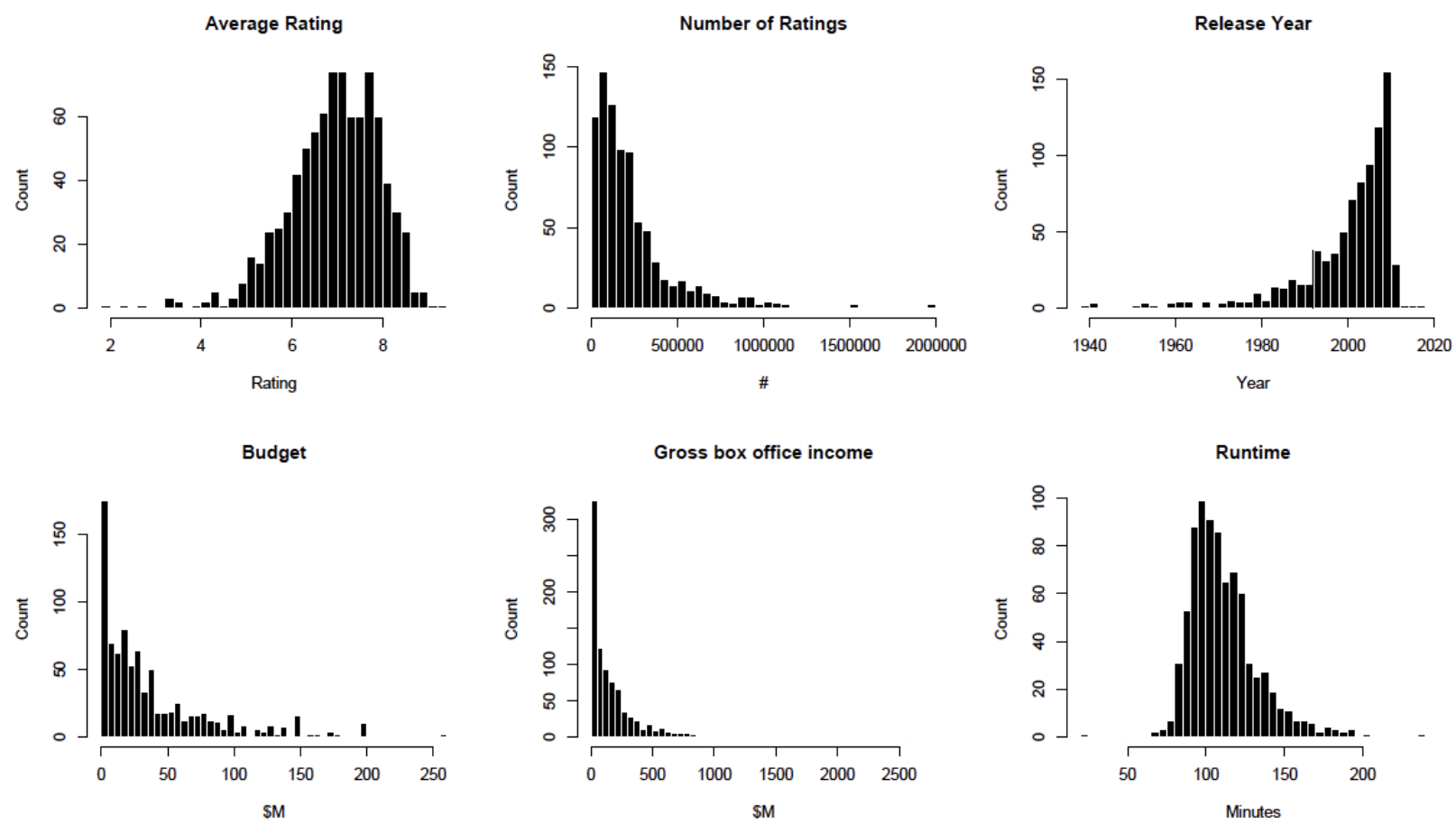


\section{SUPPLEMENTAL FIGURE 4}

\section{OUT OF SAMPLE AGGREGATE FAN PERSONALITIES VARIANCE EXPLAINE}

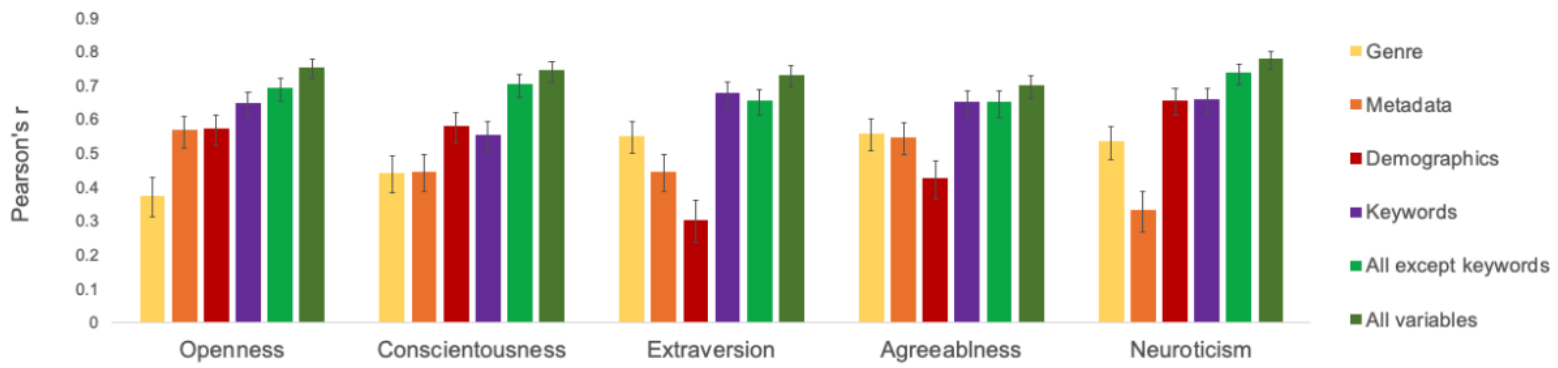

NOTE.-Predictive accuracy (Spearman correlation between actual and predicted values) of the five dimensions of the average fan personality profiles. Each color denotes a model trained using a different subset of the study's variables. This analysis is identical to the main analysis, except that the reduced keyword vectors were composed by projecting the keyword vectors of all titles in the Movie Likes dataset onto the 100 latent dimensions calculated by performing SVD on the keyword matrix of the 10,000 most voted feature film titles on IMDb as for 2018 with the exception of the movies that are included in the Movie Likes dataset. This analysis demonstrates that our results hold when there is no overlap between the dataset used to compute the SVD dimensions and the data used to train and test the models. 


\section{SUPPLEMENTAL FIGURE 5}

DISTRIBUTIONS OF THE BIG FIVE TRAITS ACROSS STUDY 3 PARTICIPANTS
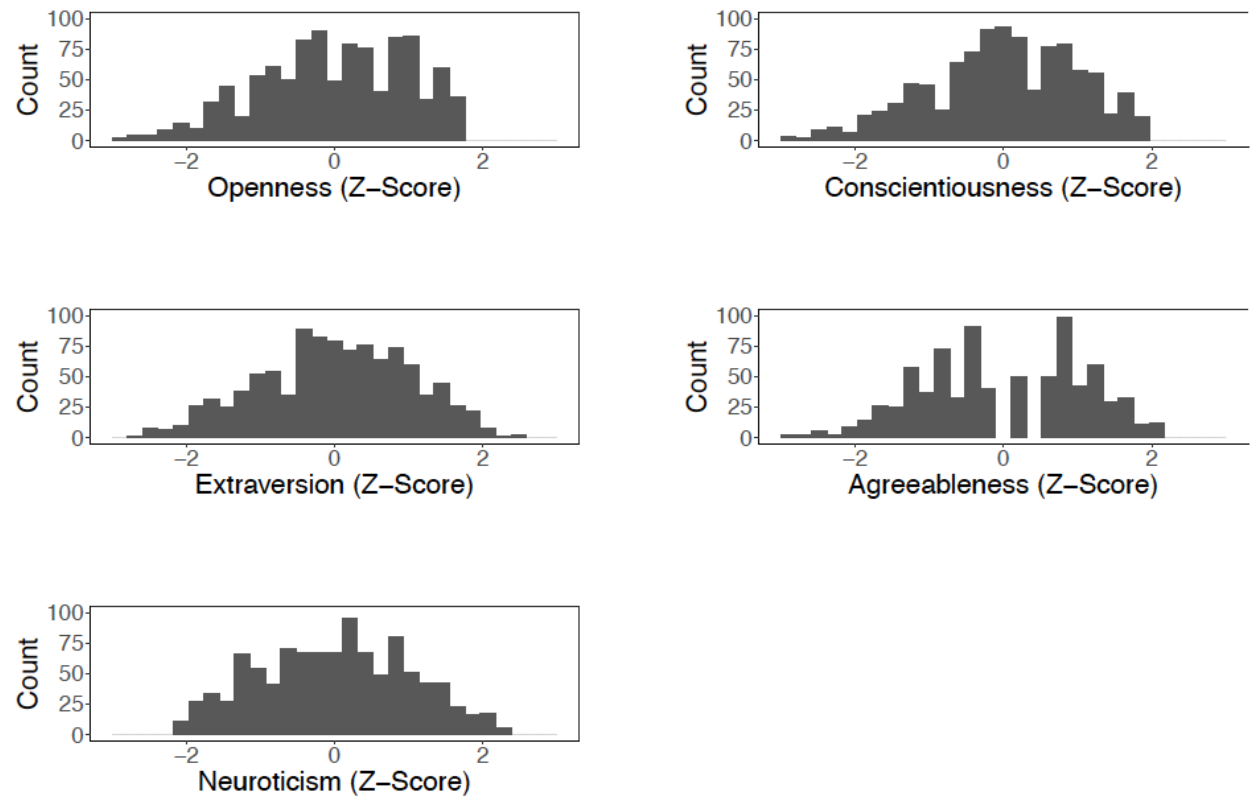

SUPPLEMENTAL FIGURE 6

DISTRIBUTIOTNS OF BEHAVIORAL OUTCOMES ACROSS STUDY 3 PARTICIPANTS
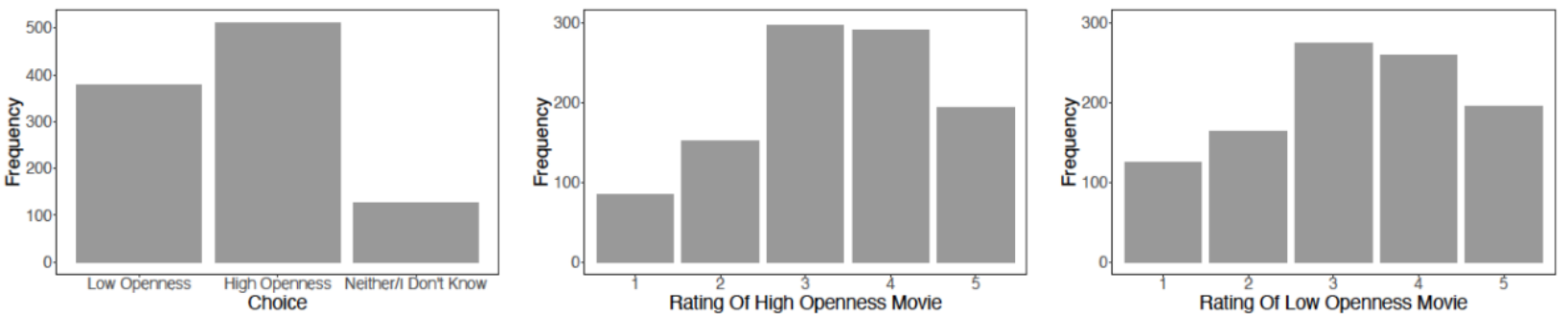
SUPPLEMENTAL TABLE 1

\section{THE MOVIES WITH THE TOP/BUTTOM 10 AVERAGE FAN PERSONALITY PROFILES FOR EACH PERSONALITY DIMENSION}

\begin{tabular}{|c|c|c|c|}
\hline Title & Year & Genre & $\mathbf{Z}$ \\
\hline \multicolumn{4}{|l|}{ Openness - high } \\
\hline $\begin{array}{l}\text { Waking Life } \\
\mathrm{Pi} \\
\text { A Scanner Darkly } \\
\text { The Science of Sleep } \\
\text { The Fountain } \\
\text { Mulholland Drive } \\
\text { The Darjeeling Limited } \\
\text { Being John Malkovich } \\
\text { The Buddha } \\
\text { The Life Aquatic with Steve Zissou }\end{array}$ & \begin{tabular}{l|}
2001 \\
1998 \\
2006 \\
2006 \\
2006 \\
2001 \\
2007 \\
1999 \\
2010 \\
2004
\end{tabular} & $\begin{array}{l}\text { Animation | Drama | Fantasy } \\
\text { Drama } \mid \text { Horror } \mid \text { Mystery | Sci-Fi | Thriller } \\
\text { Animation | Crime | Drama | Mystery | Sci-Fi | Thriller } \\
\text { Comedy | Drama | Fantasy | Romance } \\
\text { Drama | Sci-Fi } \\
\text { Drama } \mid \text { Mystery | Thriller } \\
\text { Adventure } \mid \text { Comedy | Drama } \\
\text { Comedy | Drama | Fantasy } \\
\text { Documentary } \\
\text { Adventure |Comedy | Drama }\end{array}$ & $\begin{array}{l}.96 \\
.91 \\
.88 \\
.87 \\
.87 \\
.86 \\
.84 \\
.81 \\
.80 \\
.79\end{array}$ \\
\hline \multicolumn{4}{|l|}{ Openness - low } \\
\hline $\begin{array}{l}\text { Anjaana Anjaani } \\
\text { Shrek Forever After } \\
\text { Get Rich or Die Tryin' } \\
\text { 8 Seconds } \\
\text { Step Up 3D } \\
\text { Hannah Montana: The Movie } \\
\text { Boy } \\
\text { Another Cinderella Story } \\
\text { Kuch Kuch Hota Hai } \\
\text { Facing the Giants } \\
\end{array}$ & \begin{tabular}{l|}
2010 \\
2010 \\
2005 \\
1994 \\
2010 \\
2009 \\
2010 \\
2008 \\
1998 \\
2006 \\
\end{tabular} & $\begin{array}{l}\text { Comedy | Drama } \mid \text { Musical | Romance } \\
\text { Animation | Adventure | Comedy | Family | Fantasy | Romance } \\
\text { Biography | Crime | Drama | Music } \\
\text { Biography | Drama | Sport | Western } \\
\text { Drama | Music | Romance } \\
\text { Comedy | Drama | Family | Music | Romance } \\
\text { Comedy | Drama } \\
\text { Comedy | Family | Music | Romance } \\
\text { Comedy | Drama | Musical | Romance } \\
\text { Drama | Sport }\end{array}$ & $\begin{array}{l}-.30 \\
-.29 \\
-.23 \\
-.21 \\
-.19 \\
-.18 \\
-.16 \\
-.16 \\
-.15 \\
-.15 \\
\end{array}$ \\
\hline \multicolumn{4}{|l|}{ Conscientiousness - high } \\
\hline $\begin{array}{l}\text { Ladder } 49 \\
\text { Love Jones } \\
\text { Steel Magnolias } \\
\text { Brown Sugar } \\
\text { National Lampoon's Christmas Vacation } \\
\text { The Guardian } \\
\text { The Wedding Planner } \\
\text { Patch Adams } \\
\text { To Kill a Mockingbird } \\
\text { The Best Man } \\
\end{array}$ & \begin{tabular}{l|}
2004 \\
1997 \\
1989 \\
2002 \\
1989 \\
2006 \\
2001 \\
1998 \\
1962 \\
1999 \\
\end{tabular} & $\begin{array}{l}\text { Action } \mid \text { Drama } \mid \text { Thriller } \\
\text { Drama } \mid \text { Romance } \\
\text { Comedy | Drama } \mid \text { Romance } \\
\text { Romance | Comedy | Drama | Music } \\
\text { Comedy } \\
\text { Action } \mid \text { Adventure | Drama } \\
\text { Comedy | Romance } \\
\text { Biography | Comedy | Drama | Romance } \\
\text { Crime | Drama } \\
\text { Comedy | Drama } \\
\end{array}$ & $\begin{array}{l}.33 \\
.33 \\
.22 \\
.19 \\
.18 \\
.18 \\
.18 \\
.18 \\
.15 \\
.15 \\
\end{array}$ \\
\hline \multicolumn{4}{|l|}{ Conscientiousness - low } \\
\hline $\begin{array}{l}\text { Yellow Submarine } \\
\text { Party Monster } \\
\text { The Human Centipede (First Sequence) } \\
\text { My Neighbor Totoro } \\
\text { This Is England } \\
\text { Hard Candy } \\
\text { Battle Royale } \\
\text { Wristcutters: A Love Story } \\
\text { Monster High } \\
\text { Spirited Away }\end{array}$ & $\begin{array}{l}1968 \\
2003 \\
2009 \\
1988 \\
2006 \\
2005 \\
2000 \\
2006 \\
1989 \\
2001 \\
\end{array}$ & $\begin{array}{l}\text { Animation } \mid \text { Adventure } \mid \text { Comedy } \mid \text { Family } \mid \text { Fantasy } \mid \text { Musical } \\
\text { Biography | Crime } \mid \text { Drama } \mid \text { Thriller } \\
\text { Horror } \\
\text { Animation } \mid \text { Family } \mid \text { Fantasy } \\
\text { Crime | Drama } \\
\text { Crime | Drama } \mid \text { Thriller } \\
\text { Adventure } \mid \text { Drama } \mid \text { Sci-Fi } \mid \text { Thriller } \\
\text { Comedy | Drama } \mid \text { Fantasy | Romance } \\
\text { Comedy | Horror } \mid \text { Sci-Fi } \\
\text { Animation } \mid \text { Adventure } \mid \text { Family } \mid \text { Fantasy } \mid \text { Mystery } \\
\end{array}$ & $\begin{array}{l}-.52 \\
-.47 \\
-.47 \\
-.47 \\
-.45 \\
-.44 \\
-.44 \\
-.43 \\
-.42 \\
-.41 \\
\end{array}$ \\
\hline \multicolumn{4}{|l|}{ Extraversion - high } \\
\hline $\begin{array}{l}8 \text { Seconds } \\
\text { ATL } \\
\text { The Wood } \\
\text { Old School } \\
\text { Friday Night Lights } \\
\text { Unforgivable } \\
\text { Love \& Basketball } \\
\text { Baby Boy } \\
\text { Friday } \\
\text { Juice }\end{array}$ & \begin{tabular}{l|}
1994 \\
2006 \\
1999 \\
2003 \\
2004 \\
2011 \\
2000 \\
2001 \\
1995 \\
1992 \\
\end{tabular} & $\begin{array}{l}\text { Biography | Drama | Sport | Western } \\
\text { Comedy | Crime | Drama | Music | Romance } \\
\text { Comedy | Drama | Romance } \\
\text { Comedy } \\
\text { Action | Drama | Sport } \\
\text { Drama } \\
\text { Drama | Romance | Sport } \\
\text { Crime | Drama | Romance | Thriller } \\
\text { Comedy | Drama } \\
\text { Action | Crime | Drama | Thriller } \\
\end{array}$ & $\begin{array}{l}.32 \\
.29 \\
.28 \\
.26 \\
.26 \\
.26 \\
.25 \\
.25 \\
.24 \\
.24 \\
\end{array}$ \\
\hline \multicolumn{4}{|l|}{ Extraversion - low } \\
\hline $\begin{array}{l}\text { Ghost in the Shell } \\
\text { Kiki's Delivery Service } \\
\text { My Neighbor Totoro } \\
\text { Akira } \\
\text { Silent Hill } \\
\text { Battle Royale } \\
\text { Princess Mononoke } \\
\text { Aliens } \\
\text { Howl's Moving Castle } \\
\end{array}$ & $\begin{array}{l}2017 \\
1989 \\
1988 \\
1988 \\
2006 \\
2000 \\
1997 \\
1986 \\
2004 \\
\end{array}$ & $\begin{array}{l}\text { Action | Drama | Sci-Fi | Thriller } \\
\text { Animation | Adventure | Drama | Family | Fantasy } \\
\text { Animation | Family | Fantasy } \\
\text { Animation | Action | Drama | Sci-Fi | Thriller } \\
\text { Horror } \\
\text { Adventure | Drama | Sci-Fi | Thriller } \\
\text { Animation | Adventure | Fantasy } \\
\text { Action | Adventure | Sci-Fi | Thriller } \\
\text { Animation | Adventure |Family |Fantasy } \\
\end{array}$ & $\begin{array}{l}-.59 \\
-.55 \\
-.52 \\
-.50 \\
-.50 \\
-.49 \\
-.47 \\
-.47 \\
-.45 \\
\end{array}$ \\
\hline
\end{tabular}


SUPPLEMENTAL TABLE 1 (CONTINUED)

\begin{tabular}{|c|c|c|c|}
\hline Title & Year & Genre & $\underline{Z}$ \\
\hline \multicolumn{4}{|l|}{ Agreeableness - high } \\
\hline Facing the Giants & 2006 & Drama $\mid$ Sport & .40 \\
\hline Letters to God & 2010 & Drama | Family & .38 \\
\hline Fireproof & 2008 & Drama Romance & .33 \\
\hline The Passion of the Christ & 2004 & Drama & .28 \\
\hline The Lake House & 2006 & Drama | Fantasy | Romance & .24 \\
\hline The Buddha & 2010 & Documentary & .22 \\
\hline Patch Adams & 1998 & Biography | Comedy | Drama | Romance & .21 \\
\hline Ever After: A Cinderella Story & 1998 & Comedy | Drama | Romance & .21 \\
\hline Pay It Forward & 2000 & Drama & .20 \\
\hline You've Got Mail & 1998 & \begin{tabular}{l|l|l} 
Comedy & Drama & Romance \\
\end{tabular} & .20 \\
\hline \multicolumn{4}{|l|}{ Agreeableness - low } \\
\hline Hellraiser & 1987 & Horror | Thriller & -.46 \\
\hline Hannibal Rising & 2007 & Adventure | Crime | Drama | Thriller | War & -.45 \\
\hline Heathers & 1988 & Comedy & -.44 \\
\hline Red Dragon & 2002 & Crime | Drama | Thriller & -.43 \\
\hline Party Monster & 2003 & Biography | Crime | Drama | Thriller & -.40 \\
\hline Get Rich or Die Tryin' & 2005 & Biography $\mid$ Crime $\mid$ Drama $\mid$ Music & -.40 \\
\hline Hannibal & 2001 & Crime | Drama | Thriller & -.39 \\
\hline Lord of War & 2005 & Crime Drama Thriller & -.39 \\
\hline The Human Centipede (First Sequence) & 2009 & Horror & -.39 \\
\hline Taxi Driver & 1976 & Crime Drama & -.39 \\
\hline \multicolumn{4}{|l|}{ Neuroticism - high } \\
\hline Girl, Interrupted & 1999 & Biography | Drama & -.41 \\
\hline Thirteen & 2003 & Drama & -.41 \\
\hline The Craft & 1996 & Drama | Fantasy | Horror | Thriller & -.35 \\
\hline Silent Hill & 2006 & Horror & -.33 \\
\hline Wristcutters: A Love Story & 2006 & Comedy | Drama | Fantasy | Romance & -.33 \\
\hline The Incubus & 1982 & Horror | Thriller & -.31 \\
\hline Heathers & 1988 & Comedy & -.31 \\
\hline Hard Candy & 2005 & Crime | Drama | Thriller & -.29 \\
\hline Marie Antoinette & 2006 & Biography | Drama | History | Romance & -.28 \\
\hline Corpse Bride & 2005 & Animation $\mid$ Drama $\mid$ Family $\mid$ Fantasy $\mid$ Musical $\mid$ Romance & -.28 \\
\hline \multicolumn{4}{|l|}{ Neuroticism - low } \\
\hline Friday Night Lights & 2004 & Action | Drama | Sport & .35 \\
\hline Mission: Impossible & 1996 & Action | Adventure | Thriller & .35 \\
\hline Boyz $\mathrm{n}$ the Hood & 1991 & Crime | Drama & .34 \\
\hline Ip Man 2 & 2010 & Action | Drama | Sport & .33 \\
\hline Paid in Full & 2002 & Action | Crime | Drama & .33 \\
\hline Shooter & 2007 & Action | Crime | Drama | Mystery | Thriller & .33 \\
\hline The Wood & 1999 & Comedy | Drama | Romance & .31 \\
\hline Ip Man & 2008 & Action | Biography | Drama | Sport & .31 \\
\hline We Were Soldiers & 2002 & Action | Drama | History | War & .31 \\
\hline Menace II Society & 1993 & Crime | Drama | Thriller & .31 \\
\hline
\end{tabular}




\section{SUPPLEMENTAL TABLE 2}

SUMMARY STATISTICS FOR NON-CATEGORICAL METADATA VARIABLES

\begin{tabular}{|l|c|c|c|c|}
\hline & Mean & SD & Min & Max \\
\hline Rating & 6.99 & 1.00 & 1.9 & 9.3 \\
Rating count & $240,514.57$ & $254,013.78$ & 137 & 1982609 \\
Budget & $44,827,549.90$ & $45,068,769.27$ & 15,000 & $260,000,000$ \\
Gross & $216,904,282.66$ & $231,813,657.28$ & 252,207 & $2,787,965,087$ \\
ROI & 28.78 & 531.57 & -0.90 & $12,889.39$ \\
Num & & & & \\
keywords & 168.05 & 100.04 & 7 & 865 \\
Runtime & 111.54 & 21.88 & 22 & 238 \\
\hline
\end{tabular}


SUPPLEMENTAL TABLE 3

GENRE CATEGORIES REPRESENTED IN THE STUDY

\begin{tabular}{|l|c|}
\hline Genre & \# of titles \\
Action & 194 \\
Adventure & 186 \\
Animation & 76 \\
Biography & 42 \\
Comedy & 349 \\
Crime & 134 \\
Documentary & 6 \\
Drama & 402 \\
Family & 126 \\
Fantasy & 144 \\
History & 27 \\
Horror & 91 \\
Music & 42 \\
Musical & 48 \\
Mystery & 80 \\
Romance & 238 \\
Sci-Fi & 110 \\
Sport & 36 \\
Thriller & 213 \\
War & 34 \\
Western & 9 \\
\hline
\end{tabular}


SUPPLEMENTAL TABLE 4

REGRESSION ANALYSES WITH AFPP DIMENSIONS AS DEPENDENT VARIABLES (FULL MODEL, STANDARDIZED COEFFICIENTS)

\begin{tabular}{|c|c|c|c|c|c|}
\hline & & & ndent varial & & \\
\hline & Openness & Iscientiousr & Extraversion & greeablene & Neuroticism \\
\hline & (1) & (2) & (3) & (4) & (5) \\
\hline Age & $0.120^{* *}$ & $0.663^{* * *}$ & -0.049 & $0.193^{* * *}$ & $-0.226^{* * *}$ \\
\hline & $(0.036)$ & $(0.036)$ & $(0.039)$ & $(0.039)$ & $(0.034)$ \\
\hline Female & $-0.213^{* * *}$ & $0.341^{* * *}$ & $0.155^{* *}$ & $0.367^{* * *}$ & $0.356^{* * *}$ \\
\hline & $(0.040)$ & $(0.041)$ & $(0.044)$ & $(0.044)$ & $(0.038)$ \\
\hline Relationship & $0.347^{* * *}$ & $-0.387^{* * *}$ & -0.025 & $-0.202^{* * *}$ & $0.392^{* * *}$ \\
\hline & $(0.033)$ & $(0.033)$ & $(0.036)$ & $(0.036)$ & $(0.032)$ \\
\hline Rating & $0.318^{* * *}$ & $-0.104^{*}$ & $-0.232^{* * *}$ & $0.093^{*}$ & 0.043 \\
\hline & $(0.038)$ & $(0.039)$ & $(0.042)$ & $(0.042)$ & $(0.037)$ \\
\hline Rating count & -0.022 & $-0.085^{*}$ & 0.019 & -0.027 & 0.009 \\
\hline & $(0.035)$ & $(0.036)$ & $(0.039)$ & $(0.039)$ & $(0.034)$ \\
\hline Year & 0.035 & -0.033 & 0.041 & 0.019 & -0.038 \\
\hline & $(0.033)$ & $(0.034)$ & $(0.037)$ & $(0.036)$ & $(0.032)$ \\
\hline Log (Budget) & $-0.113^{*}$ & $0.167^{* * *}$ & -0.042 & $0.133^{* *}$ & $-0.103^{*}$ \\
\hline & $(0.037)$ & $(0.037)$ & $(0.041)$ & $(0.040)$ & $(0.035)$ \\
\hline Log (Gross) & $-0.166^{* * *}$ & $0.140^{* * * *}$ & $0.106^{* *}$ & $0.122^{* * *}$ & $-0.065^{*}$ \\
\hline & $(0.029)$ & $(0.030)$ & $(0.032)$ & $(0.032)$ & $(0.028)$ \\
\hline ROI & -0.038 & 0.039 & 0.026 & 0.053 & -0.044 \\
\hline & $(0.025)$ & $(0.026)$ & $(0.028)$ & $(0.028)$ & $(0.024)$ \\
\hline Runtime & -0.051 & 0.023 & 0.025 & $-0.097^{*}$ & 0.056 \\
\hline & $(0.034)$ & $(0.035)$ & $(0.038)$ & $(0.038)$ & $(0.033)$ \\
\hline Genre: Action & -0.145 & $0.309^{* * *}$ & -0.047 & $0.315^{* * *}$ & $-0.239^{* *}$ \\
\hline & $(0.076)$ & $(0.077)$ & $(0.084)$ & $(0.083)$ & $(0.073)$ \\
\hline Genre: adventure & $0.201^{*}$ & $-0.161^{*}$ & $-0.269^{* *}$ & 0.138 & 0.081 \\
\hline & $(0.075)$ & $(0.076)$ & $(0.083)$ & $(0.083)$ & $(0.072)$ \\
\hline Genre: animation & 0.045 & $-0.267^{*}$ & -0.184 & $-0.375^{*}$ & 0.116 \\
\hline & $(0.127)$ & $(0.128)$ & $(0.140)$ & $(0.139)$ & $(0.122)$ \\
\hline Genre: biography & 0.074 & -0.180 & 0.013 & 0.022 & 0.233 \\
\hline & $(0.129)$ & $(0.130)$ & $(0.143)$ & $(0.141)$ & $(0.123)$ \\
\hline Genre: comedy & -0.035 & $-0.135^{*}$ & 0.122 & $0.169^{*}$ & -0.007 \\
\hline & $(0.068)$ & $(0.068)$ & $(0.075)$ & $(0.074)$ & $(0.065)$ \\
\hline Genre: crime & -0.029 & 0.043 & $0.391^{* * * *}$ & $-0.499^{* * * *}$ & $-0.210^{*}$ \\
\hline
\end{tabular}




\begin{tabular}{|c|c|c|c|c|c|}
\hline & $(0.079)$ & $(0.080)$ & $(0.088)$ & $(0.087)$ & $(0.076)$ \\
\hline Genre: documentary & $\begin{array}{c}0.013 \\
(0.299)\end{array}$ & $\begin{array}{c}0.055 \\
(0.303)\end{array}$ & $\begin{array}{c}0.175 \\
(0.331)\end{array}$ & $\begin{array}{l}-0.252 \\
(0.328)\end{array}$ & $\begin{array}{l}-0.111 \\
(0.287)\end{array}$ \\
\hline Genre: drama & $\begin{array}{l}0.158^{*} \\
(0.064)\end{array}$ & $\begin{array}{l}-0.163^{*} \\
(0.064)\end{array}$ & $\begin{array}{l}-0.127 \\
(0.070)\end{array}$ & $\begin{array}{l}-0.132 \\
(0.070)\end{array}$ & $\begin{array}{c}0.100 \\
(0.061)\end{array}$ \\
\hline Genre: family & $\begin{array}{l}-0.241^{*} \\
(0.100)\end{array}$ & $\begin{array}{l}-0.034 \\
(0.101)\end{array}$ & $\begin{array}{l}-0.186 \\
(0.111)\end{array}$ & $\begin{array}{l}0.381^{* * *} \\
(0.110)\end{array}$ & $\begin{array}{l}-0.053 \\
(0.096)\end{array}$ \\
\hline Genre: fantasy & $\begin{array}{c}0.453^{* * *} \\
(0.075)\end{array}$ & $\begin{array}{c}-0.282^{* * *} \\
(0.076)\end{array}$ & $\begin{array}{c}-0.513^{* * *} \\
(0.083)\end{array}$ & $\begin{array}{l}-0.114 \\
(0.082)\end{array}$ & $\begin{array}{l}0.230^{* *} \\
(0.072)\end{array}$ \\
\hline Genre: history & $\begin{array}{c}0.282 \\
(0.162)\end{array}$ & $\begin{array}{c}0.321 \\
(0.164)\end{array}$ & $\begin{array}{l}-0.278 \\
(0.179)\end{array}$ & $\begin{array}{c}0.082 \\
(0.177)\end{array}$ & $\begin{array}{l}-0.193 \\
(0.155)\end{array}$ \\
\hline Genre: horror & $\begin{array}{c}0.008 \\
(0.097)\end{array}$ & $\begin{array}{l}-0.172 \\
(0.099)\end{array}$ & $\begin{array}{c}-0.536^{* * *} \\
(0.108)\end{array}$ & $\begin{array}{c}-0.663^{* * *} \\
(0.107)\end{array}$ & $\begin{array}{c}0.582^{\text {*** }} \\
(0.093)\end{array}$ \\
\hline Genre: music & $\begin{array}{l}-0.022 \\
(0.117)\end{array}$ & $\begin{array}{c}0.095 \\
(0.118)\end{array}$ & $\begin{array}{c}0.155 \\
(0.129)\end{array}$ & $\begin{array}{c}0.151 \\
(0.128)\end{array}$ & $\begin{array}{l}-0.129 \\
(0.112)\end{array}$ \\
\hline Genre: musical & $\begin{array}{c}0.229 \\
(0.119)\end{array}$ & $\begin{array}{l}-0.223 \\
(0.120)\end{array}$ & $\begin{array}{c}0.025 \\
(0.132)\end{array}$ & $\begin{array}{c}0.158 \\
(0.131)\end{array}$ & $\begin{array}{c}0.066 \\
(0.114)\end{array}$ \\
\hline Genre: mystery & $\begin{array}{c}0.099 \\
(0.092)\end{array}$ & $\begin{array}{c}0.085 \\
(0.093)\end{array}$ & $\begin{array}{l}-0.153 \\
(0.102)\end{array}$ & $\begin{array}{c}0.160 \\
(0.101)\end{array}$ & $\begin{array}{l}-0.031 \\
(0.088)\end{array}$ \\
\hline Genre: romance & $\begin{array}{l}-0.035 \\
(0.073)\end{array}$ & $\begin{array}{l}0.155^{*} \\
(0.074)\end{array}$ & $\begin{array}{c}0.106 \\
(0.081)\end{array}$ & $\begin{array}{l}0.212^{*} \\
(0.080)\end{array}$ & $\begin{array}{l}-0.151^{*} \\
(0.070)\end{array}$ \\
\hline Genre: sci.fi & $\begin{array}{c}0.473^{* * *} \\
(0.084)\end{array}$ & $\begin{array}{c}-0.381^{* * * *} \\
(0.085)\end{array}$ & $\begin{array}{c}-0.623^{* * *} \\
(0.093)\end{array}$ & $\begin{array}{l}-0.096 \\
(0.092)\end{array}$ & $\begin{array}{l}0.270^{* * *} \\
(0.081)\end{array}$ \\
\hline Genre: sport & $\begin{array}{c}-0.628^{* * *} \\
(0.130)\end{array}$ & $\begin{array}{c}0.630^{* * * *} \\
(0.131)\end{array}$ & $\begin{array}{c}0.762^{* * *} \\
(0.144)\end{array}$ & $\begin{array}{c}0.712^{* * *} \\
(0.142)\end{array}$ & $\begin{array}{c}-0.741^{\text {*** }} \\
(0.124)\end{array}$ \\
\hline Genre: thriller & $\begin{array}{l}-0.021 \\
(0.075)\end{array}$ & $\begin{array}{c}0.066 \\
(0.075)\end{array}$ & $\begin{array}{l}-0.231^{*} \\
(0.082)\end{array}$ & $\begin{array}{l}-0.080 \\
(0.082)\end{array}$ & $\begin{array}{c}0.126 \\
(0.071)\end{array}$ \\
\hline Genre: western & $\begin{array}{l}-0.115 \\
(0.242)\end{array}$ & $\begin{array}{l}-0.152 \\
(0.244)\end{array}$ & $\begin{array}{c}0.014 \\
(0.267)\end{array}$ & $\begin{array}{c}0.280 \\
(0.265)\end{array}$ & $\begin{array}{l}-0.270 \\
(0.232)\end{array}$ \\
\hline Genre: war & $\begin{array}{l}-0.040 \\
(0.140)\end{array}$ & $\begin{array}{l}0.391^{*} \\
(0.141)\end{array}$ & $\begin{array}{l}-0.227 \\
(0.155)\end{array}$ & $\begin{array}{l}-0.203 \\
(0.153)\end{array}$ & $\begin{array}{l}-0.038 \\
(0.134)\end{array}$ \\
\hline Constant & $\begin{array}{l}-0.164^{*} \\
(0.083)\end{array}$ & $\begin{array}{c}0.132 \\
(0.084)\end{array}$ & $\begin{array}{l}0.306^{* *} \\
(0.092)\end{array}$ & $\begin{array}{l}-0.048 \\
(0.092)\end{array}$ & $\begin{array}{l}-0.066 \\
(0.080)\end{array}$ \\
\hline Observations & 846 & 846 & 846 & 846 & 846 \\
\hline $\mathrm{R}^{2}$ & 0.528 & 0.516 & 0.421 & 0.432 & 0.566 \\
\hline Adjusted $\mathrm{R}^{2}$ & 0.510 & 0.498 & 0.399 & 0.410 & 0.549 \\
\hline Residual Std. Error $(\mathrm{df}=814)$ & 0.700 & 0.709 & 0.775 & 0.768 & 0.671 \\
\hline F Statistic $(\mathrm{df}=31 ; 814)$ & $29.374^{* * *}$ & $28.040^{* * *}$ & $19.130^{* * *}$ & $19.948^{* * *}$ & $34.227^{* * *}$ \\
\hline
\end{tabular}

Note:

${ }^{*} \mathrm{p}<0.05$ (uncorrected); ${ }^{* *} \mathrm{p}<0.05$ (corrected); ${ }^{* * *} \mathrm{p}<0.01$ (corrected) 
SUPPLEMENTAL TABLE 5

REGRESSION ANALYSES WITH AFPP DIMENSIONS AS DEPENDENT VARIABLES (FULL MODEL, UNSTANDARDIZED COEFFICIENTS)

\begin{tabular}{|c|c|c|c|c|c|}
\hline & \multicolumn{5}{|c|}{ Dependent variable: } \\
\hline & \multicolumn{5}{|c|}{ Openness Conscientiousness Extraversion Agreeableness Neuroticism } \\
\hline & (1) & (2) & (3) & (4) & (5) \\
\hline \multirow[t]{2}{*}{$\overline{\text { Age }}$} & $0.012^{* *}$ & $0.036^{* * *}$ & -0.003 & $0.010^{* * *}$ & $-0.012^{* * *}$ \\
\hline & $(0.003)$ & $(0.002)$ & $(0.002)$ & $(0.002)$ & $(0.002)$ \\
\hline \multirow[t]{2}{*}{ Female } & $-0.280^{* * *}$ & $0.249^{* * *}$ & $0.129^{* *}$ & $0.253^{* * *}$ & $0.265^{* * *}$ \\
\hline & $(0.053)$ & $(0.030)$ & $(0.037)$ & $(0.030)$ & $(0.029)$ \\
\hline \multirow[t]{2}{*}{ Relationship } & $1.152^{* * * *}$ & $-0.716^{* * *}$ & -0.054 & $-0.352^{* * *}$ & $0.736^{* * *}$ \\
\hline & $(0.109)$ & $(0.062)$ & $(0.077)$ & $(0.063)$ & $(0.059)$ \\
\hline \multirow[t]{2}{*}{ Rating } & $0.072^{* * * *}$ & $-0.013^{*}$ & $-0.034^{* * * *}$ & $0.011^{*}$ & 0.006 \\
\hline & $(0.009)$ & $(0.005)$ & $(0.006)$ & $(0.005)$ & $(0.005)$ \\
\hline \multirow[t]{2}{*}{ Rating count } & -0.00000 & $-0.00000^{*}$ & 0.000 & -0.000 & 0.000 \\
\hline & $(0.00000)$ & $(0.00000)$ & $(0.00000)$ & $(0.00000)$ & $(0.00000)$ \\
\hline \multirow[t]{2}{*}{ Year } & 0.001 & -0.0003 & 0.0005 & 0.0002 & -0.0004 \\
\hline & $(0.001)$ & $(0.0003)$ & $(0.0004)$ & $(0.0004)$ & $(0.0003)$ \\
\hline \multirow[t]{2}{*}{ Log (Budget) } & $-0.047^{*}$ & $0.039^{* * *}$ & -0.011 & $0.029^{* *}$ & $-0.024^{*}$ \\
\hline & $(0.015)$ & $(0.009)$ & $(0.011)$ & $(0.009)$ & $(0.008)$ \\
\hline \multirow[t]{2}{*}{ Log (Gross) } & $-0.096^{* * *}$ & $0.045^{* * *}$ & $0.039^{* *}$ & $0.037^{* * *}$ & $-0.021^{*}$ \\
\hline & $(0.017)$ & $(0.010)$ & $(0.012)$ & $(0.010)$ & $(0.009)$ \\
\hline \multirow[t]{2}{*}{ ROI } & -0.00002 & 0.00001 & 0.00001 & 0.00001 & -0.00001 \\
\hline & $(0.00001)$ & $(0.00001)$ & $(0.00001)$ & $(0.00001)$ & $(0.00001)$ \\
\hline \multirow[t]{2}{*}{ Runtime } & -0.001 & 0.0001 & 0.0002 & $-0.001^{*}$ & 0.0003 \\
\hline & $(0.0004)$ & $(0.0002)$ & $(0.0003)$ & $(0.0002)$ & $(0.0002)$ \\
\hline \multirow[t]{2}{*}{ Genre: action } & -0.033 & $0.039^{* * *}$ & -0.007 & $0.037^{* * *}$ & $-0.031^{* *}$ \\
\hline & $(0.017)$ & $(0.010)$ & $(0.012)$ & $(0.010)$ & $(0.009)$ \\
\hline \multirow[t]{2}{*}{ Genre: adventure } & $0.046^{*}$ & $-0.020^{*}$ & $-0.039^{* *}$ & 0.016 & 0.010 \\
\hline & $(0.017)$ & $(0.010)$ & $(0.012)$ & $(0.010)$ & $(0.009)$ \\
\hline \multirow[t]{2}{*}{ Genre: animation } & 0.010 & $-0.034^{*}$ & -0.027 & $-0.045^{*}$ & 0.015 \\
\hline & $(0.029)$ & $(0.016)$ & $(0.020)$ & $(0.017)$ & $(0.016)$ \\
\hline \multirow[t]{2}{*}{ Genre: biography } & 0.017 & -0.023 & 0.002 & 0.003 & 0.030 \\
\hline & $(0.029)$ & $(0.016)$ & $(0.021)$ & $(0.017)$ & $(0.016)$ \\
\hline \multirow[t]{2}{*}{ Genre: comedy } & -0.008 & $-0.017^{*}$ & 0.018 & $0.020^{*}$ & -0.001 \\
\hline & $(0.015)$ & $(0.009)$ & $(0.011)$ & $(0.009)$ & $(0.008)$ \\
\hline Genre: crime & -0.007 & 0.005 & $0.056^{* * *}$ & $-0.059^{* * *}$ & $-0.027^{*}$ \\
\hline
\end{tabular}




\begin{tabular}{|c|c|c|c|c|c|}
\hline & $(0.018)$ & $(0.010)$ & $(0.013)$ & $(0.010)$ & $(0.010)$ \\
\hline Genre: documentary & $\begin{array}{c}0.003 \\
(0.068)\end{array}$ & $\begin{array}{c}0.007 \\
(0.038)\end{array}$ & $\begin{array}{c}0.025 \\
(0.048)\end{array}$ & $\begin{array}{l}-0.030 \\
(0.039)\end{array}$ & $\begin{array}{l}-0.014 \\
(0.037)\end{array}$ \\
\hline Genre: drama & $\begin{array}{c}0.036^{*} \\
(0.014)\end{array}$ & $\begin{array}{l}-0.021^{*} \\
(0.008)\end{array}$ & $\begin{array}{l}-0.018 \\
(0.010)\end{array}$ & $\begin{array}{l}-0.016 \\
(0.008)\end{array}$ & $\begin{array}{c}0.013 \\
(0.008)\end{array}$ \\
\hline Genre: family & $\begin{array}{l}-0.055^{*} \\
(0.023)\end{array}$ & $\begin{array}{l}-0.004 \\
(0.013)\end{array}$ & $\begin{array}{l}-0.027 \\
(0.016)\end{array}$ & $\begin{array}{l}0.045^{* *} \\
(0.013)\end{array}$ & $\begin{array}{l}-0.007 \\
(0.012)\end{array}$ \\
\hline Genre: fantasy & $\begin{array}{c}0.103^{\text {**** }} \\
(0.017)\end{array}$ & $\begin{array}{c}-0.036^{* * *} \\
(0.010)\end{array}$ & $\begin{array}{c}-0.074^{* * *} \\
(0.012)\end{array}$ & $\begin{array}{l}-0.014 \\
(0.010)\end{array}$ & $\begin{array}{l}0.030^{* *} \\
(0.009)\end{array}$ \\
\hline Genre: history & $\begin{array}{c}0.064 \\
(0.037)\end{array}$ & $\begin{array}{c}0.041 \\
(0.021)\end{array}$ & $\begin{array}{l}-0.040 \\
(0.026)\end{array}$ & $\begin{array}{c}0.010 \\
(0.021)\end{array}$ & $\begin{array}{l}-0.025 \\
(0.020)\end{array}$ \\
\hline Genre: horror & $\begin{array}{c}0.002 \\
(0.022)\end{array}$ & $\begin{array}{l}-0.022 \\
(0.012)\end{array}$ & $\begin{array}{c}-0.077^{* * *} \\
(0.016)\end{array}$ & $\begin{array}{c}-0.079^{* * *} \\
(0.013)\end{array}$ & $\begin{array}{c}0.075^{* * *} \\
(0.012)\end{array}$ \\
\hline Genre: music & $\begin{array}{l}-0.005 \\
(0.027)\end{array}$ & $\begin{array}{c}0.012 \\
(0.015)\end{array}$ & $\begin{array}{c}0.022 \\
(0.019)\end{array}$ & $\begin{array}{c}0.018 \\
(0.015)\end{array}$ & $\begin{array}{l}-0.017 \\
(0.014)\end{array}$ \\
\hline Genre: musical & $\begin{array}{c}0.052 \\
(0.027)\end{array}$ & $\begin{array}{l}-0.028 \\
(0.015)\end{array}$ & $\begin{array}{c}0.004 \\
(0.019)\end{array}$ & $\begin{array}{c}0.019 \\
(0.016)\end{array}$ & $\begin{array}{c}0.009 \\
(0.015)\end{array}$ \\
\hline Genre: mystery & $\begin{array}{c}0.022 \\
(0.021)\end{array}$ & $\begin{array}{c}0.011 \\
(0.012)\end{array}$ & $\begin{array}{l}-0.022 \\
(0.015)\end{array}$ & $\begin{array}{c}0.019 \\
(0.012)\end{array}$ & $\begin{array}{l}-0.004 \\
(0.011)\end{array}$ \\
\hline Genre: romance & $\begin{array}{l}-0.008 \\
(0.017)\end{array}$ & $\begin{array}{l}0.020^{*} \\
(0.009)\end{array}$ & $\begin{array}{c}0.015 \\
(0.012)\end{array}$ & $\begin{array}{l}0.025^{*} \\
(0.009)\end{array}$ & $\begin{array}{l}-0.019^{*} \\
(0.009)\end{array}$ \\
\hline Genre: sci.fi & $\begin{array}{c}0.107^{* * *} \\
(0.019)\end{array}$ & $\begin{array}{c}-0.048^{* * *} \\
(0.011)\end{array}$ & $\begin{array}{c}-0.090^{* * *} \\
(0.013)\end{array}$ & $\begin{array}{l}-0.011 \\
(0.011)\end{array}$ & $\begin{array}{l}0.035^{* *} \\
(0.010)\end{array}$ \\
\hline Genre: sport & $\begin{array}{c}-0.142^{* * *} \\
(0.029)\end{array}$ & $\begin{array}{c}0.080^{* * * *} \\
(0.017)\end{array}$ & $\begin{array}{c}0.110^{* * *} \\
(0.021)\end{array}$ & $\begin{array}{c}0.085^{\text {*** }} \\
(0.017)\end{array}$ & $\begin{array}{c}-0.095^{* * *} \\
(0.016)\end{array}$ \\
\hline Genre: thriller & $\begin{array}{l}-0.005 \\
(0.017)\end{array}$ & $\begin{array}{c}0.008 \\
(0.010)\end{array}$ & $\begin{array}{l}-0.033^{*} \\
(0.012)\end{array}$ & $\begin{array}{l}-0.009 \\
(0.010)\end{array}$ & $\begin{array}{c}0.016 \\
(0.009)\end{array}$ \\
\hline Genre: western & $\begin{array}{l}-0.026 \\
(0.055)\end{array}$ & $\begin{array}{l}-0.019 \\
(0.031)\end{array}$ & $\begin{array}{c}0.002 \\
(0.039)\end{array}$ & $\begin{array}{c}0.033 \\
(0.032)\end{array}$ & $\begin{array}{l}-0.035 \\
(0.030)\end{array}$ \\
\hline Genre: war & $\begin{array}{l}-0.009 \\
(0.032)\end{array}$ & $\begin{array}{l}0.049^{*} \\
(0.018)\end{array}$ & $\begin{array}{l}-0.033 \\
(0.022)\end{array}$ & $\begin{array}{l}-0.024 \\
(0.018)\end{array}$ & $\begin{array}{l}-0.005 \\
(0.017)\end{array}$ \\
\hline Constant & $\begin{array}{c}-0.958 \\
(1.242)\end{array}$ & $\begin{array}{l}-0.678 \\
(0.700)\end{array}$ & $\begin{array}{l}-1.045 \\
(0.873)\end{array}$ & $\begin{array}{l}-1.203 \\
(0.714)\end{array}$ & $\begin{array}{c}0.838 \\
(0.675)\end{array}$ \\
\hline Observations & 846 & 846 & 846 & 846 & 846 \\
\hline $\mathrm{R}^{2}$ & 0.528 & 0.516 & 0.421 & 0.432 & 0.566 \\
\hline Adjusted $\mathrm{R}^{2}$ & 0.510 & 0.498 & 0.399 & 0.410 & 0.549 \\
\hline Residual Std. Error $(\mathrm{df}=814)$ & 0.159 & 0.090 & 0.112 & 0.091 & 0.086 \\
\hline F Statistic $(\mathrm{df}=31 ; 814)$ & $29.374^{* * *}$ & $28.040^{* * *}$ & $19.130^{* * *}$ & $19.948^{* * *}$ & $34.227^{* * *}$ \\
\hline
\end{tabular}

Note:

${ }^{*} \mathrm{p}<0.05$ (uncorrected); ${ }^{* *} \mathrm{p}<0.05$ (corrected); ${ }^{* * *} \mathrm{p}<0.01$ (corrected) 
SUPPLEMENTAL TABLE 6

PREDICTIVE ACCURACIES FOR DIFFERENT PREDICTION MODELS

\begin{tabular}{|c|c|c|c|c|c|c|}
\hline & & Ope & Con & Ext & Agr & Neu \\
\hline \multirow{6}{*}{$\begin{array}{l}\text { LASSO } \\
\text { Lambda }=0.0001\end{array}$} & Genre & .37 & .44 & .55 & .55 & .53 \\
\hline & Metadata & .49 & .42 & .42 & .52 & .30 \\
\hline & Demographics & .57 & .58 & .30 & .42 & .65 \\
\hline & Keywords & .63 & .53 & .67 & .64 & .65 \\
\hline & All but keywords & .68 & .68 & .63 & .64 & .72 \\
\hline & All variables & .72 & .72 & .71 & .67 & .76 \\
\hline \multirow{6}{*}{$\begin{array}{l}\text { LASSO } \\
\text { Lambda }=.01\end{array}$} & Genre & .36 & .41 & .52 & .54 & .51 \\
\hline & Metadata & .59 & .43 & .42 & .53 & .31 \\
\hline & Demographics & .57 & .56 & .28 & .39 & .65 \\
\hline & Keywords & .62 & .45 & .62 & .60 & .60 \\
\hline & All but keywords & .71 & .66 & .63 & .62 & .71 \\
\hline & All variables & .75 & .69 & .70 & .65 & .74 \\
\hline \multirow[t]{6}{*}{ Linear } & Genre & .37 & .44 & .54 & .55 & .53 \\
\hline & Metadata & .07 & .03 & .00 & .03 & .01 \\
\hline & Demographics & .57 & .58 & .30 & .42 & .65 \\
\hline & Keywords & .63 & .53 & .67 & .63 & .65 \\
\hline & All but keywords & -.02 & -.02 & -.01 & .05 & -.01 \\
\hline & All variables & .05 & .03 & .04 & -.01 & .02 \\
\hline \multirow{6}{*}{$\begin{array}{l}\text { Ridge } \\
\text { Alpha }=10\end{array}$} & Genre & .37 & .44 & .55 & .55 & .53 \\
\hline & Metadata & .55 & .41 & .42 & .51 & .30 \\
\hline & Demographics & .57 & .58 & .30 & .42 & .65 \\
\hline & Keywords & .63 & .53 & .67 & .63 & .65 \\
\hline & All but keywords & .68 & .68 & .63 & .64 & .72 \\
\hline & All variables & .72 & .71 & .70 & .68 & .76 \\
\hline \multirow{6}{*}{$\begin{array}{l}\text { Ridge } \\
\text { Alpha=100 }\end{array}$} & Genre & .37 & .44 & .55 & .55 & .53 \\
\hline & Metadata & .56 & .42 & .43 & .53 & .32 \\
\hline & Demographics & .57 & .57 & .30 & .42 & .65 \\
\hline & Keywords & .63 & .53 & .67 & .64 & .65 \\
\hline & All but keywords & .69 & .68 & .64 & .65 & .73 \\
\hline & All variables & .74 & .72 & .72 & .69 & .77 \\
\hline
\end{tabular}

NOTE.- simple linear regression models yielded poor performance in models that had a large number of metadata variables due to overfitting.

SUPPLEMENTAL TABLE 7 
PREDICTIVE ACCURACIES FOR DIFFERENT PREDICTION MODELS

\begin{tabular}{|l|ccccc|}
\hline & Ope & Con & Ext & Agr & Neu \\
\hline Genre & .37 & .44 & .55 & .56 & .53 \\
Metadata & .56 & .44 & .44 & .54 & .33 \\
Demographics & .57 & .58 & .30 & .42 & .65 \\
Keywords & .64 & .55 & .67 & .65 & .66 \\
All except keywords & .69 & .70 & .65 & .65 & .74 \\
All variables & .75 & .74 & .73 & .70 & .78 \\
\hline
\end{tabular}

NOTE.- This analysis is identical to the main analysis, except that the reduced keyword vectors were composed by projecting the keyword vectors of all titles in the Movie Likes dataset onto the 100 latent dimensions calculated by performing SVD on the keyword matrix of the 10,000 most voted feature film titles on IMDb as for 2018, with the exception of the movies that are included in the Movie Likes dataset. This analysis demonstrates that our results hold when there is no overlap between the dataset used to compute the SVD dimensions and the data used to train and test the models. 


\section{SUPPLEMENTAL TABLE 8}

\section{RELATIONSHIPS BETWEEN MOVIE THEMES AND FAN PERSONALITIES}

Partial Correlations between the average fan personality profiles and the plots' psychological themes across movies, controlling for demographics and non-categorical metadata variables

\begin{tabular}{|c|c|c|c|c|c|c|c|}
\hline & $\mathbf{O}$ & $\mathbf{C}$ & $\mathbf{E}$ & $\mathbf{A}$ & $\mathbf{N}$ & Lexical examples & Top plot keywords \\
\hline $\begin{array}{l}\text { Personal Concerns } \\
\text { Death } \\
\text { Religion } \\
\text { Money } \\
\text { Home } \\
\text { Leisure } \\
\text { Work } \\
\end{array}$ & $\begin{array}{r}.20 \\
. .25 \\
-.11 \\
-.10 \\
-.06 \\
.01 \\
\end{array}$ & $\begin{array}{l}-.11 \\
\mathbf{- . 1 6} \\
.06 \\
.02 \\
-.01 \\
.04 \\
\end{array}$ & $\begin{array}{l}\frac{-.32}{. .23} \\
\frac{.13}{.05} \\
. .17 \\
.01 \\
\end{array}$ & $\begin{array}{l}\frac{-.22}{-.04} \\
\frac{.19}{.05} \\
.16 \\
. .21 \\
\end{array}$ & $\begin{array}{l}\frac{.26}{.20} \\
\frac{-.16}{.00} \\
-.07 \\
-.07 \\
\end{array}$ & $\begin{array}{l}\text { bury, coffin, kill } \\
\text { altar, church } \\
\text { audit, cash, owe } \\
\text { kitchen, landlord } \\
\text { cook, chat, movie } \\
\text { job, majors, xerox }\end{array}$ & $\begin{array}{l}\text { death, death-of-mother, death-of-father } \\
\text { reference-to-jesus-christ, christian, catholic-church } \\
\text { money, pay-phone, debt } \\
\text { bedroom, kitchen, house } \\
\text { dance, singing-in-a-car, listening-to-music } \\
\text { teacher-student-relationship, college-student, high-school-student }\end{array}$ \\
\hline $\begin{array}{l}\text { Drives } \\
\text { Achieve } \\
\text { Power } \\
\text { Reward } \\
\text { Risk } \\
\end{array}$ & $\begin{array}{r}.10 \\
.16 \\
-.01 \\
.04 \\
\end{array}$ & $\begin{array}{l}-.05 \\
-.09 \\
.00 \\
-.04 \\
\end{array}$ & $\begin{array}{l}\frac{-.14}{-.12} \\
-.04 \\
-. .17 \\
\end{array}$ & $\begin{array}{r}\frac{.23}{.06} \\
. .25 \\
-.01 \\
\end{array}$ & $\begin{array}{l}-.02 \\
.07 \\
-.10 \\
.11 \\
\end{array}$ & $\begin{array}{l}\text { win, success, better } \\
\text { superior, bully } \\
\text { take, prize, benefit } \\
\text { danger, doubt }\end{array}$ & $\begin{array}{l}\text { title-at-the-end. loss-of-loved-one, falling-in-love } \\
\text { one-man-army, good-versus-evil, character-says-i-love-you } \\
\text { good-versus-evil, long-take, falling-in-love } \\
\text { danger, fear, child-in-peril }\end{array}$ \\
\hline $\begin{array}{l}\text { Perceptual Processes } \\
\text { Seeing } \\
\text { Hearing } \\
\text { Feeling } \\
\end{array}$ & $\begin{array}{r}.07 \\
.12 \\
-.05 \\
.06 \\
\end{array}$ & $\begin{array}{l}\frac{-.14}{-.17} \\
.01 \\
-.13 \\
\end{array}$ & $\begin{array}{l}-.10 \\
-.23 \\
.09 \\
. .15 \\
\end{array}$ & $\begin{array}{r}.05 \\
.01 \\
. \mathbf{2 1} \\
.02 \\
\end{array}$ & $\begin{array}{r}\frac{.13}{.17} \\
-.03 \\
.15 \\
\end{array}$ & $\begin{array}{l}\text { look, heard, feeling } \\
\text { view, saw, seen } \\
\text { listen, hearing } \\
\text { feels, touch }\end{array}$ & $\begin{array}{l}\text { scream, nipples-visible-through-clothing falling-in-love } \\
\text { looking-at-oneself-in-a-mirror. nipples-visible-through-clothing. talking-to-the-camera } \\
\text { listening-to-music, scream. singing } \\
\text { bare-butt, hit-in-the-crotch falling-in-love }\end{array}$ \\
\hline $\begin{array}{l}\text { Biological Processes } \\
\text { Body } \\
\text { Health } \\
\text { Ingestion } \\
\text { Sexual }\end{array}$ & $\begin{array}{r}.05 \\
.04 \\
.10 \\
-.05 \\
.07\end{array}$ & $\begin{array}{l}\frac{-.14}{-.13} \\
\frac{.16}{-.07} \\
-.12 \\
\end{array}$ & $\begin{array}{l}.03 \\
-.03 \\
-.04 \\
.11 \\
.14 \\
\end{array}$ & $\begin{array}{r}-.12 \\
-.13 \\
-. .18 \\
.04 \\
-.21 \\
\end{array}$ & $\begin{array}{l}. .16 \\
. .18 \\
.01 \\
.01 \\
.14 \\
\end{array}$ & $\begin{array}{l}\text { eat, blood, pain } \\
\text { cheek, hands, spit } \\
\text { clinic, flu, pill } \\
\text { dish, eat, pizza } \\
\text { horny, love, incest }\end{array}$ & $\begin{array}{l}\text { penis, nipples, nipples-visible-through-clothing } \\
\text { penis, nipples, bare-butt } \\
\text { pain, doctor, vomiting } \\
\text { eating, pizza, drink } \\
\text { kissing-while-having-sex, masturbation, lesbian-kiss }\end{array}$ \\
\hline $\begin{array}{l}\text { Affective Processes } \\
\text { Positive Emotions } \\
\text { Negative Emotions } \\
\text { Anxiety } \\
\text { Anger } \\
\text { Sadness } \\
\end{array}$ & $\begin{array}{l}.13 \\
.08 \\
.16 \\
.17 \\
.11 \\
.02 \\
\end{array}$ & $\begin{array}{l}\frac{-.16}{-.10} \\
\frac{-.17}{-.18} \\
\frac{. .13}{-.04} \\
\end{array}$ & $\begin{array}{l}-.10 \\
-.06 \\
-.11 \\
-.23 \\
-.03 \\
.07 \\
\end{array}$ & $\begin{array}{r}.00 \\
. .18 \\
\frac{-.15}{-.14} \\
. .16 \\
.09 \\
\end{array}$ & $\begin{array}{l}\frac{.15}{.03} \\
\frac{.23}{.27} \\
\frac{.18}{.03} \\
\end{array}$ & $\begin{array}{l}\text { happy, cried } \\
\text { love, nice, sweet } \\
\text { hurt, ugly, nasty } \\
\text { worried, fearful } \\
\text { hate, kill, annoyed } \\
\text { crying, grief, sad } \\
\end{array}$ & $\begin{array}{l}\text { character-says-i-love-you, good-versus-evil, love } \\
\text { character-says-i-love-you, love, good-versus-evil } \\
\text { fear, panic, paranoia } \\
\text { fear, panic, paranoia } \\
\text { bully, evil-man, scream } \\
\text { character-says-i-love-you, crying-man, crying-woman }\end{array}$ \\
\hline $\begin{array}{l}\text { Social Processes } \\
\text { Family } \\
\text { Friends } \\
\text { Female references } \\
\text { Male references } \\
\end{array}$ & $\begin{array}{r}-.02 \\
-.06 \\
-.07 \\
.02 \\
-.02 \\
\end{array}$ & $\begin{array}{l}-.02 \\
.00 \\
.02 \\
-.08 \\
-.01 \\
\end{array}$ & $\begin{array}{l}.11 \\
.09 \\
. \mathbf{1 9} \\
.08 \\
. \mathbf{1 3} \\
\end{array}$ & $\begin{array}{c}.11 \\
.09 \\
.11 \\
-.01 \\
.10 \\
\end{array}$ & $\begin{array}{l}-.02 \\
-.03 \\
-.08 \\
.04 \\
-.06 \\
\end{array}$ & $\begin{array}{l}\text { mate, talk, they } \\
\text { daughter, dad, aunt } \\
\text { buddy, neighbor } \\
\text { girl, her, mom } \\
\text { boy, his, dad } \\
\end{array}$ & $\begin{array}{l}\text { character-says-i-love-you, mother-daughter-relationship, little-girl } \\
\text { mother-son-relationship, mother-daughter-relationship, father-daughter-relationship } \\
\text { friend, boyfriend-girlfriend-relationship, ex-boyfriend-ex-girlfriend-relationship } \\
\text { girl. girl-in-panties, little-girl } \\
\text { uncle-nephew-relationship, father-son-relationship, brother-brother-relationship }\end{array}$ \\
\hline $\begin{array}{l}\text { Cognitive Processes } \\
\text { Insight } \\
\text { Causation }\end{array}$ & $\begin{array}{l}.12 \\
.17 \\
.16 \\
\end{array}$ & $\begin{array}{l}\frac{-.14}{-.15} \\
. .16 \\
\end{array}$ & $\frac{-.16}{-.21}$ & $\begin{array}{l}.10 \\
.07 \\
.04\end{array}$ & $\begin{array}{r}.11 \\
.13 \\
.14 \\
\end{array}$ & $\begin{array}{l}\text { cause, know, ought } \\
\text { think, know } \\
\text { because, effect }\end{array}$ & $\begin{array}{l}\text { character-says-i-love-you, character-repeating-someone-else's-dialogue, good-vs-evil } \\
\text { character-repeating-someone-else's-dialogue, character-says-i-love-you, talking-to- camera } \\
\text { character-says-i-love-you, character-repeating-someone-else's-dialogue, lifting-someone- } \\
\text { into-the-air }\end{array}$ \\
\hline
\end{tabular}

Significance level (Bonferroni corrected): $\mathbf{p}<\mathbf{0 . 0 5} ; \underline{\mathbf{P}<\mathbf{0 . 0 1}}$ 


\section{SUPPLEMENTAL TABLE 9}

STUDY 3 RESULTS (CHOICE)

\begin{tabular}{|c|c|c|c|c|c|c|}
\hline & \multicolumn{6}{|c|}{ Dependent variable: Choice } \\
\hline & (1) & (2) & (3) & (4) & (5) & (6) \\
\hline \multirow[t]{2}{*}{ Openness } & $0.181^{* * * *}$ & $0.160^{* *}$ & $0.172^{* * *}$ & $0.142^{* *}$ & $0.192^{* * * *}$ & $0.191^{* *}$ \\
\hline & $(0.061)$ & $(0.065)$ & $(0.065)$ & $(0.068)$ & $(0.071)$ & $(0.075)$ \\
\hline Big Five controls & No & Yes & No & Yes & No & Yes \\
\hline Observations & 1,137 & 1,137 & 1,018 & 1,018 & 891 & 891 \\
\hline Log Likelihood & -773.538 & -765.418 & -695.403 & -687.604 & -598.634 & -592.008 \\
\hline Akaike Inf. Crit. & $1,563.076$ & $1,554.835$ & $1,406.806$ & $1,399.209$ & $1,213.268$ & $1,208.016$ \\
\hline
\end{tabular}

NOTE.- Logistic regressions quantifying the relationship between participants' Openness and their choice of the High-O movie, akin to models A and B in Table 3, but using alternative analytical choices. Models 1-2 include participants who indicated watching one or more of the movies before; Models 3-4 do not winzorise any of the personality measures. Models 5-6 exclude participants who reported being indifferent between the two movies. All models include controls for gender, age and pair fixed effects. Standard Errors in Parenthesis. 
SUPPLEMENTAL TABLE 10

STUDY 3 RESULTS (RATINGS)

\begin{tabular}{|c|c|c|c|c|c|c|c|c|}
\hline & \multicolumn{8}{|c|}{ Dependent variable: } \\
\hline & \multicolumn{4}{|c|}{ High-O Rating } & \multicolumn{4}{|c|}{ Low-O Rating } \\
\hline & (1) & (2) & (3) & (4) & (5) & (6) & (7) & (8) \\
\hline \multirow[t]{2}{*}{ Openness } & $0.138^{* * *}$ & $0.107^{* * * *}$ & $0.139^{* * * *}$ & $0.105^{* * *}$ & -0.039 & $-0.094^{* *}$ & -0.040 & $-0.092^{* *}$ \\
\hline & $(0.035)$ & $(0.037)$ & $(0.037)$ & $(0.039)$ & $(0.038)$ & $(0.039)$ & $(0.040)$ & $(0.041)$ \\
\hline Big Five controls & No & Yes & No & Yes & No & Yes & $\mathrm{Np}$ & Yes \\
\hline Observations & 1,137 & 1,137 & 1,018 & 1,018 & 1,137 & 1,137 & 1,018 & 1,018 \\
\hline Log Likelihood & $-1,785.168$ & $-1,779.134$ & $-1,600.028$ & $-1,593.613$ & $-1,860.962$ & $-1,840.147$ & $-1,670.459$ & $-1,652.918$ \\
\hline Akaike Inf. Crit. & $3,586.335$ & $3,582.268$ & $3,216.055$ & $3,211.226$ & $3,737.924$ & $3,704.294$ & $3,356.917$ & $3,329.836$ \\
\hline
\end{tabular}

NOTE.- OLS regressions quantifying the relationship between participants' Openness and their ratings of the High-O and Low-O movies, akin to models C-D and E-F in Table 3 but using alternative analytical choices. Models 1-2 and 4-5 include participants who indicated watching one or more of the movies before; Models 3-4 and 6-7 do not winzorise any of the personality measures. All models include controls for gender, age and pair fixed effects. Standard Errors in Parenthesis. 